\title{
Otoacoustic emissions in preterm infants
}

Citation for published version (APA):

Brienesse, P. (1998). Otoacoustic emissions in preterm infants. [Doctoral Thesis, Maastricht University]. Universiteit Maastricht. https://doi.org/10.26481/dis.19981210pb

Document status and date:

Published: 01/01/1998

DOI:

10.26481/dis.19981210pb

Document Version:

Publisher's PDF, also known as Version of record

\section{Please check the document version of this publication:}

- A submitted manuscript is the version of the article upon submission and before peer-review. There can be important differences between the submitted version and the official published version of record.

People interested in the research are advised to contact the author for the final version of the publication, or visit the DOI to the publisher's website.

- The final author version and the galley proof are versions of the publication after peer review.

- The final published version features the final layout of the paper including the volume, issue and page numbers.

Link to publication

\footnotetext{
General rights rights.

- You may freely distribute the URL identifying the publication in the public portal. please follow below link for the End User Agreement:

www.umlib.nl/taverne-license

Take down policy

If you believe that this document breaches copyright please contact us at:

repository@maastrichtuniversity.nl

providing details and we will investigate your claim.
}

Copyright and moral rights for the publications made accessible in the public portal are retained by the authors and/or other copyright owners and it is a condition of accessing publications that users recognise and abide by the legal requirements associated with these

- Users may download and print one copy of any publication from the public portal for the purpose of private study or research.

- You may not further distribute the material or use it for any profit-making activity or commercial gain

If the publication is distributed under the terms of Article $25 \mathrm{fa}$ of the Dutch Copyright Act, indicated by the "Taverne" license above, 


\section{OTOACOUSTIC EMISSIONS IN PRETERM INFANTS}





\section{OTOACOUSTIC EMISSIONS IN PRETERM INFANTS}

\section{PROEFSCHRIFT}

ter verkrijging van de graad van doctor aan de Universiteit Maastricht, op gezag van de Rector Magnificus, Prof. dr. A.C. Nieuwenhuijzen Kruseman, volgens het besluit van het College van Decanen, in het openbaar te verdedigen op donderdag 10 december 1998 om 16.00 uur

door

Patrick Brienesse 
Promotores:

Prof.dr. J.J. Manini

Prof.dr. C.E. Blanco

Co-promotor:

Dr. W. J. Maertzdorf

Beoordelingscommissie:

Prof.dr. J. Troost (Voorzitter)

Prof.dr. J. de Haan

Prof.dr. R. Probst (Kantonsspital Basel, Zwitserland)

Prof.dr. D.W. Slaaf

Prof.dr.ir. H.P. Wit (Rijks Universiteit Groningen)

Publication of this thesis was financially supported by:

GN Danavox Nederland BV

Oticon Nederland BV

Electro Medical Instruments BV

Entermed Audiologie BV

Veenhuis Medical Audio BV

Beltone Nederland 
Aan mijn ouders Aan Annemarijke 


\section{ABBREVIATIONS}

OAE

SOAE

CEOAE

DPOAE

TEOAE

SFOAE

BERA

$\mathrm{IHC}$

$\mathrm{OHC}$

PCA

GA

NICU

SPL

HIL

FFT

FSR

OFSR

$d f_{i,}$

$\mathrm{dA}_{\mathrm{I}}$.

$d A_{s}$ otoacoustic emissions

spontaneous OAE

click evoked $\mathrm{OAE}$

distortion product $\mathrm{OAE}$

transient evoked $\mathrm{OAE}$

stimulus frequency $\mathrm{OAE}$

brainstem evoked response audiometry

inner hair cells

outer hair cells

post-conceptional age

gestational age

neonatal intensive care unit

sound pressure level

hearing level

fast Fourier transformation

frequency shift rate

overall frequency shift rate

long-term difference in frequency

long-term difference in amplitude

short-term difference in amplitude 


\section{CONTENTS}

1. General introduction.

2. Click evoked otoacoustic emission measurement in preterm infants. Brienesse, P., Maerizdorf, W.J., Anteunis, L.J.C., Mann, J.J and Blanco, C.E. (1998). Eur J Pediatr, in press.

3. Otoacoustic emissions in preterm infants: indications for cochlear development?

Brienesse, P., Antewnis, L.J.C., Wit, H.P., Gavilanes, A.W.D. and Maerizdorf, W.J. (1996). Audiology 35:296-306.

4. Frequency shift of individual Spontaneous OtoAcoustic Emissions in preterm infants.

Brienesse, P., Antetmis, L.J.C., Maertzdorf, W.J., Blanco, C.E and Manni, J.J. (1997). Pediatr Res 42:478-483.

5. Long-term and short-term variations in amplitude and frequency of spontaneous otoacoustic emissions in preterm infants.

Brienesse, P., Maertzdorf, W.J., Antemis, L.J.C., Manm, J.J. and Blanco, C.E. (1998). Audiology, in press.

6. Distortion product otoacoustic emission latency in preterm and term infants. Evidence for cochlear maturation.

Brienesse, P., Antewnis, LJ.C., Maertzdorf, W.J., Blanco, C.E. and Manni, J.J. (submitted).

7. General discussion and summary.

Samenvatting.

List of publications.

Nawoord. 


\section{CHAPTER}

\section{General introduction}




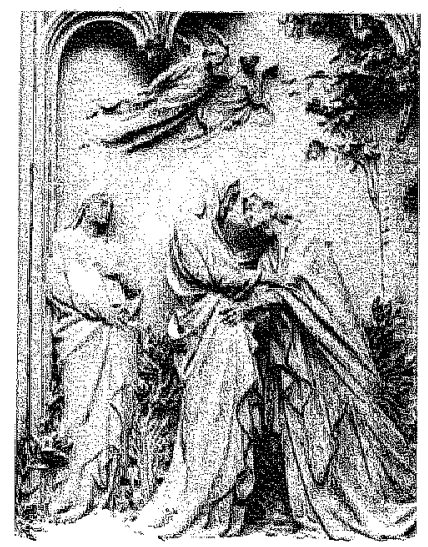


Probably the first evidence that human hearing begins during fetal life can be read in the Holy Bible, Luke chapter 1(44):

"For, lo, as soon as the voice of thy salutation sounded in mine ears, the babe leaped in my womb for joy."

This occurred after the greeting of Mary to Elisabeth, who was in her sixth month of pregnancy at that time (Luke chapter 1(36)). More recently, this phenomenon has been confirmed by many authors, reporting that fetal behavioural responses to auditory stimuli can consistently be registered from 28 weeks post-conceptional age (PCA) onwards (Birnholz and Benacerraf, 1983; Querleu et al., 1988; Ruben, 1992; Hepper and Shahidullah, 1994), which is in good agreement with the term of Elisabeth's pregnancy at the time of Mary's visit. For instance, Birnholz and Benacerraf reported on the blink-startle responses to vibroacoustic stimulation using high-resolution ultrasound imaging. Responses were first elicited between 24 and 25 weeks PCA and were present consistently after 28 weeks PCA (Birnholz and Benacerraf, 1983). Others reported head, arm or upper body movements (Hepper and Shahidullah, 1994), change in heart rate (Johansson et al, 1964; Bench and Vass, 1970; Grimwade et al., 1971; Graham et al., 1978), and even electrophysiological reactions (Barden et al., 1968; Sakabe et al., 1969), in response to various acoustic stimuli, including speech (Querleu et al., 1988).

The onset of hearing depends on the maturation of the cochlea, since the cocllea is the last element to function during the course of ontogenesis of the auditory system (Romand, 1983). A completely coiled cochlea can be observed in the human fetus during the ninth week of gestation, and the first signs of the differentiation of the organ of Corti occur one week later (Sanchez Fernandez et al., 1983; Pujol and Lavigne Rebillard, 1985). Proceeding from the base toward the apex, the inner and outer hair cells (IHC and OHC) differentiate from the cochlear epithelium, and can be recognized in the 11 to 12 week old fetal cochlea (Pujol and Lavigne Rebillard, 1985). In the 12th week, classical afferent synapses can be seen first at IHC and later at OHC (Pujol et al., 1991). The onset of hu- 
man cochlear function, as estimated from comparitive studies with experimental mammals, appears around 20 weeks PCA, and coincides with a rapid phase of development in which the afferent nerve endings of the $\mathrm{OHC}$ are progressively replaced by efferents (Romand, 1983; Pujol, 1985). As described above, the first fetal behavioural responses to auditory stimulation can be recorded a few weeks later, around 28 weeks PCA.

The development of the human cochlea is accompanied by a simultaneous development of the middle ear structures (Saunders et al., 1983). By the 22nd week PCA, the human auditory ossicles are completely formed, and the ossification of these ossicles is completed by approximately 32 weeks PCA. The clearance of mesenchyme in the middle ear is completed at about 36 weeks PCA. The tympanic membrane thins until about 26 weeks $\mathrm{PCA}$, at which time the attachments of the tympanic membrane to the tympanic ring are also complete (Saunders et al., 1983). Although the size of the human tympanic ring is full grown around 22 weeks PCA, the fusion of this ring with the temporal bone only starts at about 35 weeks PCA and continues postnatally (Saunders et al., 1983; Saunders et al., 1993). Both the changes in orientation of the tympanic membrane and the expansion of the middle ear cavity also continue throughout postnatal life (Saunders et $a l ., 1983$ ). The effect of these structural changes on the transfer function of the middle ear is largely unknown. As a consequence, little is known about the functional development of the middle ear in preterm infants. In the first two years of life, Keefe et al. (1993) have demonstrated a strong influence of external ear canal and middle ear development on input impedance and reflection coefficient responses. In preterm infants, these developmental influences might even be stronger.

In general, the definition of the end of human cochlear development depends on the method used. Morphological findings, for instance, indicate that the cochlea is already mature by 30 weeks PCA (Pujol et al., 1991). In order to estimate the end of the functional cochlear development, intrauterine behavioural responsiveness studies as mentioned above are less appropriate. It is well known, that behaviour- 
al responses still develop beyond birth, since these responses also depend on the maturity of the response system and/or the connections between the sensory and response systems (Olsho et al., 1988). In preterm infants, more direct objective methods can be applied, as for instance brainstem evoked response audiometry (BERA). Although these responses are still not adultlike at birth, Eggermont et al. (1991) estimated the mechanisms of the human cochlea to be mature at 30 to 35 weeks PCA, using the difference in wave I latency between adjacent frequency bands. Only the higher frequencies between 5.7 and $11.3 \mathrm{kHz}$ showed a delayed maturation, stressing the frequency dependence in cochlear maturation.

The present study, however, reports on the registration of an alternative objective measure in preterm infants, namely otoacoustic emissions (OAE). As described in the following sections, OAE are believed to be of cochlear origin, which makes it an obvious alternative for the evaluation of cochlear function. Changes in the $\mathrm{OAE}$ properties could therefore well be expected to reflect cochlear maturation.

\section{INTRODUCTION TO OTOACOUSTIC EMISSIONS}

In 1958, Elliot reported ripples in the audiogram in two adult subjects, which were stable over a period of at least two months (Elliot, 1958). These threshold sensitivity changes showed a pattern of consecutive minima and maxima with increasing frequency, and were later confirmed by many other observations. In the search for an explanation of this phenomenon of "auditory microstructure", $\mathrm{dr}$. David Kemp found that the subjective loudness at low stimulus levels showed similar patterns. He correlated the feature of this microstructure with the occurrence of transient tonal timnitus, which lead to the formulation of the following hypothesis (Kemp and Martin, 1976):

"... a framework of highly iuned resonant systems assists in the reception of near threshold sounds. The mechanism must be active and must be at least partly peripheral as it is susceptible to pressure changes in the cochlea."

In the search for proof of these resonant systems, he stimulated the ear with 


\section{Chapter 1}

acoustic pulses and discovered the subsequent presence of echo-like sounds in the ear canal, which he called "stimulated acoustic emissions" (Kemp, 1978). The interval between the stimulus and the emissions was too long to be explained by a simple passive echo phenomenon. These stimulated acoustic emissions later proved to be generated by the inner ear and are now known as otoacoustic emissions.

Kemp, however, was not the first to propose an active mechanism in the inner ear. In 1948, Gold already suggested an active mechanical oscillation to account for the high frequency selectivity of human hearing, which could not be reached by passive mechanical tuning alone (Gold, 1948). He further stated that if these active oscillations are present, a certain fraction of the acoustic energy is expected to radiate out. Without any stimulation, a sensitive microphone in the external ear canal might be able to pick up these oscillations and so prove their mechanical origin (Gold, 1948). It was not until 1980, that both Kemp and Wilson demonstrated the spontaneous presence of continuous tones in the external ear canal, which they called "objective tinnitus" (Kemp and Chum, 1980; Wilson, 1980). Nowadays, these tones are denoted as spontaneous otoacoustic emissions (SOAE).

\section{TYPES OF OAE}

\section{Spontaneous OAE}

Since SOAE appear without any stimulation, they can simply be registered with a sensitive microphone sealed in the external ear canal. Frequency analysis of the microphone signal reveals the SOAE as one or more narrow-band frequency components rising above the background noise, with amplitudes generally up to $20 \mathrm{~dB}$ sound pressure level (SPL). The frequency of these pure tone-like signals is stable over time. When observed over a period of several months, SOAE exhibit a stability up to typically one percent of the initial frequency, whereas the amplitude of SOAE fluctuates with time (Probst et al., 1991). The prevalence of SOAE depends on the eventual noise floor of the recordings. In normai hearing adults, the SOAE prevalence is about 30 percent of ears, and about 40 to 50 
Table 1.1: Overview of $O A E$.

\begin{tabular}{ll}
\hline Type of OAE & Type ol stimulus \\
\hline Spontaneous OAE (SOAE) & no stimulus \\
$\begin{array}{l}\text { Synchronized SOAE } \\
\text { Transient evoked OAE (TEOAE): } \\
\text { click evoked OAE (CEOAE) } \\
\text { tone-burst OAE }\end{array}$ & short stimuli: \\
clicks \\
Stimulus frequency OAE (SFOAE) & tone-bursts \\
Distortion product OAE (DPOAE) & one continuous tone
\end{tabular}

percent of subjects. In ears with sensorineural hearing loss of about $25 \mathrm{~dB}$ Hearing level (HL) or more, SOAE are generally absent. The relatively low prevalence of SOAE among the different types of OAE limits its clinical applicability.

Neonates exhibit both higher average SOAE amplitudes and frequency range compared to adults, whereas no age-related changes have been demonstrated in SOAE prevalence (Burns et al., 1992; Burns et al., 1994). In preterm infants, similar SOAE characteristics were found as in neonates (Bonfils et al., 1992a; Morlet et al., 1993; Morlet et al., 1995).

Although SOAE arise spontaneously, an alternative method of registering SOAE uses a synchronizing click stimulus. Synchronization of the SOAE frequencies to a click stimulus enables a time domain averaging technique, similar to the technique used in the registration of transient evoked OAE (TEOAE) described in the next section. Through this time averaging technique, the measurement of synchronized SOAE is less susceptible to environmental noise, since the noisy episodes can be excluded from further analysis. Especially in the neonatal intensive care unit (NICU), the measurement of synchronized SOAE is therefore preferred to the measurement of 'true' SOAE as described above. Since both methods yield similar results in terms of SOAE frequency (Wable and Collet, 1994; Burr et al., 1997), all SOAE registrations of the present study were performed using click 
synchronization.

\section{Click evoked OAE}

A wide range of stimuli can be used to evoke an OAE. In the family of transient evoked OAE (TEOAE), elicited by a short acoustic stimulus followed by the subsequent OAE, the click evoked OAE (CEOAE) are the most commonly used. CEOAE are registered with a probe sealed in the ear canal, containing a sensitive microphone and a small telephone to offer the click stimulus. In order to reduce background noise, multiple responses to multiple clicks are being averaged in a time domain of up to 20 ms post click stimulus (Figure 2.1). The click stimulus has the advantage of containing a wide range of frequencies. The CEOAE therefore represent the activity of a wide range of the cochlear partition in one response waveform. In a normal hearing population, the prevalence of CEOAE is near to 100 percent, whereas CEOAE are generally absent in ears with a sensorineural hearing loss of $35 \mathrm{~dB} \mathrm{HL}$ or more (Probst et al, 1991). CEOAE are widely being proposed and implemented in both targeted and universal hearing screening programmes in the newborn (American Academy of Pediatrics, 1995), since the CEOAE measurement is a relatively quick, non-invasive and objective screening instrument. On the other hand, the eventual field sensitivity of screening with CEOAE is still largely unknown (Lutman et al., 1997).

Compared to adults, the CEOAE of neonates show the same tendency as SOAE: in neonates, CEOAE demonstrate a larger average amplitude, with higher main frequency components (Probst et al, 1991). The first cross-sectional studies of CEOAE in preterm infants found no difference in CEOAE amplitude and frequency contents between preterm and term infants (Bonfils et al. 1992a; Morlet et al. 1993).

Other forms of TEOAE use more frequency specific stimuli such as short tonebursts, resulting in OAE with limited frequency contents around the stimulus frequency. In this way, it is possible to obtain more detailed information on different frequency regions of the cochlear partition. Although the measurement 
technique of tone-burst $\mathrm{OAE}$ is very similar to $\mathrm{CEOAE}$, investigation of the entire cochlear partition with tone burst requires several runs with different stimulus frequencies. For sake of stability, it is best to minimize the total test time, wich makes tone-burst OAE less suitable to be used in the noisy environment of the NICU. In the present study, CEOAE were therefore used to obtain a broad-band frequency response in a minimal span of time.

\section{Distortion product OAE}

In contrast to TEOAE, in which stimulus and response are separated in time, OAE can also be evoked by continuous stimulation, resulting in a continuous response. In distortion product OAE (DPOAE) for instance, two continuous pure tones of frequency $f 1$ and $f 2$ (with $f 2>f 1$ ) are presented in the ear canal. This results in multiple continuous response tones, or distortion products, at frequencies related to $f 1$ and $f 2$ by simple algebraic expressions. The most prominent distortion product occurs at the frequency $2 f 1-f 2$. In the power spectrum of the ear canal signal, both $f, f 2$ and the distortion products can be detected as sharp peaks rising above the adjacent noise floor. The measurement of DPOAE is less susceptible to environmental noise than CEOAE, since the analysis only focuses on a small range around the expected $2 f 1-f 2$ frequency. On the other hand, the total registration time increases when multiple registrations at different frequencies are being made ('DP-gram').

Although DPOAE can still be present at frequencies with sensorineural hearing losses as high as $65 \mathrm{~dB} \mathrm{HL}$ (Moulin et al, 1994), it is possible to differentiate between normal and impaired ears by differences in DPOAE amplitude or threshold, thereby using DPOAE as a frequency specific hearing screening instrument (Gorga et al., 1993; Moulin et al., 1994; Gorga et al., 1996; Stover et al, 1996).

Up to now, the correlation between DPOAE amplitude and sensorineural hearing loss however is found to be too weak to predict auditory threshold at a given frequency with any great accuracy (Nelson and Kimberley, 1992; Avan and Bonfils, 1993; Moulin et al., 1994; Gorga et al., 1996). 
As is the case with other OAE, average DPOAE amplitudes are larger in neonates than in adults (Bonfils et al, 1992b). In 1993, Smurzynski et al. were the first to report on DPOAE in preterm infants, showing the feasibility of DPOAE for this population (Smurzynski et al., 1993).

Another type of OAE with continuous stimulation are the stimulus frequency OAE (SFOAE), which are elicited by a single pure tone. By slowly sweeping the frequency of this tone, the level of the ear canal signal will demonstrate a ripple effect in the frequency regions in which the stimulus tone moves in and out of phase with the returning evoked OAE. The registration of SFOAE are technically more complex than other types of OAE, which makes it clinically less accessible at this point. From a clinical point of view, CEOAE and DPOAE are the two most applicable forms of OAE.

\section{COCHLEAR PHYSIOLOGY AND OAE}

For many decades, the main questions in the theory of hearing have been how the ear reaches its sensitivity and how it discriminates pitch. Mainly through the work of von Békésy, it has long since been known that the mechanical properties of the basilar membrane play an important role (Békésy, 1956). Both the width and the stiffness of the coiled basilar membrane change from base to apex. Von Békésy observed that sound induces traveling waves along the basilar membrane. The maximum of these traveling waves shifts its location along the membrane with a change of frequency (Békésy, 1956). By this passive mechanical tuning, high frequencies are processed at the base, and low frequencies at more apical locations along the basilar membrane. The frequency selectivity of human hearing is, however, higher than can be explained by this mechanical tuning, or in the words of von Békésy (1970):

"The human ear can detect a pitch change of 10 per cent of a pure tone in a time interval of two cycles. The inner ear, representing the combination of a mechanical and a nervous system, therefore seems to be superior to filters based on pure resonance and energy accumulation." 
The first description of CEOAE by Kemp (1978), caused a revolution in the ideas of cochlear mechanics. He proposed the presence of an active resonant system in the cochlea. The positive mechanical feedback of this system can amplify the vibration on the basilar membrane, which is thought to enhance both the sensitivity" and the frequency selectivity of the cochlea. To date, the details of active and passive cochlear mechanics are still not fully understood. Since in isolated OHC changes in length have been reported as a result of intracellular current administration (Brownell et al., 1985), OHC are believed to play a key role in the 'cochlear amplifier. The active force which $\mathrm{OHC}$ could apply to the basilar membrane supports the idea that the $\mathrm{OHC}$ act as the feedback motor in the fine funing mechanism of the cochlea (Iwasa and Chadwick, 1992). Since it is possible that a fraction of the acoustic energy of these active oscillations of the OHC is radiated out, it is now generally believed that the OHC are the source of OAE. Though this working model of OAE is generally being adhered to, it is still under discussion. It is for instance not clear whether the $\mathrm{OHC}$ are the only or main source of the motile activity, since SOAE have been reported in different species without OHC-like structures in the inner ear (van Dijk et al, 1989). More fundamentally, there has recently been some controversy over whether the cochlear amplifier is indeed active, and is indeed an amplifier (Burns et al., 1998). Allen et al. (Allen and Fahey, 1992; Allen, 1996) suggested an alternative passive model to account for the responses seen in basilar membrane cochlear mechanics. Others however, reject his ideas and still argue for the existence of active signal processing in the cochlea (Burns et al., 1998; Tubis and Talmadge, 1998).

\section{OBJECTIVE OF THIS THESIS}

In 1993, the properties of the cochlear mechanism were believed to be mature at 32 weeks PCA, since no statistically significant variation of the amplitude and spectrum of CEOAE could be found among different age groups of preterm infants ranging from 32 to 41 weeks PCA (Bonfils et al., 1992a; Morlet et al, 1993). Chuang ef al. (1993) however believed that the properties of the emission spectrum might be related to $\mathrm{PCA}$, based on longitudinal observations of some CEOAE spectra. 
Taking off from that point, the goal of the present study was to monitor and register changes in OAE in the PCA between 28 and 40 weeks, in order to gain insight in the underlying mechanisms of cochlear and middle ear maturation.

Firstly, Chapter 2 addresses the general problems of OAE measurement in preterm infants. Chapter 3 presents the results of the longitudinal registration of CEOAE amplitude changes, along with some preliminary results of SOAE frequency shifts. In Chapter 4 , the SOAE frequency shift is further described and analyzed. Chapter 5 presents the variation in the amplitude of $\mathrm{SOAE}$ in preterm infants. In Chapter 6 , differences in cochlear traveling wave delay between preterm and term infants are estimated by means of DPOAE latency measurement. 


\section{REFERENCES}

Allen, J. B. (1996). "A review of active and passive basilar membrane cochlear mechanics," $\mathrm{J}$ Acoust Soc Am 99, 2582.

Allen, J. B. and Fahey, P. F. (1992). "Using acoustic distortion products to measure the cochlear amplifier gain on the basilar membrane," J Acoust Soc Am 92, 178-188.

American Academy of Pediatrics (1995). "Joint Committee on Infant Hearing 1994 Position Statement.," Pediatrics 95, 152-156

Avan, P. and Bonfils, P. (1993), "Frequency specificity of human distortion product otoacoustic emissions," Audiology 32, 12-26.

Barden, T. P., Peltzman, P. and Graham, J. T. (1968). "Human fetal electroencephalographic response to intrauterine acoustic signals," Am J Obstet Gynecol 100, 1128-1134.

Békésy, G. v. (1956). "Current status of theories of hearing," Science 123, 779-783.

Békésy, G. v. (1970). "Travelling waves as frequency analysers in the cochlea," Nature 225, 1207-1209.

Bench, R. J. and Vass, A (1970). "Fetal audiometry," Lancet 1, 91-92.

Birnholz, J. C. and Benacerraf, B. R. (1983). "The development of human fetal hearing," Science 222, 516-5 18 .

Bonfils, P., Francois, M., Avan, P., Londero, A., Trotoux, J. and Narcy, P. (1992a). "Spontaneous and evoked otoacoustic emissions in preterm neonates," Laryngoscope 102, 182-186.

Bonfils, P., Avan, P., Francois, M., Trotoux, J. and Narcy, P. (1992b). "Distortion-product otoacoustic emissions in neonates: normative data," Acta Otolaryngol (Stockh) 112, 739. 744.

Brownell, W. E., Bader, C. R., Bertrand, D. and de Ribaupierre, Y. (1985). "Evoked mechanical responses of isolated cochlear outer hair cells," Science 227, 194-196.

Burns, E. M., Arehart, K. H. and Campbell, S. L. (1992). "Prevalence of spontaneous otoacoustic emissions in neonates," J Acoust Soc Am 91. 1571-1575.

Burns, E. M., Campbelll, S. L. and Arehart, K. H. (1994). "Longitudinal measurements of spontaneous otoacoustic emissions in infants," J Acoust Soc Am 95, 385-394.

Burns, E. M., Keefe, D. H. and Ling, R. B. (1998). "Energy reflectance in the ear canal can exceed unity near spontaneous otoacoustic emission frequencies," J Acoust Soc Am 103, 462-474.

Burr, S. A., Mullueran, M. and Degg, C. (1997). "Characterization of "Click-Synchronized Spontaneous Oto-Acoustic Emissions" (CSSOAEs) in humans," Br If Audiol 31, 93-94.

Chuang, S. W., Gerber, S. E. and Thornton, A. R. (1993) "Evoked otoacoustic emissions in preterm infants," Int J Pediatr Otorhinolaryngol 26, 39-45.

Eggermont, J. J., Ponton, C. W., Coupland, S. G. and Winkelaar, R. (1991). "Maturation of the traveling-wave delay in the human cochlea," J Acoust Soc Am 90, 288-298. 
Elliot, E (1958). "A ripple effect in the audiogram," Nature 181, 1076.

Gold, T. (1948). "Hearing II. The physical basis of the action of the cochlea," Proc R Soc Lond B Biol Sci 135, 492-498.

Gorga, M. P., Neely, S. T., Bergman, B., Beauchaine, K. L., Kaminski, J. R., Peters, J, and Jesteadt, W. (1993). "Otoacoustic emissions from normal-hearing and hearing-impaired subjects: distortion product responses," J Acoust Soc Am 93, 2050-2060.

Gorga, M. P., Stover, L. Neely, S. T. and Montoya, D. (1996). "The use of cumulative distributions to determine critical values and levels of confidence for clinical distortion product otoacoustic emission measurements," J Acoust Soc Am 100, 968-977.

Graham, F. K., Leavitt, L. A. and Strock, B. D. (1978). "Precocious cardiac orienting in a human anencephalic infant," Science 199, 322-324.

Grimwade, J. C., Walker, D. W., Bartlett, M, Gordon, S. and Wood, C. (1971). "Human fetal heart rate change and movement in response to sound and vibration," Am J Obstet Gynecol 109, 86-90.

Hepper, P. G. and Shahidullah, B. S. (1994). "Development of fetal hearing," Arch Dis Child 71, F81-87.

Iwasa, K. H. and Chadwick, R. S. (1992). "Elasticity and active force generation of cochlear outer hair cells," J Acoust Soc Am 92, 3169-3173.

Johansson, $\mathrm{B}_{\text {x, }}$ Wedenberg, $\mathrm{E}$. and Westin, $\mathrm{B}$. (1964). "Measurement of tone response by the human foetus.," Acta Otolaryngol (Stockh) 57, 188-192.

Keffe, D. H., Bulen, J. C., Arehart, K. H. and Burns, E. M. (1993). "Ear-canal impedance and reflection coefficient in human infants and adults," J Acoust Soc Am 94, 2617-2638.

Kemp, D. T. (1978). "Stimulated acoustic emissions from within the human auditory system," J Acoust Soc Am 64, 1386-1391.

Kemp, D. T. and Chum, R. (1980). "Properties of the generator of stimulated acoustic emissions," Hear Res 2, 213-232.

Kemp, D. T. and Martin, J. A. (1976). 13th International Congress of Audiology, Italy.

Lutman, M. E., Davis, A. C., Fortnum, H M. and Wood, S. (1997). "Field sensitivity of targeted neonatal hearing screening by transient- evoked otoacoustic emissions," Ear Hear 18, 265-276.

Morlet, T., Collet, L., Salle, B. and Morgon, A. (1993). "Functional maturation of cochlear active mechanisms and of the medial olivocochlear system in humans," Acta Otolaryngol (Stockh) 113, 271-277.

Morlet, T., Lapillonne, A., Ferber, C., Duclaux, R., Sann, L., Putet, G., Salle, B. and Collet, L. (1995). "Spontaneous otoacoustic emissions in preterm neonates: prevalence and gender effects," Hear Res 90, 44-54.

Moulin, A., Bera, J. C. and Collet, L. (1994). "Distortion product otoacoustic emissions and 
sensorineural hearing loss," Audiology 33, 305-326.

Nelson, D. A and Kimberley, B. P. (1992). "Distortion-product emissions and auditory

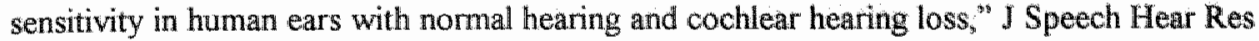
35, 1142-1159.

Olsho, L. W., Koch, E. G., Carter, E. A. Halpin, C. F. and Spetner, N. B. (1988). "Pure-tone sensitivity of human infants," J Acoust Soc Am 84, 1316-1324.

Probst, R, Lonsbury Martin, B. L. and Martin, G. K. (1991). "A review of otoacoustic emissions," J Acoust Soc Am 89, 2027-2067.

Pujol, R. (1985). "Morphology, synaptology and electrophysiology of the developing cochlea," Acta Otolaryngol (Stockh) Suppl 421, 5-9.

Pujol, R. and Lavigne Rebillard, M. (1985). "Early stages of innervation and sensory cell differentiation in the human fetal organ of Corti, "Acta Otolaryngol (Stockh) Suppl 423, 4350

Pujol, R., Lavigne Rebillard, M. and Uziel, A. (1991). "Development of the human cochlea," Acta Otolaryngol (Stockh) Suppl 482, 7-12.

Querleu, D., Renard, X., Versyp, F, Paris Delrue, L. and Crepin, G. (1988). "Fetal hearing," Eur J Obstet Gynecol Reprod Biol 28, 191-212.

Romand, R (1983). "Development of the cochlea," in Development of auditory and vestibular systems, edited by R. Romand (Academic Press, New York), pp. 47-88.

Ruben, R. J. (1992). "The ontogeny of human hearing," Acta Otolaryngol (Stockh) 112, 192196.

Sakabe, N., Arayama, T. and Suzuki, T. (1969). "Human fetal evoked response to acoustic stimulation," Acta Otolaryngol (Stockh) Suppl 252, 29-36.

Sanchez Fernandez, J. M., Rivera, J. M. and Macias, J. A. (1983). "Early aspects of human cochlea development and tectorial membrane histogenesis," Acta Otolaryngol (Stockh) 95, 460-469.

Saunders, J. C., Doan, D. E. and Cohen, Y. E. (1993) "The contribution of middle-ear sound conduction to auditory development," Comp Biochem Physiol 106, 7-13.

Saunders, J. C., Kaltenbach, J. A and Relkin, E. M. (1983). "The structural and functional development of the outer and middle ear," in Development of andirory and vestibular systems, edited by R. Romand (Academic Press, New York), pp. 3-25.

Smurzynski, J., Jung, M. D., Lafreniere, D., Kim, D. O., Kamath, M. V., Rowe, J. C., Holman, M. C. and Leonard, G. (1993) "Distortion-product and click-evoked otoacoustic emissions of preterm and full-term infants," Ear Hear 14, 258-274

Stover, L., Gorga, M. P., Neely, S. T. and Montoya, D. (1996). "Toward optimizing the clinical utility of distortion product otoacoustic emission measurements," J Acoust Soc Am $100,956-967$. 
Tubis, A. and Talmadge, C. L. (1998). "Ear canal reflectance in the presence of spontaneous otoacoustic emissions. I. Limit-cycle oscillator model," I Acoust Soc Am 103, 454-461.

van Dijk, P., Wit, H. P. and Segenhout, J. M. (1989). "Spontaneous otoacoustic emissions in the European edible frog (Rana esculenta): spectral details and temperature dependence," Hear Res 42, 273-282.

Wable, J. and Collet, L. (1994). "Can synchronized otoacoustic emissions really be attributed to SOAEs?" Hear Res 80, 141-145.

Wilson, J. P. (1980). "Model for cochlear echoes and tinnitus based on an observed electrical correlate," Hear Res 2, 527-532. 


\section{CHAPTER}

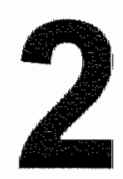

\section{Click evoked otoacoustic emission measurement in preterm infants}

Brienesse, P., Anteunis, L. J. C., Maertzdorf, W. J., Manni, J. J. and Blanco, C. E. (1998). Eur J Pediatr, in press. 
Chapter 2 


\section{ABSTRACT}

Click evoked otoacoustic emissions (CEOAE) are acoustic responses produced by the inner ear, reflecting functional auditory integrity. We studied both the success rate of the CEOAE method and the CEOAE presence in preterm infants during their stay at the neonatal intensive care unit (NICU), by analysis of the results of longitudinal CEOAE measurements in 19 preterm infants. The CEOAE method proved to be feasible in the majority of the population under study; the CEOAE measurement failed in eight percent of the total of 226 attempts. Within the range of 30 to 40 weeks post-conceptional age (PCA) the CEOAE presence increased from about 50 to 80 percent. These results show the possible clinical application of CEOAE in a NICU for the monitoring of cochlear function during treatment of preterm infants. Conclusion: Bedside CEOAE measurement in preterm infants in a NICU is feasible at a PCA as low as 30 weeks. 


\section{INTRODUCTION}

Otoacoustic emissions (OAE) are a form of acoustic energy emitted by the inner ear (Probst et al., 1991; Zorowka, 1993). It finds its origin in the process of perception in the organ of Corti. In 1978, Kemp (1978) first reported on these sounds which are now known as OAE. It is presently believed that the OAE are produced by the active contraction of the outer hair cells in the organ of Corti, as a result of normal cochlear function.

OAE can both arise spontaneously or be evoked by acoustic stimulation. When a short acoustic click is used as a stimulus, the resulting emissions are denoted as click evoked OAE (CEOAE). These CEOAE arise in the form of a broadband acoustic signal of up to $20 \mathrm{~ms}$ duration after the click and can easily be measured with a sensitive microphone placed in the external ear canal. This particular kind of OAE has proven its clinical merits as a sensitive, non-invasive and objective screening tool for normal cochlear function (Probst et al., 1991; Zorowka, 1993). CEOAE have a nearly 100 percent incidence among normal hearing subjects and have proven to be generally absent in patients with sensorineural hearing losses exceeding 30 to $35 \mathrm{~dB}$ HL. CEOAE can already objectively be recorded a few days after birth. The method of CEOAE measurement has been recommended by the National Institutes of Health (1993) for universal hearing screening of healthy newborn infants, despite the fact that the practical implementation of a universal screening protocol based on CEOAE leaves many questions unanswered and is still under discussion (Curnock, 1993; Bess and Paradise, 1994; Watkin, 1996; Davis et al., 1997).

Compared to healthy, low risk infants, neonatal intensive care unit (NICU) survivors show a 4.4 to 7.1 times higher prevalence of sensorineural hearing loss (Davis et al, 1997). Eavey et al. (1995) even reported a prevalence in NICU survivors up to 50 times higher than in normal newborns. Preterm infants therefore deserve special attention in this regard. In contrast with the measurement of auditory brainstem responses, the CEOAE method has the advantage of being a quick and relatively simple, non-invasive hearing screening instrument. The noisy 
enviromment of a NICU, however, is far from ideal with regard to the acoustic assessment of CEOAE. In order to increase the likelihood of detecting CEOAE in preterm infants, screening of this high risk group with CEOAE is preferably done as close as possible to the time of hospital discharge, at a post-conceptional age (PCA) of 37 to 39 weeks (Stevens et al., 1989; Kennedy et al., 1991; Uziel and Piron, 1991; Meredith et al., 1994). To explore the further application of CEOAE in the NICU beyond hearing screening, CEOAE have been measured in preterm infants in the University Hospital of Maastricht since 1993 by longitudinal observation of the CEOAE properties during their whole stay at the NICU, not only just prior to the time of discharge. In order to obtain an indication of the feasibility of CEOAE in a NICU, we present the results of the CEOAE measurements at different $\mathrm{PCA}$, in terms of success rate and CEOAE presence using three different criteria.

\section{METHODS}

All measurements were performed with the ILO88 Otoacoustic Emission Analyser (Otodynamics, London UK: version 3.94), as described elsewhere (Kemp et al., 1990). An example of a CEOAE recording in a premature infant is given in Figure 2.1. The CEOAE were measured using the neonatal probe with disposable tip. A rectangular click stimulus of $80 \mu$ s electrical duration was used. The probe was fitted and refitted when necessary until the frequency components of the stimulus were as equally distributed in the frequency domain as possible, with a minimal noise leakage into the meatus. All measurements were performed in the NICU without disturbing the normal clinical practice. Whenever possible, the heating and ventilation system of the incubator were switched off for a few minutes, in order to reduce the background noise during CEOAE registration.

All recordings were judged subjectively on the presence of CEOAE by the first author, by visual estimation of the reproducibility of the CEOAE waveform and the presence of spectral energy of the response in excess of the background noise. Since there is no consensus on objective criteria for CEOAE presence (Dirckx ef 


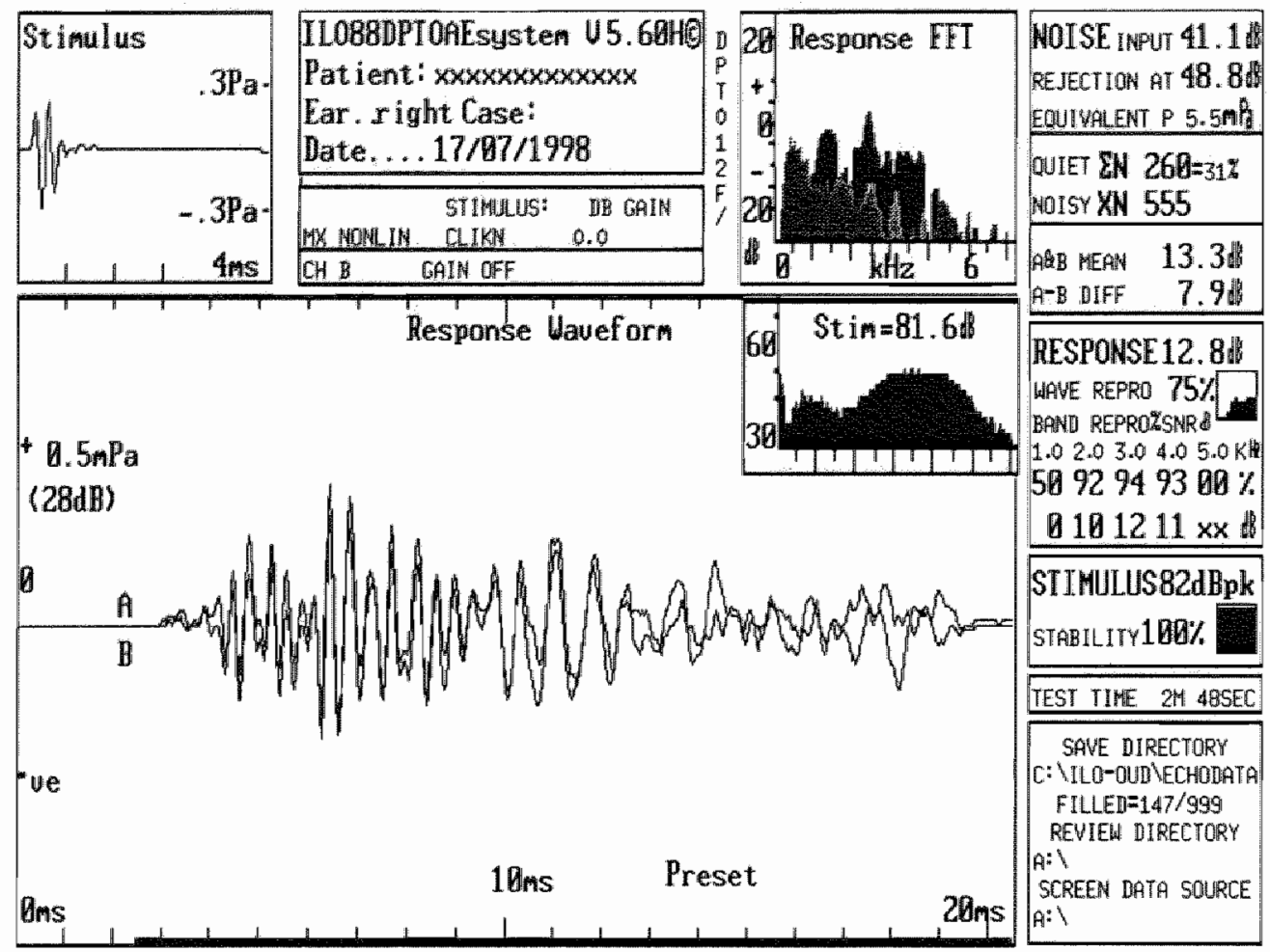

Figure 2.1.

Typical example of a CEOAE recording as given by the ILO88. It concerns the CEOAE taken from the right ear of a premature girl born at $3 /$ weeks $P C A$ with a birth weight of 1230 grams. This particular CEOAE is recorded inside the NICU during normal clinical practice at 36 weeks PCA. The waveform of the evoking click stimulus is plotted in the upper left of the window. The resulting CEOAE or 'Response waveform' is plotted in the largest lower left part. This latter response is the averaged result of 260 single clicks, divided into two simultameowsly recorded data buffers, 'A' and 'B', giving a direct visual control of the reproducibility of the CEOAE registration. This reproducibility is also presented as a percentage after mathematical crosscorrelation of the wo waveforms $A$ and $B$ ("WAVE REPRO $75 \% "$ in this particular case). The frequency content of the response woveform is given as the unshaded area in the upper window, denoted as 'Response FFT. The shaded area represents an estimate of the background noise, calculated from the misfit of the two buffers $A$ and $B$. The intensity of the response waveform and the background noise are also presented numerically in $D B S P L$, calculated from the mean response of the two waveforms $A$ and $B(A \& B M E A N 13.3 \mathrm{~dB}$ ), and the difference between the two waveforms $A$ and $B$ ( $A-B$ DIFF $7.9 \mathrm{~dB}$ ) respectively. The difference between these two walues can be used as an estimate of the signal to noise ratio. 
Table 2.1. Study characteristics and risk factors for sensormenal hearing loss of the 19 inforts under study.

\begin{tabular}{lll}
\hline PCA at birth (weeks) & Median: & 28.6 \\
& Range: & $25.6-32.0$ \\
Birth weight $(g)$ & Median: & 1010 \\
& Range: & $760-1940$ \\
Sex (male/female) & $8 / 11$ &
\end{tabular}

Occurrence of risk factors for sensorineural hearing loss (number of infants and percentage)

$\begin{array}{lll}\text { Birth weight < } 1500 \mathrm{~g} & 17 & (89 \%) \\ \text { Mechanical ventilation } & 8 & (42 \%) \\ \text { Administration of aminoglycosides } & 8 & (42 \%) \\ \text { Asphyyia at birth } & 6 & (32 \%) \\ \text { Hyperbilirubinaemia } & 3 & (16 \%) \\ \text { Meningitis } & 1 & (5 \%) \\ \text { Multiple bradycardic periods } & 12 & (63 \%) \\ \text { Sepsis } & 5 & (26 \%) \\ \text { Hypotension } & 4 & (21 \%) \\ \text { Persistent ductus arteriosus } & 4 & (21 \%)\end{array}$

al., 1996), the results from two more arbitrary chosen objective criteria are presented: (1) a reproducibility above 40 percent ('WAVE REPRO' in ILO88 terms); (2) a signal to noise ratio above $3 \mathrm{~dB}$ (being the difference between 'A\&B MEAN' and 'A-B DIFF' in ILO88 terms). Recordings without clear CEOAE and an eventual noise level (A-B DIFF') above $15 \mathrm{~dB}$ sound pressure level (SPL) were considered as failing attempts (see Figure 2.1 for more details).

\section{Patients}

Results are presented from a group of 19 preterm infants (38 ears) undergoing longitudinal CEOAE measurements in the NICU during the period from November 1993 to September 1994. During this period, there were no selection criteria other than monitoring CEOAE until term. Informed parental consent was obtained in each case.

Characteristics of the 19 infants are given in Table 2.1. A total of 226 attempts were made to register CEOAE. The number of CEOAE measurements per infant varied from three to 20 . The age of the infants at the time of CEOAE measure- 


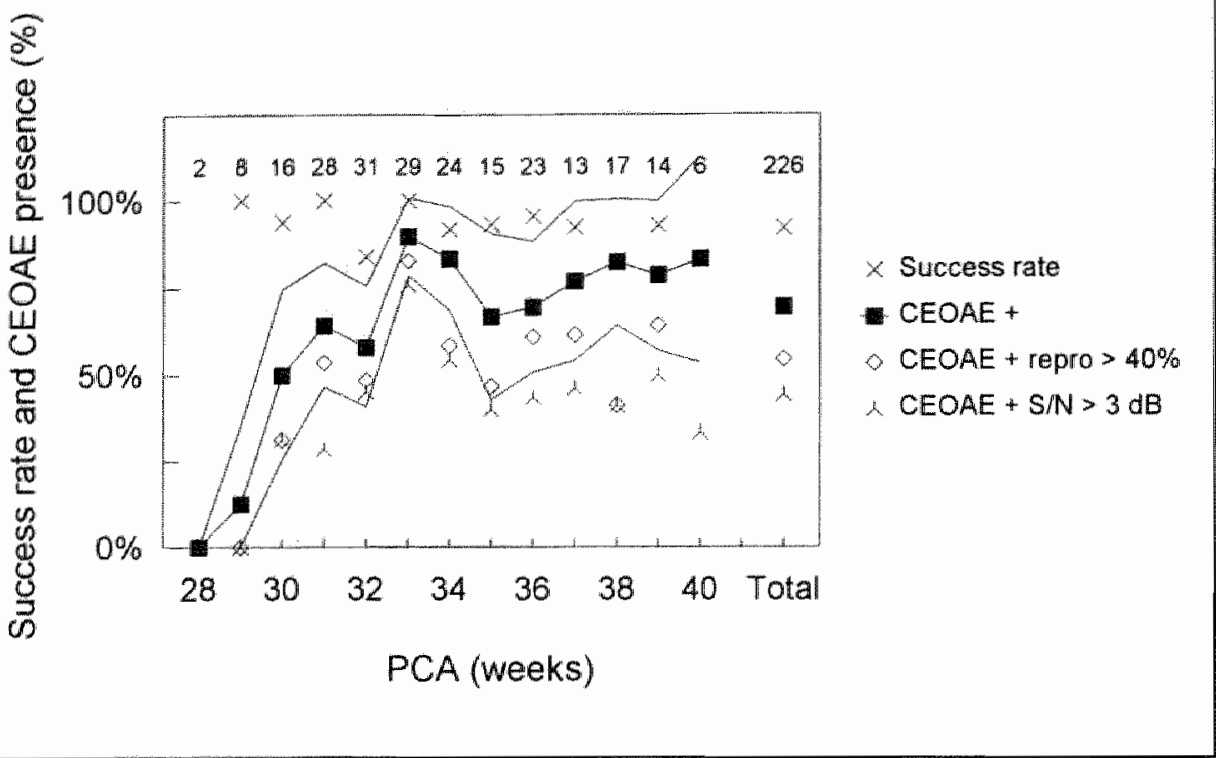

\section{Figure 2.2.}

Results of success rate and CEOAE presence in each week PCA, using three different criteria for CEOAE presence: (1) the subjective visual imferpretation of CEOAE (filled squares, with the 95 percent interval denoted by the solid lines); (2) a reproducibility above 40 percent (open diamonds) and (3) a signal to noise ratio above 3 aB (tripodal cross). The mumbers in the top denote the total number of attempts to register CEOAE within each week of PCA.

ment varied from 28.5 to 40.6 weeks PCA, or from 0 to 90 days after birth.

\section{Statistics}

Results are presented as median and range. Success rate and CEOAE presence are presented as a percentage of ears.

\section{RESULTS}

In 157 of the 226 attempts (69\%) CEOAE could be registered. Of these 157 recordings 123 (54\% of the total 226 attempts) showed a reproducibility above 40 percent, from which a total of 100 recordings ( $44 \%$ of the total 226 ) reached a signal to noise ratio $>3 \mathrm{~dB}$. In 51 of the 226 attempts $(23 \%)$ no CEOAE could 
be registered, despite the good circumstances during the measurements. In 18 of the 226 attempts $(8 \%)$ the CEOAE measurements could not be completed due to restlessness of the infant, or unavoidable treatment related high levels of ambient noise (above $55 \mathrm{~dB}$ peak equivalent). CEOAE registration during mechanical ventilation was possible as long as the ventilation rate did not exceed approximately 30 cycles per minute, although the continuous gas flow during positive end-expiratory pressure (PEEP) and continuous positive airway pressure (CPAP) generally interfered with CEOAE measurements.

The presenre of CEOAE and success rate are presented as a function of PCA in Figure 2.2. The CEOAE presence showed a trend of gradual increase from about 50 to 80 percent between weeks 30 and $40 \mathrm{PCA}$, apart from the relatively good results in weeks 33 and 34 . Using the objective criteria for CEOAE presence resulted in a similar trend. The CEOAE presence was lowered by about 15 percent by the use of the criterion of a reproducibility above 40 percent and with an additional 10 percent when the more strict criterion of a signal to noise ratio above $3 \mathrm{~dB}$ was applied. The success rate did not show any PCA related effect (Figure 2.2), apart from the fact that in week 28 all attempts to measure CEOAE failed. Therefore in the younger group of infants a considerable amount did not (yet) show CEOAE, despite sufficient conditions for CEOAE registration.

The test time, as registered by the ILO88, ranged from one minute 53 seconds to 15 minutes and 26 seconds per ear (median five minutes). The mean total test time per infant, including the equipment setup and probe placement, was approximately 15 minutes.

\section{DISCUSSION}

In the majority of the population in this study, CEOAE measurement proved feasible during the stay on the NICU, for the number of failing attempts was restricted to eight percent, regardless of the PCA of the infant. In the PCA range from 30 weeks to term, the CEOAE presence increased from about 50 to 80 percent around 40 weeks PCA. These results confirm a similar study under com- 


\section{Chapter 2}

parable circumstances by van Zanten et al. (1995), who were able to register CEOAE in 60 to 70 percent of cases with a PCA between 30 and 45 weeks, using a similar subjective CEOAE scoring method as in the present study. Since multiple registrations are made in one individual ear at different $\mathrm{PCA}$ in both studies, the CEOAE presence cannot be interpreted as a CEOAE prevalence per week PCA. These observations of CEOAE presence are therefore merely an indication for the CEOAE prevalence.

Earlier reports on screening of a NICU population around 37 to 39 weeks PCA yielded CEOAE presence around 79 percent, which is in good accordance with the present findings (Stevens et al., 1989; Uziel and Piron, 1991). The CEOAE presence observed in this study did not reach the 95 percent incidence of CEOAE reported in healthy term infants (Stevens et al., 1989; Uziel and Piron, 1991; Kok er al., 1993). This can be explained by the relatively high levels of background noise in the NICU due to the hum of the medical equipment present and noises produced by the activities during the normal clinical practice in the NICU. This elevated level of background noise possibly hinders the successful assessment of the lower level CEOAE within the population, yielding a lower CEOAE presence compared to measurements in healthy term infants, in which the circumstances can be optimized in this respect. In most of the preterm infants receiving mechanical ventilation a CEOAE registration is not possible due to the high level of background noise caused by the gas flow close to the recording microphone in the external ear canal.

Another explanation for the relatively low CEOAE presence might be a higher incidence of middle ear effusion in premature infants due, for instance, to longterm nasotracheal intubation (van Zanten et al., 1995; Sutton et al., 1996), blocking the retrograde transmission of the CEOAE through the middle ear. Since there are no validated methods available to measure the middle ear characteristics or pathology in infants below the age of four months (Holte et al., 1991; Smurzynski, 1994), an estimation of the middle ear effect on the data from our preterm population is not possible. 
Based on a cross-sectional study of CEOAE properties, no statistically significant variation of the amplitude and spectrum of the CEOAE could be found among the different age groups ranging from 32 to 41 weeks PCA (Bonfils et al, 1992; Morlet et al., 1993). In a preliminary report, however, an increasing CEOAE amplitude at increasing PCA in preterm infants has been reported by longitudinal observation of OAE properties of individual ears (Smurzynski, 1994). This might indicate that $\mathrm{OAE}$ properties are not yet fully mature in preterm infants. The increase of CEOAE amplitude was later confirmed by both longitudinal and cross-sectional studies (Brienesse et al., 1995; van Zanten et al., 1995; Brienesse et al., 1996). The increase of CEOAE amplitude in preterm infants could account for the observation of increasing CEOAE presence with increasing PCA. The lower level CEOAE of the younger infants are more difficult to register than the higher level CEOAE of the older ones, especially in the NICU circumstances where high levels of background noise are present. A lower CEOAE presence might therefore be expected in the younger infants.

As expected, the percentage of CEOAE presence in the present study depends on the preferred criterion for CEOAE interpretation. In particular, the recordings with a higher level of background noise resulted in a lower signal to noise ratio and reproducibility and consequently in a lower CEOAE presence when the two more strict objective criteria were used (Figure 2.2). The lack of consensus regarding the objective numerical criterion to be used has been addressed by Dirckx et al. (1996), who reported that for a given set of CEOAE recordings, prevalence varies from 61 to 90 percent, depending on the 21 different ways of numerical scoring that are used by 25 teams for neonatal hearing screening. In the results of the present study, the use of the three different criteria resulted in a similar effect on the CEOAE presence. Nevertheless, even the most strict criterion of a signal to noise ratio above $3 \mathrm{~dB}$ resulted in a considerable CEOAE presence down to 30 percent of ears in infants with a PCA of 30 weeks (Figure 2.2).

CEOAE are being used in the NICU in hearing screening protocols for infants at 
risk at PCAs above 37 weeks (Stevens et al, 1989; Kennedy et al, 1991; Uziel and Piron, 1991; Meredith et al., 1994). The applicability of CEOAE as a screening tool in the NICU is restricted to the time as close as possible to hospital discharge, for any screening tool used too early in the sick infants of the NICU is expected to be a poor predictor of the long-term outcome. In our view, the applicability of CEOAE below the PCA of 37 weeks lies in the monitoring of auditory integrity. It is our experience that once a CEOAE is detected in a preterm infant, it is very likely to appear again at later moments, regardless of the PCA, which makes it possible to monitor CEOAE by performing longitudinal measurements (Smurzynski, 1994; Brienesse et al., 1995; Brienesse et al., 1996). Although the CEOAE presence at the PCA around 30 weeks is about 50 percent, it is increasing with time, so that the percentage of infants who can be monitored for auditory integrity is increasing likewise.

Preterm infants generally are at high risk for acquiring hearing loss, due for instance to the occurrence of hypoxic periods or treatment with potential ototoxic drugs. CEOAE could be sensitive for the acute influences of these events on the auditory integrity. A possible clinical application of CEOAE might therefore be the monitoring of the cochlear function during treatment with ototoxic drugs (Hotz et al., 1994). Maybe CEOAE can be helpful in determining the optimal administration strategy of potential ototoxic drugs. The fact that NICU survivors demonstrate sensorineural hearing loss up to 50 times more frequently than normal newborns (Eavey et al., 1995) justifies further research for both the basic properties and possible clinical merits of CEOAE in preterm infants during their stay on the NICU.

\section{ACKNOWLEDGEMENTS}

The authors wish to thank all parents and NICU personnel for their co-operation. This study was supported by grants from the Heinsius-Houbolt Foundation and the Special Clinical Research Fund of the University Hospital Maastricht. 


\section{REFERENCES}

Bess, F. H. and Paradise, J. L. (1994). "Universal screening for infant thearing impaiment: not simple, not risk-free, not necessarily beneficial, and not presently justified," Pediatrics 93 , $330-334$.

Bonfils, P., Francois, M., Avan, P., Londero, A., Trotoux, J. and Narcy, P. (1992) "Spontaneous and evoked otoacoustic emissions in preterm neonates," Laryngoscope $102,182-186$. Brienesse, P., Anteunis, L. J. C., Wit, H. P., Gavilanes, A. W. D. and Maertzdorf, W. J. (1995). "A longitudinal prospective study of otoacoustic emissions in preterm infants: an indication for cochlear maturation?," Pediatr Res 37, 251A.

Brienesse, P., Anteunis, L. I. C., Wit, H. P., Gavilanes, A. W. D. and Maertzdorf, W. J. (1996). "Otoacoustic emissions in preterm infants: indications for cochlear development?" Audiology 35, 296-306.

Curnock, D. A. (1993) "Identifying hearing impairment in infants and young children," $\mathrm{Br}$ Med J 307, 1225-1226.

Davis, A., Bamford, J., Wilson, I., Ramkalawan, T., Forshaw, M. and Wright, S. (1997). "A critical review of the role of neonatal hearing screening in the detection of congenital hearing impairment," Health Technol Assessment 1 (10).

Dirckx, J. J., Daemers, K., Somers , T., Offeciers, F. E. and Govaerts, P. J. (1996). "Numerical assessment of TOAE screening results: currently used criteria and their effect on TOAE prevalence figures," Acta Otolaryngol (Stockh) 116, 672-679.

Eavey, R. D., Bertero, M d. C., Thornton, A. R., Herrmann, B. S., Joseph, J. M., Gliklich, $\mathbb{R}$. E., Krishnamoorthy, K. S. and Todres, I. D. (1995). "Failure to clinically predict NICU hearing loss" "Clin Pediatr 34, 138-145.

Holte, L., Margolis, R. H. and Cavanaugh, R. M., Jr. (1991). "Developmental changes in multifrequency tympanograms," Audiology 30, 1-24.

Hotz, M. A., Harris, F. P. and Probst, R. (1994). "Otoacoustic emissions: an approach for monitoring aminoglycoside-induced ototoxicity, "Laryngoscope 104, 1130-1 134.

Kemp, D. T. (1978). "Stimulated acoustic emissions from within the human auditory system," J Acoust Soc Am 64, 1386-1391.

Kemp, D. T., Ryan, S. and Bray, P. (1990). "A guide to the effective use of otoacoustic emissions," Ear Hear 11, 93-105.

Kennedy, C. R., Kümm, L., Dees, D. C., Evans, P. I. Hunter, M., Lenton, S. and Thornton, R. D. (1991). "Otoacoustic emissions and auditory brainstem responses in the newborn," Arch Dis Child 66, 1124-1129.

Kok, M. R., van Zanten, G. A., Brocaar, M. P. and Wallenburg, H. C. S. (1993). "Clickewoked oto-acoustic emissions in 1036 ears of healthy newborns," Audiology 32, $213-224$.

Meredith, R., Stephens, D., Hogan, S., Cartlidge, P. H. and Drayton, M. (1994). "Screening 
for hearing loss in an at-risk neonatal population using evoked otoacoustic emissions," Scand Audiol 23, 187-193.

Morlet, T, Collet, L., Salle, B. and Morgon, A. (1993). "Functional maturation of cochlear active mechanisms and of the medial olivocochlear system in humans," Acta Otolaryngol (Stockh) 113, 271-277.

National Institutes of Health (1993). "Early identification of hearing impairment in infants and young children," NIH Consensus Statement 11, 1-24.

Probst, R., Lonsbury Martin, B. L. and Martin, G. K. (1991). "A review of otoacoustic emissions," J Acoust Soc Am 89, 2027-2067.

Srnurzynski, J. (1994). "Longitudinal measurements of distortion-product and click-evoked otoacoustic emissions of preterm infants: preliminary results," Ear Hear 15, 210-223.

Stevens, J. C., Webb, H. D., Hutchinson, J., Connell, J., Smith, M. F. and Buffin, J. T. (1989). "Click evoked otoacoustic emissions compared with brain stem electric response," Arch Dis Child 64, 1105-1111.

Sutton, G. J., Gleadle, P. and Rowe, S. J. (1996). "Tympanometry and otoacoustic emissions in a cohort of special care neonates," $\mathrm{Br} J$ Audiol 30, 9-17.

Uziel, A and Piron, J. P. (1991). "Evoked otoacoustic emissions from normal newborns and babies admitted to an intensive care baby unit," Acta Otolaryngol (Stockh) Suppl 482, 8591.

wan Zanten, B. G., Kok, M. R., Brocaar, M. P. and Sauer, P. J. (1995). "The click-evoked otoacoustic emission, c-EOAE, in preterm-born infants in the post conceptional age range between 30 and 68 weeks," Int J Pediatr Otorhinolaryngol Suppl 32, S187-197.

Watkin, P. M. (1996) "Neonatal otoacoustic emission screening and the identification of deafness," Arch Dis Child 74, F16-F25.

Zorowka, P. G. (1993). "Otoacoustic emissions: a new method to diagnose hearing impairment in children," Eur J Pediatr 152, 626-634. 


\section{CHAPTER}

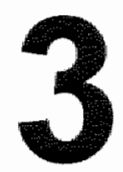

\section{Otoacoustic emissions in preterm infants: indications for cochlear development?}

Brienesse, P., Anteunis, L. J. C., Wit, H. P., Gavilanes, A. W. D., Maertzdorf, W. J. (1996). Audiology 35, 296-306. 
Chapter 3 


\section{ABSTRACT}

A longitudinal study of click evoked otoacoustic emissions (CEOAE) in 19 ears of 11 preterm infants (post-conceptional age ( $\mathrm{PCA}$ ): 30-39 wks) resulted in at total of 90 CEOAE recordings. All but one of the 19 ears showed an increase of CEOAE amplitude at increasing PCA. The mean increase rate was $1.36 \mathrm{~dB}$ per week (dB/wk) for the left ears $(n=11, \mathrm{SD}=1.04 \mathrm{~dB} / \mathrm{wk})$, and $1.17 \mathrm{~dB} /$ wk for the right ears ( $n=8, \mathrm{SD}=0.87 \mathrm{~dB} / \mathrm{wk}$ ). In six ears of three infants we were able to follow a total of 15 frequencies of spontaneous otoacoustic emissions (SOAE). All of the monitored SOAE frequencies showed a positive shift in frequency with time, ranging from about $10 \mathrm{~Hz} / \mathrm{wk}$ around $2000 \mathrm{~Hz}$ to about $50 \mathrm{~Hz} / \mathrm{wk}$ around $5000 \mathrm{~Hz}$. This increase of CEOAE amplitude and SOAE frequency indicates that OAE properties are not fully developed in preterm infants. Although the influence of middle ear properties cannot be excluded or proved, the observed SOAE frequency shift suggests development of the fine structures in the cochlea itself. 


\section{INTRODUCTION}

Otoacoustic emissions (OAE) are sounds of cochlear origin (Kemp, 1978). They are believed to be produced by the active contraction of the outer hair cells in the organ of Corti. As a result of this motile activity, a pressure wave travels backward through the middle ear and can be recorded acoustically with a sensitive microphone in the meatus. Click-evoked otoacoustic emissions (CEOAE) arise as a broad-band acoustic signal of approximately $20 \mathrm{~ms}$ duration after an evoking click stimulus, whereas spontaneous $\mathrm{OAE}$ (SOAE) arise spontaneously as a continuous narrow-band signal around one or more frequencies (Probst et al., 1991).

Since the first description of OAE by Kemp (1978), much research has been done to investigate the basic properties of SOAE and CEOAE in both adults and newborn infants. Because of the nearly 100 percent incidence of CEOAE in a normal hearing population, together with the fact that no emission can be evoked in ears with a hearing loss exceeding 30 to $35 \mathrm{~dB}$ hearing level, the CEOAE has proven to be a sensitive, objective and non-invasive hearing screening instrument, with the potential to reach the goal of universal hearing screening at birth (Curnock, 1993) as formulated by the Joint Committee on Infant Hearing (1991). The SOAE, with an incidence of 35 to 50 percent among the normal hearing subjects, has merely been of scientific interest so far. Whereas OAE measurement has the potential for monitoring of the auditory integrity, little is known about the OAE properties among the preterm population, although there is a high risk for acquired hearing impairment. In the future, more information about the $\mathrm{OAE}$ properties might lead to a greater feasibility of $\mathrm{OAE}$ in the neonatal intensive care unit (NICU), because a possible clinical application might be the monitoring of the ototoxic effects of, for instance, hypoxic periods or hyperbilirubinemia. Maybe CEOAE can be helpful in determining the optimal administration strategy of potential ototoxic drugs.

On the one hand, the outer hair cell properties were believed to be mature at 32 weeks of post-conceptional age (PCA), since no statistically significant variation 
Table 3.1. Characteristics of the 11 infants under study.

\begin{tabular}{lllll}
\hline Infant & Birth weight & Gender & $\begin{array}{l}\text { Gestationall age } \\
\text { at birth } \\
(\text { wks })\end{array}$ & Risk factors \\
& $(\mathrm{kg})$ & male & 28.6 & (see legend) \\
\hline p1 & 1.00 & male & 28.6 & $1,2^{*}$ \\
p2 & 1.32 & male & 29.6 & 1,2 \\
p3 & 0.99 & female & 29.6 & 1 \\
p4 & 0.82 & female & 29.0 & $1,2,3$ \\
p5 & 1.27 & male & 29.0 & 1,2 \\
p6 & 1.07 & male & 31.9 & 1,2 \\
p7 & 1.94 & female & 31.9 & 3 \\
p8 & 1.85 & female & 31.0 & $1,2 * 4$ \\
p9 & 1.23 & fermale & 28.0 & $1,2,4$ \\
p10 & 1.01 & male & 27.3 & $1,2^{*}, 4$ \\
p11 & 0.94 & & &
\end{tabular}

Risk factors for sensorineural hearing impairment are (Joint Committee on Infant Hearing, 1991):

1. Birth weight less than $1.5 \mathrm{~kg}$.

2. Administration of potential atotoxic medication ( $2^{*}$ for more than five days).

3. Depression (low Apgar score, or asphyxia) at birth, as judged by a paediatrician.

4. Prolonged mechanical ventilation for a duration of more than nine days. None of the risk factors occurred during the period of DAE measurements.

of the amplitude and spectrum of the CEOAE could be found among the different age groups ranging from 32 to 41 weeks post conception (Bonfils et al, 1992; Morlet et al., 1993). The incidence and overall frequency distribution of SOAE in this population showed the same tendency as in normal fullterm newborns (Morlet ef al., 1993). On the other hand, Chuang ef al. (1993) believed that the properties of the emission spectrum might be related to PCA, based on longitudinal observations of some CEOAE spectra. Recently, we started to monitor the CEOAE of preterm infants. Based on the first results, we presumed a longitudinal intra-individual increase of the CEOAE amplitude (Brienesse et al., 1994). On the supposition that OAE properties are not yet fully developed in preterm infants, we conducted a prospective longitudinal study of the intra-individual changes in CEOAE and SOAE properties of 11 preterm infants. Here we present the results concerning the CEOAE amplitude and the SOAE frequency. 


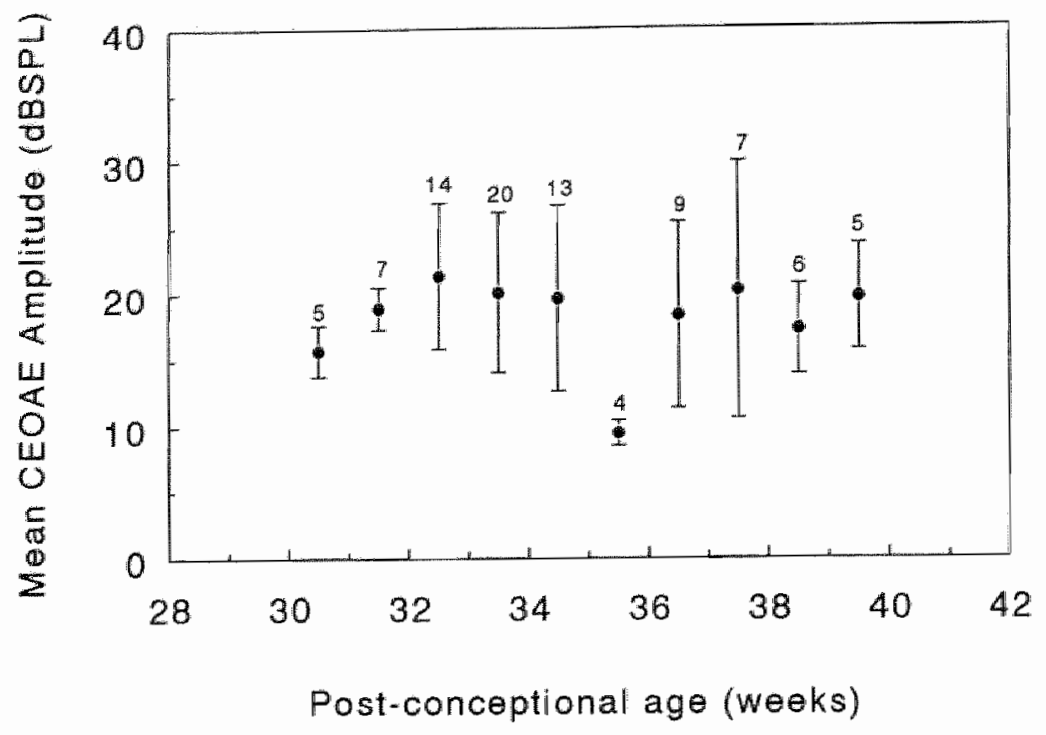

\section{Figure 3.1.}

Cross-sectional data analysis of all 90 CEOAE measurements in 19 ears under study, representing the mean CEOAE amplinde in $D B S P L$ wirhin each week of PCA. The numbers of measurements per group are giwen on top of each error bar. In accordance with earlier studies (Bonfils et al., 1992; Morlet et al., 1993), no statistical significant change in CEOAE amplitude with PCA could be found, whereas the majority of the longitudinal observations of Figure 3.2 did show an increase of $C E O A E$ amplitude with $P C A$.

\section{METHODS}

\section{Subjects}

Eleven preterm infants, admitted to the NICU, were enrolled in this prospective longitudinal study. These infants were selected from an ongoing study on the feasibility of OAE measurement in the NICU itself. Informed parental consent was obtained in each case. Ten of the infants showed one or more risk factors for sensorineural hearing impainment as formulated by the Joint Committee on Infant Hearing (1991), such as administration of potential ototoxic drugs or mechanical ventilation (Table 3.1). These risk factors occurred prior to the period of OAE measurements. 


\section{Measurements}

CEOAE and SOAE were recorded using the ILO88 Otoacoustic Emission Analyser (Otodynamics, London, UK: version 3.94), as described elsewhere (Kemp et al., 1990). All CEOAE were measured using the neonatal probe with disposable tip. A rectangular click stimulus of $80 \mu$ s electrical duration was used. The probe was fitted and refitted when necessary until the frequency components of the stimulus were as equally distributed in the frequency domain as possible, with a minimal noise leakage into the ear canal. The amplitude of the resulting acoustic click ranged from 79.6 to $82.8 \mathrm{~dB} \mathrm{SPL}$ peak equivalent $(n=90$, mean $=$ $81.4 \mathrm{~dB}$ SPL, $\mathrm{SD}=0.6 \mathrm{~dB} \mathrm{SPL})$. Each CEOAE response was the averaged result of 260 responses to a stimulus in the non-linear mode. The resulting CEOAE amplitude was directly given by the ILO88 in dB SPL ('Response' in ILO88 terms). The difference between two simultaneously recorded data buffers as calculated by the ILO88 and denoted as 'A-B' was taken as an estimate of noise. Only CEOAE's with a signal to noise ratio of $3 \mathrm{~dB}$ or more were included.

SOAE were measured using the 'SpontaneousSearch' operation mode of the ILO88, using the same probe and fitting procedure as in the CEOAE measurement described above. In this mode, the SOAE were synchronized by an $80 \mu \mathrm{s}$ pulse at a mean level of $77.2 \mathrm{~dB}$ SPL peak equivalent $(n=27, \mathrm{SD}=2.6 \mathrm{~dB}$ SPL). This pulse was repeated every $80 \mathrm{~ms}$. The synchronized SOAE were registered by time-domain averaging of the $20 \mathrm{~ms}$ to $80 \mathrm{~ms}$ post-stimulus time interval, followed by a fast Fourier transformation (FFT) with a resolution of $12.3 \mathrm{~Hz}$. Only SOAE frequencies were included which satisfied the following criteria: (1) the $\mathrm{SOAE}$ recording was the averaged result of at least 100 single responses; (2) the amplitude of the SOAE frequency was at least $-15 \mathrm{~dB}$ SPL; and (3) the amplitude of the SOAE frequency was at least $10 \mathrm{~dB}$ above the noise level in its vicinity. The latter criterion was judged visually by the first author from the FFT spectrum given by the ILO88. The second criterion was applied in order to prevent the false identification of peaks in the FFT spectrum as a SOAE. Wable and Collet (1994) performed a comparison of this ILO88 method versus a spectral average without any click synchronization, demonstrating that all peaks which 


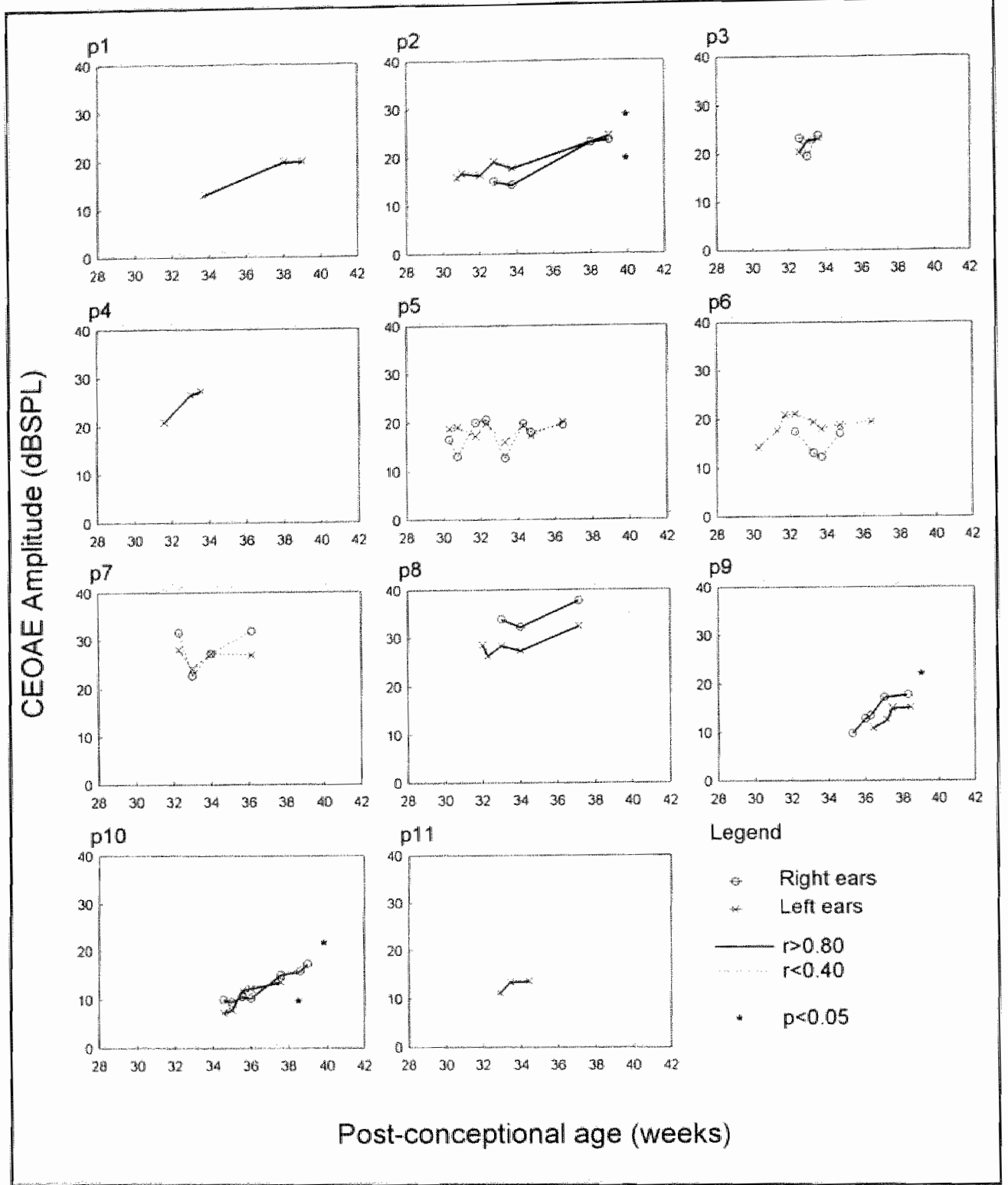

Filgure 3.2

CEOAE amplinde of both left and right ears as a function of PCA of the 11 infants under sindy. The solid lines denote high correlation coefficients $(r>0.8)$ in terms of Pearson's productmoment correlation of CEOAE amplitude with PCA. The dashed lines connect the measurements of the ears with relatively unstable courses of CEOAE amplitude $(r<0.4)$. 
Table 3.2. Pearson's product moment correlation analysis of the CEOAE anplitude with time (PCA).

\begin{tabular}{llclll}
\hline Infant & Ear & $\begin{array}{l}\text { CEOAE amplitude } \\
\text { increase rate (dB/wk) }\end{array}$ & $n$ & $r$ & $\begin{array}{l}\text { SOAE } \\
\text { presence }\end{array}$ \\
\hline p1 & Left & 1.37 & 3 & 0.99 & + (left \& right) \\
p2 & Left & 0.98 & 6 & $0.96^{*}$ & + \\
& Right & 1.56 & 4 & $0.98^{*}$ & + \\
$p 3$ & Left & 2.69 & 3 & 0.89 & \\
& Right & 0.87 & 3 & 0.19 & \\
p4 & Left & 3.35 & 3 & 0.98 & \\
p5 & Left & 0.10 & 8 & 0.14 & + \\
& Right & 0.52 & 8 & 0.35 & + \\
$p 6$ & Left & 0.42 & 8 & 0.39 & \\
& Right & -0.18 & 4 & 0.07 & \\
$p 7$ & Left & 0.10 & 4 & 0.09 & \\
& Right & 0.92 & 4 & 0.35 & \\
$p 8$ & Left & 0.94 & 5 & 0.85 & \\
& Right & 1.13 & 3 & 0.87 & \\
p9 & Left & 2.21 & 4 & 0.89 & \\
& Right & 2.70 & 5 & $0.93 *$ & \\
p10 & Left & 1.38 & 5 & $0.99 *$ & \\
& Right & 1.81 & 7 & $0.97 *$ & \\
p11 & Left & 1.43 & 3 & 0.82 & $*: p<0.05$
\end{tabular}

were not attributable to a SOAE had notably low amplitudes (around -25 to -20 dB SPL with a maximum of $-17.2 \mathrm{~dB}$ SPL).

\section{Data analysis}

The Pearson product moment correlation test was used to determine the relationship between the CEOAE amplitude and PCA. The slope of the resulting linear fit was interpreted as an estimate of the CEOAE amplitude increase rate. Results were considered significant at $p<0.05$.

\section{RESULTS}

In our experience background noise from external sources has been found to be the main limiting factor in the successful assessment of OAE. For instance, in some incubators the noise level produced by the heating and ventilation system prohibited OAE measurements. Furthermore, CEOAE registration during me- 
chanical ventilation was possible as long as the ventilation rate did not exceed approximately 30 cycles per minute, although positive end-expiratory pressure (PEEP) and continuous positive airway pressure (CPAP) generally interfered with OAE measurement.

\section{CEOAE}

In 19 ears of the 11 infants under study we succeeded in gathering a minimum of at least three successive CEOAE measurements, in a period ranging from one to eight weeks. A total of 90 CEOAE measurements were included. In Figure 3.1 the data are presented cross-sectionally by giving the mean CEOAE amplitude within each week of PCA, showing no statistical significant age related effects. Figure 3.2 shows the CEOAE amplitude levels in $\mathrm{BB}$ SPL of the 11 left and eight right ears of the 11 infants under study as a function of PCA. Table 3.2 gives the results of the anallysis of correlation between CEOAE amplitude and PCA. As calculated from the linear fits through the observations of each individual ear, all but one of the 19 ears showed an increase in CEOAE amplitude on account of a positive CEOAE amplitude increase rate. The mean CEOAE amplitude increase rate was $1.36 \mathrm{~dB} / \mathrm{wk}(n=11, \mathrm{SD}=1.04 \mathrm{~dB} / \mathrm{wk})$ for the left ears and $1.17 \mathrm{~dB} / \mathrm{wk}$ ( $n=8, \mathrm{SD}=0.87 \mathrm{~dB} / \mathrm{wk}$ ) for the right ears. Seven ears (from four patients) showed a relatively unstable course of CEOAE amplitude with PCA $(r<0.4)$, which makes the estimate of the CEOAE amplitude increase rate more speculative. Considering only the 12 ears with a relatively high correlation with PCA $(r>$ $0.8)$, the mean CEOAE amplitude increase rate was $1.79 \mathrm{~dB} / w \mathrm{k}(n=8, \mathrm{SD}=$ $0.87 \mathrm{~dB} / \mathrm{wk})$ and $1.80 \mathrm{~dB} / \mathrm{wk}(n=4, \mathrm{SD}=0.66 \mathrm{~dB} / \mathrm{wk})$ for the left and right ears respectively. Despite the limited number of observations per ear, five ears (from three patients) showed a significant increase in CEOAE amplitude $(p<0.05)$.

\section{SOAE}

In six ears out of three infants we were able to monitor a total of 15 SOAE frequencies. All these SOAEs shifted in time towards higher frequencies. Figure 3.3 shows an example of two SOAE recordings with an interval of four weeks. Another example is given in Figure 3.4, which illustrates the frequency shift of 


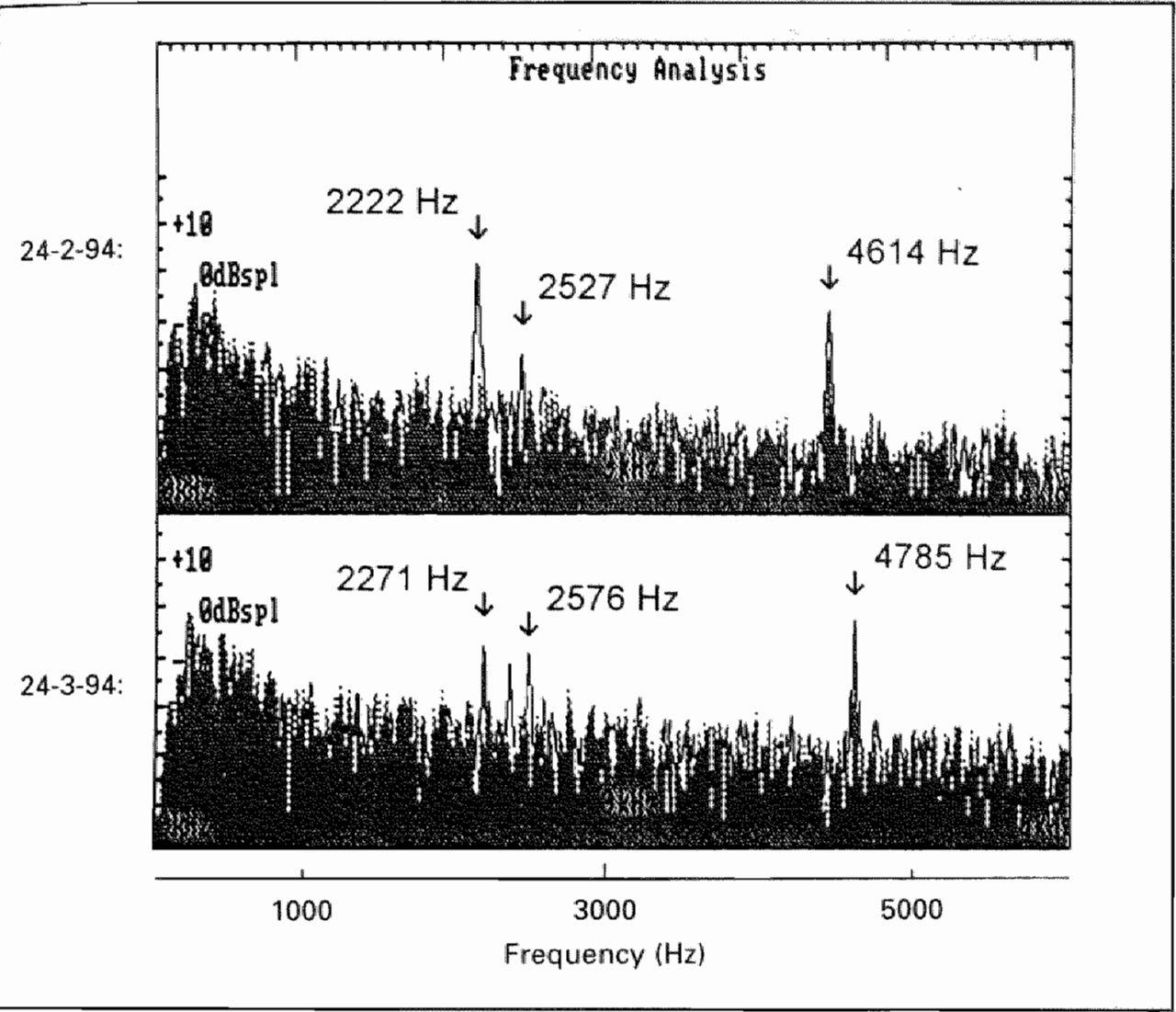

Figure 3.3.

Example of two SOAE recordings of the lefi ear of infant $p 5$, with an interval of four weeks. Both windows represent the frequency contents of the SOAE recordings, up to $6 \mathrm{kHz}$. In this particular case, various SOAE frequencies can be identified as the unshaded narrow-band peaks overcoming the shaded broadband background noise.

The individual pattern of $S O A E$ frequencies can be recognized in both recordings. More exact analysis showed a shift of all SOAE frequencies during the intermediate four weeks towards higher frequency.

four different SOAE frequencies in one infant's left ear, as a function of PCA. The amount of frequency shift tended to be frequency dependent, since higher frequencies demonstrated relatively larger frequency shifts (Figure 3.4). In Figure 3.5 the overall SOAE frequency shift rate (in $\mathrm{Hz} / \mathrm{wk}$ ) of each of the $15 \mathrm{SOAE}$ frequencies, is plotted as a function of their frequency. Regardless of any possible 


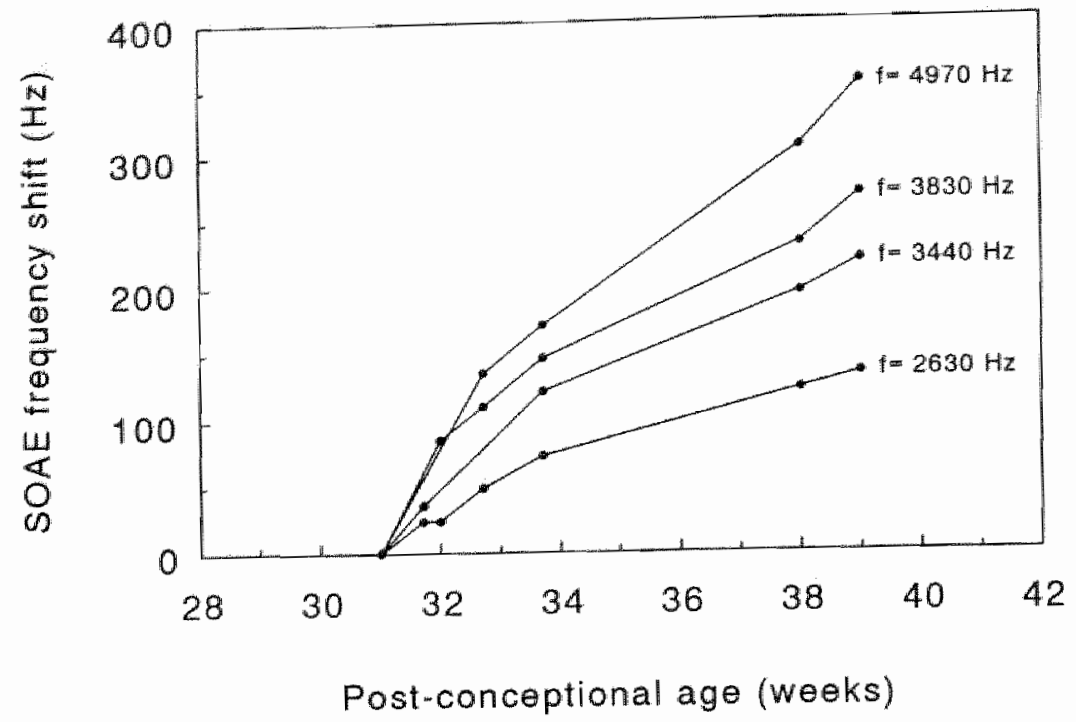

\section{Figure 3.4.}

Course of four SOAE frequencies (in $\mathrm{Hz}$ ) in the left ear of infant $\mathrm{p} 5$ as a function of $\mathrm{PCA}$. Note that the higher SOAE frequencies show a larger overall frequency shift in time than lower SOAE frequencies.

PCA related effects, the frequency shift rate roughly varied from about $10 \mathrm{~Hz} /$ wh around $2 \mathrm{kHz}$ to about $50 \mathrm{~Hz} / \mathrm{wk}$ around $5 \mathrm{kHz}$.

\section{DISCUSSION}

This longitudinal study demonstrated an overall increase in CEOAE amplitude on account of a positive correlation with PCA. Furthermore, all of the monitored SOAE frequencies showed a frequency shift towards higher frequencies. These results indicate that $\mathrm{OAE}$ properties are not yet fully developed in preterm infants below 40 weeks' gestation, and could be used as an index of maturation.

Based on the early observation of OAE in 134 ears from 67 preterm infants by Bonfils et al. (1992), the outer hair cell properties were assumed to be mature at 32 weeks post conceptional age, because in a cross-sectional analysis no signifi- 


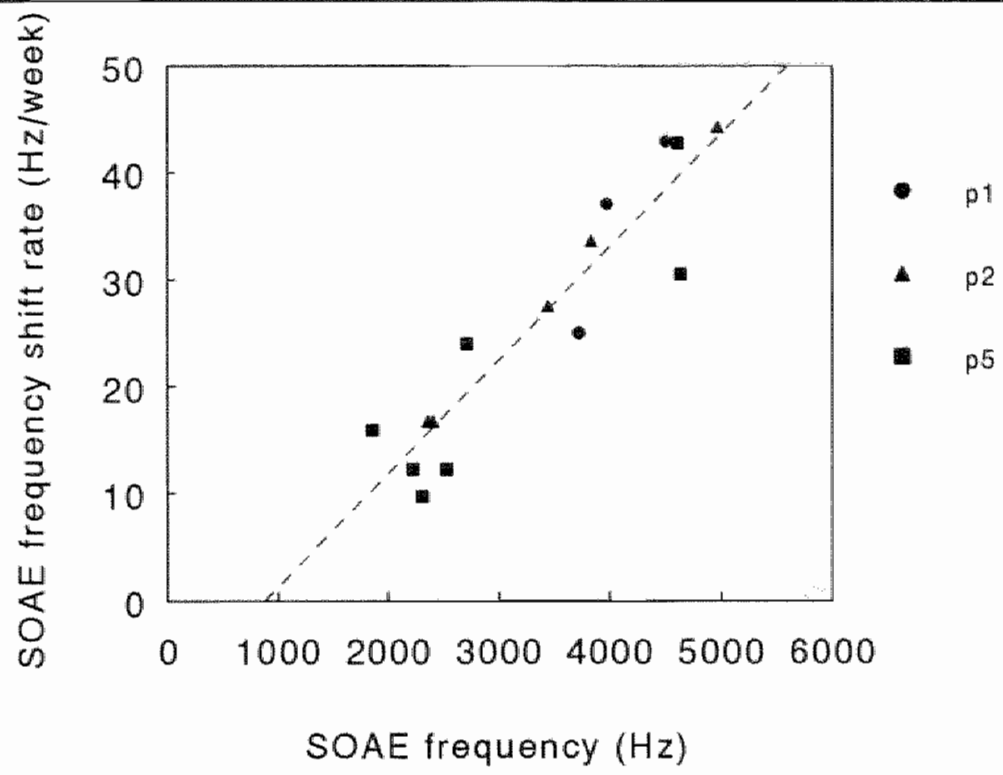

\section{Figure 3.5 .}

Rate of overall frequency shift in Hz/Wk of all 15 SOAE frequencies of infant $p 1, p 2$ and $p 5$ as a function of frequency. Regardless of any possible PCA related effects, the rafe of frequency shift roughly varies from $10 \mathrm{~Hz} / \mathrm{wk}$ around $2 \mathrm{kHz}$ to $50 \mathrm{~Hz} / \mathrm{wk}$ around $5 \mathrm{kHz}$.

cant variation of $\mathrm{CEOAE}$ amplitude with age could be found. These results were confirmed in a similar cross-sectional study of CEOAE in 42 preterm infants by Morlet et al. (1993). Only one recent crossusectional study by van Zanten et al.(1995) reported a saturating growth of the CEOAE amplitude, by analysis of the CEOAEs from 22 infants, which were selected from a larger group of 144 preterm infants. A cross-sectional analysis of the CEOAE data of the present study failed to show any significant age related effect (Figure 3.1). In a longitudinal study of some CEOAE spectra, Chuang et al. (1993) first proposed that CEOAE properties might be related to PCA. In a later study by Smurzynski (1994) the growth of amplitude of both CEOAE and distortion product OAE (DPOAE) was confirmed by longitudinal observation of 13 ears of seven preterm infants. Together with the presently observed increase in CEOAE amplitude, this is another strong indication that OAE properties are indeed not fully developed in 


\section{Chapter 3}

pretern infants. Apparently, the great inter-individual variation of CEOAE amplitude in the population under study generally masks the intra-individual maturation of this particular CEOAE property, when the data are averaged and analyzed cross-sectionally.

If the CEOAE amplitude reflects the development of the inner and/or middle ear, one would expect an intra-individual dependence in the results of those patients who had both ears tested, since the two ears of one subject do not develop independently. The results presented in Figure 3.2 and Table 3.2 indeed show an intra-individual dependence, since the CEOAE amplitude of the left and right ear of each patient often shows a similar course with PCA. This is supported by the fact that the seven ears with relatively unstable CEOAE amplitudes $(r<0.4)$ concerned only four patients ( $33, \mathrm{p} 5, \mathrm{p} 6$ and $\mathrm{p} 7$ ). All other patients had relatively stable CEOAE amplitudes ( $r>0.8$ ). Furthermore, the five ears with a significant increase in CEOAE amplitude $(p<0.05$ ) concerned the minimum of three patients ( $\mathrm{p} 2, \mathrm{p} 9$ and $\mathrm{p} 10)$. The fact that the infants under study are premature and admitted to a NICU implicates that the results might be influenced by unknown effects of their clinical condition and treatment, which could partly account for the intra-individual dependence in the observed CEOAE amplitude. We limited this problem as much as possible by ensuring that none of the acknowledged risk factors for sensorineural hearing impairment according to the position statement of the Joint Committee on Infant Hearing (1991) occurred during the period we monitored the OAE. A retrospective study of the status of the infants did not lead to the identification of any common events which could account for the relative instability of CEOAE amplitude in four of the 11 infants under study.

Another more surprising phenomenon indicating the development of OAE in preterm infants is the observed frequency shift of the SOAE. In a pilot study, Smurzynski (1994) reported the shift of nine different SOAE frequencies in two preterm infants, which is confirmed by the shift of the 15 SOAE frequencies in three infants reported in the present study. Although the results are somewhat preliminary, in view of the total number of infants investigated, the linear relation- 
ship in Figure 3.5 suggests that the SOAE frequency shift might be proportionally constant relative to the SOAE frequency. The shape of the curves in Figure 3.4 suggests that the observed SOAE frequency shift depends on the PCA. The frequency shift tends to slow down towards higher PCAs. To further investigate both tendencies, more data needs to be gathered.

It is interesting to speculate on the underlying mechanisms causing the observed changes in OAE properties. To differentiate between middle ear and cochlear influences on the development of OAE, it is essential to evaluate the status of the middle ear. However, examining the middle ear by means of otoscopy or tympanometry in preterm infants is rather controversial. It has not been determined whether tympanometry is a reliable indicator of middle ear pathology in infants below the age of four months (Holte et al, 1991), let alone in preterm infants. So, in the present study, as well as in former studies, there is a lack of information about the middle ear status during $\mathrm{OAE}$ registration. From term birth to the age of 24 months the middle ear impedance changes in a profound way, and this development is not yet complete at 24 months (Keefe et al., 1993; Keefe et al., 1994). It might be expected that the middle ear characteristics in preterm infants differ even more from adults. Although some anatomical changes might be expected in the middle ear during the last ten weeks of gestation, there is a shortage of data conceming the influence of these changes on the actual middle ear transmission (Saunders et al., 1983; Saunders et al., 1993). At this point the influence of the middle ear on the development of $\mathrm{OAE}$ remains unknown. This is especially the case where CEOAE amplitude is concerned, since there is a direct relationship between the CEOAE amplitude and the middle ear transmission. It is possible that the observed increase in CEOAE amplitude merely reflects a development of middle ear impedance in preterm infants, similar to the development reported by Keefe et al. (1993; 1994).

Considering the SOAE frequency, a possible influence of the middle ear is less straightforward, but cannot be excluded. It is known that a change of compliance of the middle ear by for instance an increase of meatal air pressure (Kemp, 1981; 
Wilson and Sutton, 1981; Schloth and Zwicker, 1983; Hauser et al., 1993) or the voluntary contraction of middle ear muscles (Burns et al., 1993), causes a shift of the frequency of a SOAE, mostly towards higher frequencies. So again it is possible that the observed shift of SOAE frequency in preterm infants is merely the effect of changes in the frequency specific loading of the cochlea by the middle ear, induced by development of middle ear impedance. Regarding the observed SOAE frequency shift in the present study, there are at least three factors which might indicate that cochlear or more central processes are involved. First, the total amount of frequency shift of the $S O A E$ reported here seems to be higher than middle ear induced SOAE frequency shifts. For instance, Kemp (1981) reported a maximal SOAE frequency shift of about $50 \mathrm{~Hz}$ per $300 \mathrm{daPa}$. The total frequency shift up to $350 \mathrm{~Hz}$ as reported in Figure 3.4 , is of a different order of magnitude. A pure middle ear influence, like a change in compliance due to stiffening of the tympanic membrane, therefore seems unlikely to be the only cause for the SOAE frequency shift observed here. Secondly and maybe of more significance, the linear relation between the SOAE frequency shift and the SOAE frequency in Figure 3.5 does not correspond to what is known about middle-earinduced SOAE frequency shifts. For instance, Hauser et al. (1993) reported that the frequency of a SOAE is more influenced by changes in middle ear pressure in lower SOAE frequencies than in frequencies in the range at $4 \mathrm{kHz}$ and above. On the contrary, in this latter range we found the largest total frequency shifts. In both these arguments however the data are compared to findings in adults which may not be applicable to preterm infant ears, since it is known that the middle ear impedance develops in a profound way during the first two years of life (Keefe $e t$ al., 1993; Keefe et al., 1994). On the other hand, Burns et al. (1994) reported a longitudinal study of OAE in infants from term birth to two years of age; they could find no substantial shift in SOAE frequency during this period. Apparently, the SOAE frequency is not influenced by the profound changes in middle ear impedance in the same period. We therefore believe that the SOAE frequency shift observed in preterm infants might indicate the development of cochlear structures which are involved in the generation of a SOAE. 
In conclusion, this longitudinal study shows developmental aspects of both CEOAE amplitude and $\mathrm{SOAE}$ frequencies. In particular, the $\mathrm{SOAE}$ frequency shift is an indication for cochlear maturation. For further differentiation among outer-, middle- and inner-ear influences, further research is indispensable.

\section{ACKNOWLEDGMENTS}

Thanks are due to all NICU personnel for their benevolent cooperation during the OAE measurements. This study was supported by the Heinsius-Houbolt Foundation. 


\section{REFERENCES}

Bonfills, P., Francois, M., Avan, P., Londero, A., Trotoux, J. and Narcy, P. (1992). "Spontaneous and evoked otoacoustic emissions in preterm neonates," Laryngoscope 102, 182-186.

Brienesse, P. Anteunis, L. J. C., Wit, H. P., Gavilanes, A. W. D. and Blanco, C. E. (1994). "Click evoked emissions in preterm infants: a longitudinal prospective study," 6th International Congress of Pediatric Otorhinolaryngology, Rotterdam, The Netherlands, p 182.

Burns, E. M., Campbell, S. L. and Arehart, K. H. (1994). "Longitudinal measurements of spontaneous otoacoustic emissions in infants," J Acoust Soc Am 95, 385-394.

Burns, E. M., Harrison, W. A., Bulen, J. C. and Keefe, D. H. (1993). "Voluntary contraction of middle ear muscles: effects on input impedance, energy reflectance and spontaneous otoacoustic emissions," Hear Res 67, 117-127.

Chuang, S. W., Gerber, S. E. and Thornton, A. R. (1993). "Evoked otoacoustic emissions in preterm infants," Int J Pediatr Otorhinolaryngol 26, 39-45.

Curnock, D. A (1993). "Identifying hearing impairment in infants and young children," $\mathrm{Br}$ Med J 307, 1225-1226.

Hauser, R., Probst, R. and Harris, F. P. (1993) "Effects of atmospheric pressure variation on spontaneous, transiently evoked, and distortion product otoacoustic emissions in normal human ears," Hear Res 69, 133-145.

Holte, L., Margolis, R. H. and Cavanaugh, R. M., Jr. (1991). "Developmental changes in multifrequency tympanograms," Audiology 30, 1-24.

Joint Committee on Infant Hearing. (1991). "Position Statement 1990," ASHA 33 (suppl 5), $67-74$.

Keefe, D. H., Bulen, J. C., Arehart, K. H. and Burns, E. M. (1993). "Ear-canal impedance and reflection coefficient in human infants and adults," J Acoust Soc Am 94, 2617-2638.

Keefe, D. H., Bulen, J. C., Campbell, S. L. and Burns, E. M. (1994). "Pressure transfer function and absorption cross section from the diffuse field to the human infant ear canal," J Acoust Soc Am 95, 355-371.

Kemp, D. T. (1978). "Stimulated acoustic emissions from within the human auditory system," J Acoust Soc Am 64, 1386-1391.

Kemp, D. T. (1981). "Physiologically active cochlear micromechanics--one source of tinnitus," Ciba Found Symp 85, 54-81.

Kemp, D. T, Ryan, S and Bray, P. (1990). "A guide to the effective use of otoacoustic emissions," Ear Hear 11, 93-105.

Morlet, T., Collet, L., Salle, B. and Morgon, A. (1993) "Functional maturation of cochlear active mechanisms and of the medial olivocochlear system in humans," Acta Otolaryngol (Stockh) 113, 271-277.

Probst, R., Lonsbury Martin, B. L. and Mariin, G. K. (1991) "A review of otoacoustic emis- 
sions," J Acoust Soc Am 89, 2027-2067.

Saunders, J. C., Doan, D. E. and Cohen, Y. E. (1993). "The contribution of middle-ear sound conduction to auditory development," Comp Biochem Physiol 106, 7-13.

Saunders, J. C., Kaltenbach, J. A. and Relkin, E. M. (1983). "The structural and functional development of the outer and middle ear," in Development of auditory and vestibular systems, edited by R. Romand (Academic Press, New York), pp. 3-25.

Schloth, E. and Zwicker, E. (1983). "Mechanical and acoustical influences on spontaneous oto-acoustic emissions," Hear Res 11, 285-293.

Smurzynski, J. (1994) "Longitudinal measurements of distortion-product and click-evoked otoacoustic emissions of preterm infants: preliminary results," Ear Hear 15, 210-223.

van Zanten, B. G., Kok, M. R., Brocaar, M. P. and Sauer, P. J. (1995). "The click-evoked otoacoustic emission, c-EOAE, in preterm-born infants in the post conceptional age range between 30 and 68 weeks," Int J Pediatr Otorhinolaryngol Suppl 32, S187-197.

Wable, J. and Collet, L. (1994). "Can synchronized otoacoustic emissions really be attributed to SOAEs?," Hear Res 80, 141-145.

Wilson, J. P. and Sutton, G. J. (1981). "Acoustic correlates of tonal tinnitus," Ciba Found Symp 85, 82-107. 
Chapter 3 


\section{CHAPTER}

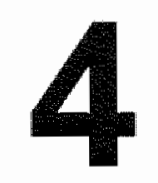

\section{Frequency shift of individual spontaneous otoacoustic emissions in preterm infants}

Brienesse, P., Anteunis, L. J. C., Maertzdorf, W. J., Blanco, C. E. and Manni, J. J. (1997). Pediatr Res 42, 478-483. 
Chapter 4 


\section{ABSTRACT}

In adults, spontaneous otoacoustic emissions (SOAE) have shown a considerable frequency stability. In preterm infants, however, the SOAE proved to show an apparent and consistent upward shift of frequency at increasing post-conceptional age (PCA). In 25 ears of 14 preterm infants (PCA: 29.1-41.3 wks) a total of 66 SOAE frequencies were monitored, ranging from 1611 to $5774 \mathrm{~Hz}$. All but one of the SOAE frequencies shifted toward higher frequency. The SOAE frequency shift rate in Hertz per week was proportionally constant relative to the SOAE frequency. The mean shift rate was $0.74 \pm 0.39 \% /$ wk. At increasing PCA, the SOAE frequency shift rate tended to slow down. A linear fit through the data predicted the SOAE frequency to stop at about 45 to 50 week PCA. The frequency dependence and time course of the SOAE frequency shift strongly suggest cochlear maturation during the last period of gestation. 


\section{INTRODUCTION}

Otoacoustic emissions (OAE) in general are believed to be generated by the outer hair cell motility in the organ of Corti, resulting in a retrograde transmission of sound through the middle ear into the external ear canal, where the OAE can be measured acoustically. Elicited by an acoustic click, these click evoked OAE (CEOAE) reflect auditory integrity on a cochlear level, since they appear to be present in almost all normal hearing ears. In about 40 to $50 \%$ of the normal hearing adults spontaneous otoacoustic emissions (SOAE) can be measured in the external ear canal in the absence of acoustic stimulation. SOAE appear as stationary acoustic narrow band signals around one or more centre frequencies, and seem to be absent in cases with hearing losses exceeding $25 \mathrm{~dB}$ hearing level (Probst et al, 1991). In neonates, the prevalence of SOAE is higher, possibly up to $93 \%$ (Kok et al., 1993). In a group of 81 preterm neonates, a prevalence of 85 $\%$ has been reported at a post-conceptional age (PCA) between 30 and 40 weeks (Morlet et al, 1995). In this group, the amplitude of the SOAE frequencies ranged from -25 to $24.3 \mathrm{~dB}$ sound pressure level (dB SPL), at a mean frequency of $3462 \mathrm{~Hz}$ (range $878-5859 \mathrm{~Hz}$ ). The mean number of SOAE frequencies per ear was 12.3. These SOAE characteristics were similar to what has been reported in full-term neonates. Compared to aduits, however, all these findings in neonates were notably higher. In adults, several studies have shown a considerable stability of individual SOAE frequencies, since the frequency fluctuation appeared to be limited to 0.4 to $1.0 \%$ when observed over a time period of several months (Probst et al., 1991). In the first two years of life, a longitudinal study of SOAE showed no substantial shift in a selection among the most pronounced frequencies of individual SOAE (Burns et al, 1994). In preterm infants, however, a preliminary study by Smurzynski (1994) reported an upward shift of SOAE frequency at increasing PCA in two cases. In order to further evaluate this phenomenon in terms of magnitude, frequency-and age dependence, we present the results of longitudinal SOAE measurements in preterm infants admitted to the neonatal intensive care unit of the University Hospital of Maastricht. 
Table 4.1. GA at birth, birth weight, risk factors and pathologies of the IA infants wnder study.

\begin{tabular}{|c|c|c|c|c|}
\hline Patient & $\begin{array}{l}\text { GA at birth } \\
\text { (wks) }\end{array}$ & $\begin{array}{l}\text { Birth weight } \\
\text { (g) }\end{array}$ & $\begin{array}{l}\text { Risk factors } \\
\text { (see legend) }\end{array}$ & Pathologies \\
\hline$\overline{p 1}$ & 29 & 1270 & 5 & multiple bradycardic periods \\
\hline p2 & 28.6 & 1320 & *. & multiple bradycardic periods \\
\hline p3 & 28.6 & 1000 & $*, t, \$$ & sepsis, multiple bradycardic periods \\
\hline $\mathrm{p} 4$ & 30.1 & 1130 & "it. II & $\begin{array}{l}\text { hypotension, persistent ductus } \\
\text { arteriosus }\end{array}$ \\
\hline p5 & 30.1 & 1440 & $", \pi$, \& & sepsis \\
\hline p6 & 24.7 & 900 & 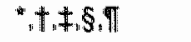 & sepsis \\
\hline p7 & 28 & 1050 & "§ & hypotension \\
\hline p8 & 27 & 1160 & 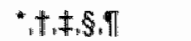 & sepsis \\
\hline pg & 31.7 & 1700 & ก & \\
\hline p10 & 31.4 & 1500 & $\S$ & \\
\hline p11 & 31.4 & 1300 & *.\$ & multiple bradycardic periods \\
\hline p12 & 27.1 & 1010 & “, $\neq, \S$ & persistent ductus arteriosus \\
\hline p13 & 30.7 & 1820 & I & \\
\hline p14 & 30.7 & 1780 & I & \\
\hline Mean & 29.3 & 1313 & & \\
\hline
\end{tabular}

Risk factors for sensorineural hearing loss according to the Joint Committee on Infant Hearing are: birth weight $<1500 \mathrm{~g}^{*}$, mechanical ventilationt, asphyxia at birth $\neq$, administration of potential ototoxic medicaltion (aminoglycosides and loop diuretics)§ and hyperbilirubinaemiaff.

\section{METHODS}

\section{Subjects}

In 25 ears of 14 preterm infants (nine male, five female) SOAE frequencies were monitored. The gestational age (GA) at birth varied from 24.7 to 31.7 weeks (based on the last day of menstruation and early fetal ultrasound examination). Further characteristics of the infants are listed in Table 4.1. The PCA at the time of SOAE registration ranged from 29.1 to 42.3 weeks. The period of PCA in which the SOAE registrations took place is given for each individual infant in Figure 4.1, together with the number of ears investigated within each week PCA. Although all infants showed one or more risk factors for sensorineural hearing impairment as stated by the Joint Committee on Infant Hearing (American Academy of Pediatrics, 1995), they all showed good reproducible CEOAE, for which they were discharged from further hearing evaluation. None of the infants was on 


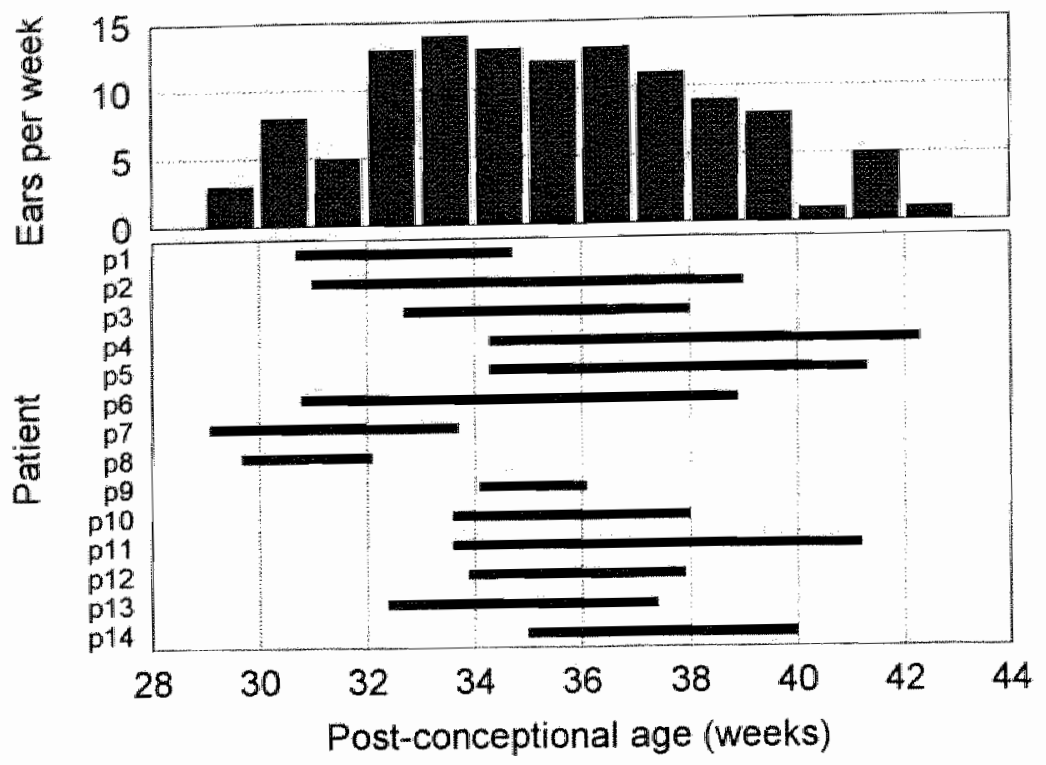

Figure 4.1.

Period of PCA in which the SOAE registrations took place for each individual infant pl to $p 14$ (bottom figure), together with the number of ears invesiggated within each week PCA (top figure).

mechanical ventilation during testing, since the background noise induced by the gas flow generally interferes with an SOAE registration.

\section{Measurements}

All measurements were performed with the ILO88 OtoAcoustic Emission Analyser version 3.94 (Otodynamics London, UK), as described elsewhere (Kemp et al., 1990). The ILO H-type OAE probe for neonatal ears was used with two different sizes of disposable tips (denoted by the manufacturer as 'tapered' and 'preemie'). The SOAE registrations took place in a neonatal intensive care unit on the bedside of incubators as well as cradles, without disturbing the normal clinical practice.

SOAE were measured using the 'SpontaneousSearch' operation mode of the 
ILO88. In this mode, the SOAE were synchronized by an $80 \mu$ s pulse at a mean level of $75.4 \mathrm{~dB}$ SPL peak equivalent $(n=145, \mathrm{SD}=2.5 \mathrm{~dB}$ SPL). This pulse was repeated every $80 \mathrm{~ms}$. The probe was fitted and refitted when necessary until the frequency components of the synchronizing pulse were as equally distributed in the frequency domain as possible, with a minimal noise leakage into the ear canal. The ILO88 extracts the SOAE by time-domain averaging of the $20 \mathrm{~ms}$ to $80 \mathrm{~ms}$ post stimulus time interval. Synchronization by a short pulse is therefore essential for the SOAE to be recognized over the non-synchronizing background noise, since frequency components with a random phase will be cancelled out eventually. The averaged signal is transformed to the frequency-domain by a fast Fourier transformation (FFT) with a resolution of $12.3 \mathrm{~Hz}$. In order to prevent the false identification of low amplitude synchronized frequency components as an SOAE (Wable and Collet, 1994), only SOAE frequencies were included that satisfied the following criteria: (1) the SOAE recording was the averaged result of at least 100 single responses; (2) the amplitude of the SOAE frequency was at least $-15 \mathrm{~dB}$ SPL; and (3) the amplitude of the SOAE frequency was at least 10 $\mathrm{dB}$ above the noise level in its vicinity. The latter criterion was judged visually by the first author from the FFT spectrum given by the ILO88.

\section{Data analysis}

From the serially registered SOAE frequencies in each individual ear, a total SOAE frequency shift, an overal frequency shift rate (OFSR) and a series of PCA dependent frequency shift rates (FSR's) were computed according to the equations listed in the appendix. The KO88 has shown to systematically give incorrect values for the absolute frequency of the SOAE. All cursor readouts proved to be $12.2 \mathrm{~Hz}$ too high (Smurzynski and Probst, 1996). Since both the OFSR and the FSR were unaffected by this error, none of our data have been corrected in this regard. The Pearson product moment correlation test was used for correlation analysis. Results were considered significant at $p<0.05$, although it should be noted that not all observations are truly independent when coming from the same infants. 

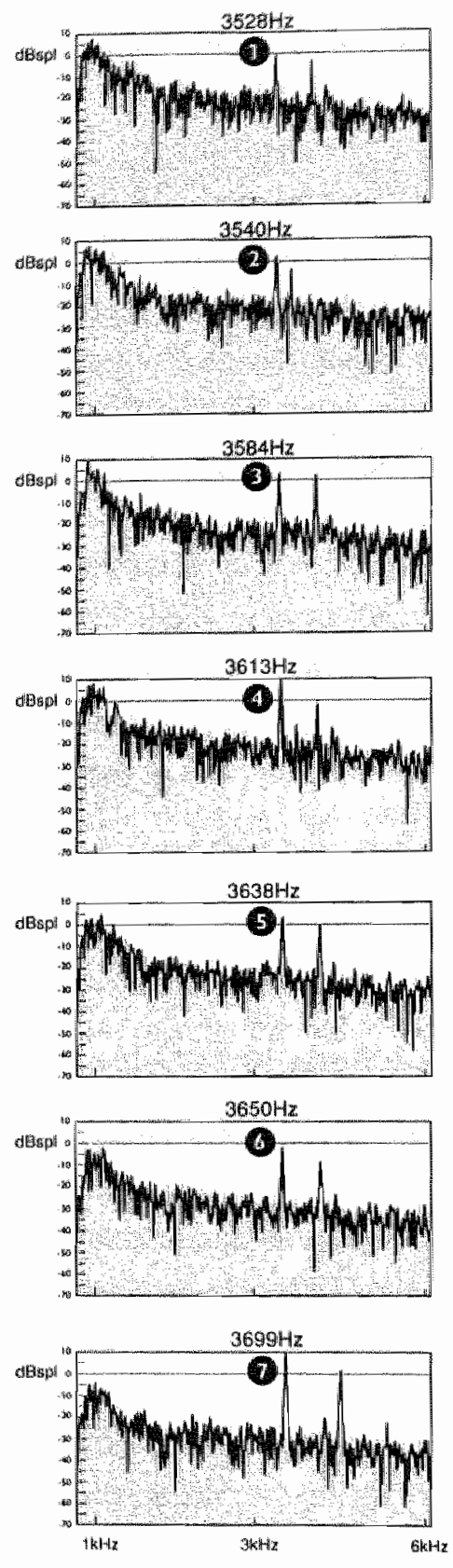

Post-conceptional age (weeks)

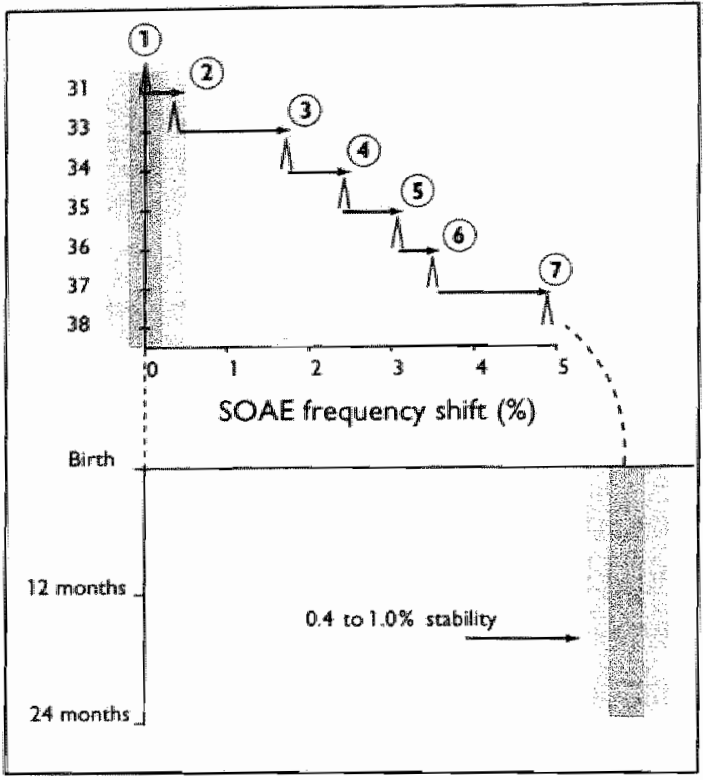

Figure 4.2.

Example of the frequency shift of SOAE's with PCA. To the left there are seven recordings of the right ear of a preterm infant, made at $P C A$ ranging from 31 to 38 weeks. In the diagram to the right the total shift in frequency of the main SOAE frequency component (numbered from 1 to 7 ) is given as a percentage of the initial SOAE frequency $(3528 \mathrm{~Hz}$ at 31 weeks $P C A$. The total frequency shift outgrows the 0.4 to $1.0 \%$ SOAE stability known from other studies. A second, higher $S O A E$ frequency can be recognized in recordings 1 . and 3 to 6 . In the second recording, this SOAE frequency is temporarily gone. This second SOAE frequency monotonically increases from $4163 \mathrm{~Hz}$ at 31 weeks $P C A$ (recording number l) to $4321 \mathrm{~Hz}$ at 37 weeks PCA (recording number 6), and has also been taken into account in the data analysis. In the recording number 7, the second SOAE frequency is only very weakly present, next to a third $S O A E$ frequency that emerges at $4663 \mathrm{~Hz}$. Since the $1.0 \%$ stability also applies to SOAEs in the first two years of life, one would expect the SOAE frequencies to stabilize around the normal vime of birth. As can be seen in Figure 4.4, the SOAE frequency shift indeed tends to stop towards a PCA around 45 to 50 weeks. 


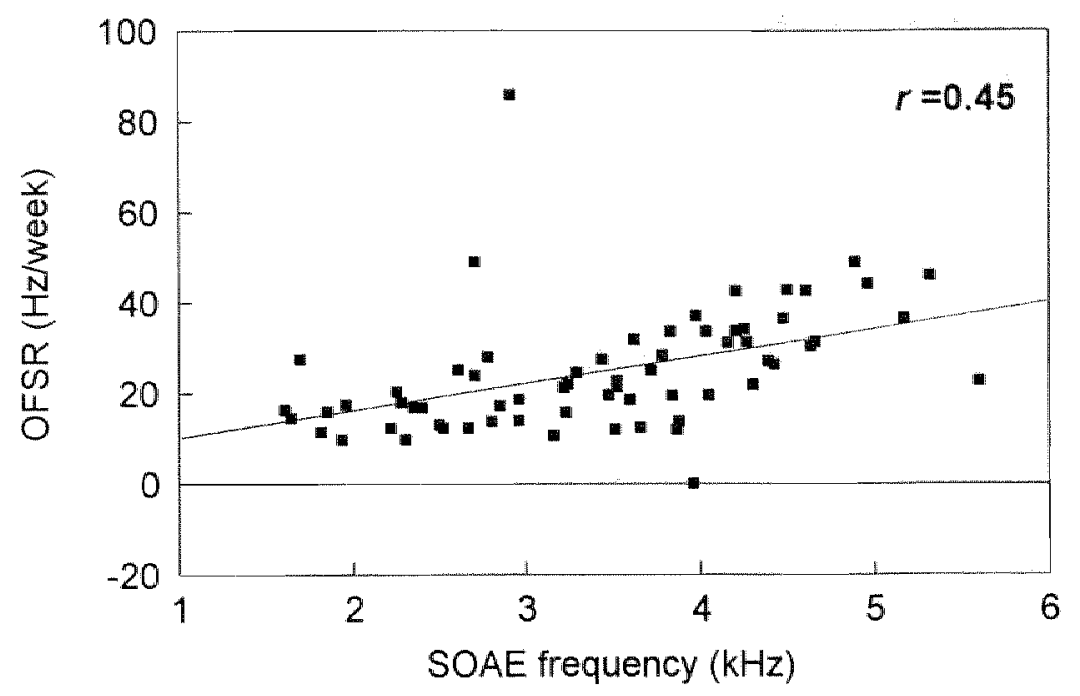

Figure 4.3.

The overall SOAE frequency shift rate (OFSR) in $\mathrm{Hz}$ per week as a function of the SOAE frequency. Higher SOAE frequencies show larger frequency shifts. The correlation between the SOAE frequency and the OFSR is significant $(n=66, r=0.45, p<0.001)$. By calculating the OFSR as a percentage of the initial SOAE frequency this frequency dependence is no longer valid.

\section{RESULTS}

In the 14 infants under study, we were able to monitor a total of $66 \mathrm{SOAE}$ frequencies in 25 ears. All but one of these SOAE frequencies $(98.5 \%$ ) shifted towards higher frequencies at increasing PCA. In $59 \mathrm{SOAE}$ frequencies (89\%), the total frequency shift exceeded the $1 \%$ stability range known from adult SOAE frequencies. An example of a shifting SOAE frequency is given in Figure 4.2 .

The observed SOAE frequencies ranged from 1611 to $5774 \mathrm{~Hz}$. The higher $\mathrm{SOAE}$ frequencies showed a larger total shift than the lower frequencies. In Figure 4.3 the overall SOAE frequency shift rate (OFSR in $\mathrm{Hz}$ per week) has 


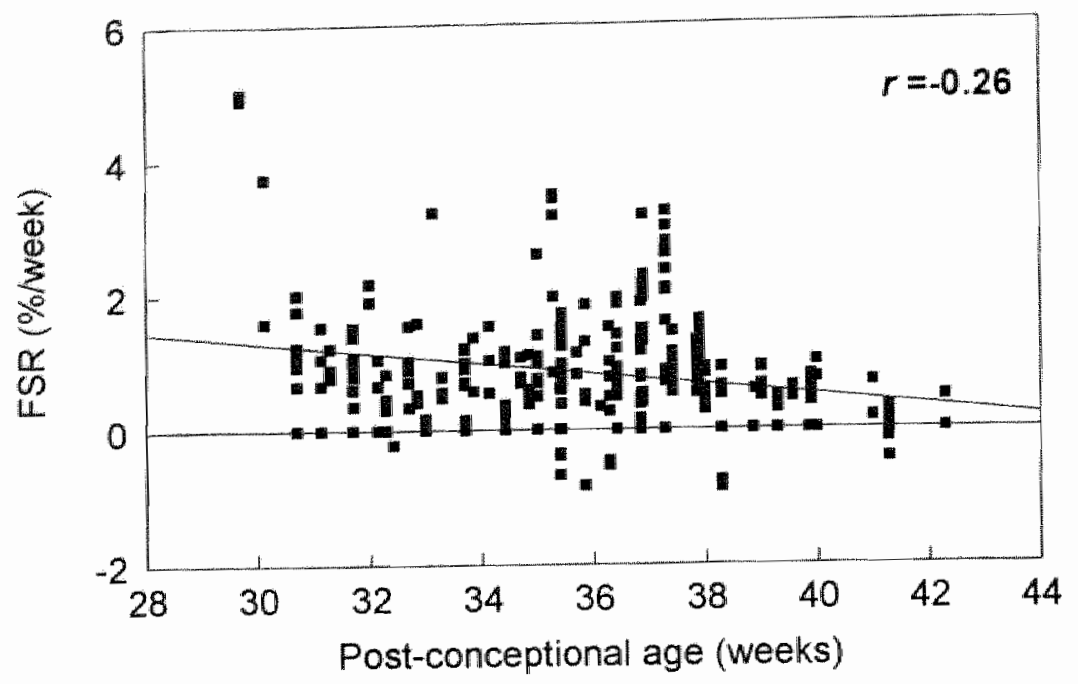

\section{Figure 4.4.}

The rate of $S O A E$ frequency shiff (FSR) in percent per week as a function of the PCA of the infant at the moment of SOAE registration. The negative correlation between the SOAE frequency shifl rate and the $P C A$ is significan $(n=282, r=-0.26, p<0.0001$ ). So at higher $P C A$, the shift of the SOAE frequency tends to slow down and stop at about 45 to 50 weeks $P C A$. for at that point the linear fit reaches an FSR of 0 or wk.

been plotted as a function of the initial value of the SOAE frequency. The positive correlation between the OFSR and the SOAE frequency proved to be highly significant ( $n=66, r=0.45, p<0.001$ ). By calculating the OFSR relative to the initial frequency in percent per week ( $\% / w k)$, this frequency dependence was no longer valid. In this manner, the mean OFSR was $0.74 \% /$ wk $(n=66, \mathrm{SD}=0.39$ $\% /$ wk, range 0-2.95).

Of each SOAE frequency multiple registrations were made at different PCA. With a mean of 5.3 longitudinal registrations per SOAE frequency ( $n=66$, range $2-11$ ), a total of 348 registrations were made. This resulted in a total of 282 observations of a SOAE frequency shift rate (FSR) in \%/wk at different PCA. In 
Figure 4.4 the FSR is plotted as a function of PCA, showing a significant negative correlation ( $n=282, r=-0.26, p<0.0001)$, meaning that at higher PCA, the frequency shift tended to slow down. A linear fit predicted the SOAE frequency shift to stop around 45 to 50 weeks PCA, for at that point the FSR reached a zero value.

\section{DISCUSSION}

This longitudinal study demonstrated an overall increase of SOAE frequencies in preterm infants. Only one of the 66 observed SOAE frequencies failed to show a substantial frequency shift, whereas all the other frequencies increased at increasing PCA.

A pilot study by Smurzynski (1994) reported SOAE measurements in two preterm infants, which were tested two and four times respectively, at different PCA ranging from 33 to 37 weeks. The overall frequency shifts presented in nine different $\mathrm{SOAE}$ frequencies ranged from 0.27 to $0.86 \% / \mathrm{wk}$. These findings were confirmed by the mean OFSR of $0.74 \% / \mathrm{wk}$ found in the present study.

The negative correlation between the FSR and PCA, as given in Figure 4.4, indicates that the SOAE frequency shift tends to slow down towards higher PCA, and to stop at a PCA around 45 to 50 weeks. Extrapolation of these results toward a group of healthy newborn infants would predict that a SOAE frequency is stable from a few weeks after birth. This finding is in accordance with earlier longitudinal observations of a selection among the most pronounced frequencies of individual SOAE in a group of healthy newborns, at the ages of $1,3,6,12$ and 24 months (Burns et al., 1994). In the infants which could be tested at both 1 and 24 months of age, a mean decrease of SOAE frequency of $-1.3 \%$ was observed over the intermediate 23 months $(n=14$, range $+1.3 \%$ to $-3.8 \%)$. The SOAE frequencies observed at both 1 and 3 months of age demonstrated a slight mean increase of $0.4 \%$ in the intermediate two months $(n=11$, range $-0.3 \%$ to +1.0 $\%$ ). For comparison, the mean OFSR of $0.74 \% /$ wk in preterm ages is about 15 times as high as in this 1 to 3 months period and, in absolute sense, about 50 
times as high as in the total 1 to 24 months period. So, one might indeed expect the FSR to slow down and stop around the normal time of birth. In adults, repeated measurements of SOAE frequency over time periods of several months yielded values for frequency fluctuation ranging from 0.4 to $1 \%$ (Probst $e t$ al., 1991). In $89 \%$ of the SOAE frequencies in our preterm population the overall frequency shift exceeded this I \% stability. In our view, the apparent and consistent frequency shift is a strong indication that SOAE properties are still developing in preterm infants.

Early cross-sectional studies of CEOAE in preterm infants assumed the outer hair cell properties to be mature at 32 weeks of PCA, since no statistically significant variation of the amplitude and spectrum of CEOAE could be found among the different age groups ranging from 32 to 41 weeks PCA (Bonfils et al, 1992; Morlet et al., 1993). Later studies, however, indicated that the CEOAE spectrum and amplitude might be related to PCA, based on longitudinal observations of these emissions (Chuang et al., 1993; Brienesse et al., 1994). This growth of CEOAE amplitude in preterm infants was indeed confirmed by further longitudinal study (Smurzynski, 1994; Brienesse et al., 1995; Brienesse et al., 1996), and later also by a further cross-sectional study (van Zanten et al., 1995). The amplitude of distortion product OAE (DPOAE), evoked by two continuous pure tones of different frequency, showed a similar growth in the same period (Smurzynski, 1994). Apparently, the maturation of OAE properties in preterm infants is not solely restricted to the SOAE frequency.

It is possible that developmental changes in the middle ear might partly account for the apparent changes in OAE amplitude and spectrum during preterm ages. An increase in OAE amplitude can for instance be explained by an improvement of the forward and reverse sound transmission to and from the cochlea. In various vertebrate species, development related changes have been shown in for instance the size of the tympanic membrane, the tympanic membrane velocity, and the area ratio between the tympanic membrane and the stapes footplate (Saunders $e t$ $a l ., 1993)$. It has been postulated that this conductive development in some spe- 
cies determines the rate of auditory sensitivity development. In human too, maturation of the middle ear structures might be expected during preterm ages. It is known that the human auditory ossicles are completely formed by the 22 nd week of GA. The ossification of these ossicles is completed around 32 weeks GA (Saunders et al., 1983). Although the size of the human tympanic ring is full grown around 22 weeks GA, the fusion of this ring with the temporal bone only starts at about 35 weeks GA and continues postnatally (Saunders et al., 1983; Saunders et $a l$, 1993). The tympanic membrane thins up to about 26 weeks GA, at which time the attachments of the tympanic membrane to the tympanic ring are also complete. The changes in orientation of the tympanic membrane continue throughout postnatal life. The expansion of the middle ear cavity also continues throughout childhood. The clearance of mesenchyme in the middle ear is completed at about 36 weeks GA (Saunders et al., 1983). So, during the period of SOAE registration in the group of infants of the present study, there are some functional changes in the middle ear that might influence the OAE properties.

However, the knowledge of the implications of these structural changes on the functional admittance of the middle ear is limited. It has not been determined whether tympanometry for instance is a reliable indicator for middle ear pathology at and below four months of age (Holte et al., 1991), let alone at preterm ages. As a consequence, little is known about the functional development of the middle ear and external ear canal in preterm infants. At the ages of 1 to 24 months after normal birth, Keefe et al. (1993) investigated the impedance of the middle ear at different frequencies. They concluded that the development of the external ear canal and middle ear strongly affects input impedance, and that this development is not yet complete at age 24 months. From these data one might expect the functional development of the middle ear to be even more profound in preterm infants.

The influence of both the development and condition of the middle ear on the observed SOAE frequency shift can not be excluded. In adults, it is known that an increase of middle ear pressure increases the frequency of a SOAE (Kemp, 
1981; Wilson and Sutton, 1981; Schloth and Zwicker, 1983; Burns et al., 1993 Hauser et al., 1993), probably by altering the frequency specific loading of the cochlea by the middle ear, and thereby changing the cochlear mechanics at the generation site of the SOAE. There are two arguments that argue against the sole influence of the middle ear development on the SOAE frequency shift reported in our group of preterm infants. Firstly, by changing middle ear pressure in adults, the SOAE frequency is more influenced below $4 \mathrm{kHz}$ than in the range at $4 \mathrm{kHz}$ and above (Hauser et al., 1993). This does not correspond with our findings, since in this latter frequency range we found the largest overall frequency shifts. On the other hand, one must be careful to compare our data to the findings in adults, especially in the light of the profound changes in middle ear impedance in young infants (Keefe et al., 1993). Secondly, according to Burns et al. (1994) there is no substantial SOAE frequency shift in healthy newborns during the first two years of life. So, in these young infants, the SOAE frequency is apparently not influenced by the profound changes in middle ear impedance during the same period reported by Keefe et al. (1993). In our view, the middle ear development is therefore unlikely to be the main explanation for the relatively large SOAE frequency shifts in preterm infants.

An explanation for the SOAE frequency shift reported in the present study might be the developmental changes in the cochlea itself, especially the maturation of the outer hair cell function. First, the positive correlation between the OFSR and the SOAE frequency (Figure 4.3) suggests an analogy between these results and the normal tonotopic organization of the cochlea. Since the higher frequencies are more closely coded on the basal part of the cochlear partition than are the lower frequencies on the more apical part, any anatomical-functional change in the high frequency regions is likely to result in a larger and broader absolute effect (in $\mathrm{Hz}$ ) on frequency than in the low frequency regions.

On the other hand, high frequency regions show a delayed course of development opposed to the lower frequency regions, which could partly account for the larger absolute effect in SOAE frequency development in high frequencies during the 
last period of gestation, as reported here. Based on studies of different vertebrate species, it has been reported that the stage of structural development of the cochlea depends on the location along the basilar membrane (Romand, 1983). The development starts in the basal first half of the first turn in the cochlea and spreads progressively toward both the apex and the basal extremity (Romand, 1983; Pujol et al., 1991). In the adult cochlea, the basal part is most sensitive for high frequencies, whereas the first responses during maturation appear within a range of medium to low frequencies. This apparent paradox can be explained by the assumption that, during early development, the basal part of the cochlea is tuned to lower frequencies than it is in a more mature state. As a consequence, the region of maximal excitation of a particular frequency will shift to a more apical location on the cochlear partition. This latter effect is known as the 'shifting place code' and has been proposed by many authors (Lippe and Rubel, 1983; Rubel and Ryals, 1983; Harris and Dallos, 1984; Pujol, 1985; Mills and Rubel, 1996). The shifting place code is used by Eggermont et al. (1991a; 1991b) to support their conclusion that the most basal part of the cochlea takes much longer to mature. They examined the travelling-wave delay between various parts of the cochlea in preterm infants by using frequency specific auditory brain-stem responses. It was found that the travelling-wave delay shows an increment with increasing age in the high frequency regions above $8000 \mathrm{~Hz}$ relative to the lower frequency regions, which is explained by a shift of the place code towards a more apical location on the cochlea. Based on the fit of these data by an exponential decay function it was concluded that the most basal part of the human cochlea reaches maturity around 70 weeks PCA, i.e. almost one-half year after term birth. Considering these results, it is not unlikely that the frequency region between 1500 and $6000 \mathrm{~Hz}$ reaches maturity around 45 to 50 weeks, reflected in a shift of SOAE frequency up to that age, as reported here.

An interesting explanation for the shifting place code was postulated by Romand (1987). He proposed that in early development, the inner hair cells are ready to function, while the outer hair cells are still immature (Romand, 1983; Pujol, 1985; Pujol et al., 1991). At this time, estimated around 20 weeks PCA (Pujol et al., 
1991), the tuning of the cochlea is mainly determined by the passive tuning of the basilar membrane. As the outer hair cells mature, this tuning is sharpened by the additional active cochlear mechanism, and the frequency of tuning for a specific cochlear location is shifted upward (Romand, 1987). In a recent study on gerbils, however, Mills and Rubel (1996) suggested that the place code shift at high frequencies must be due primarily to passive changes in basilar membrane mechanics, since the active cochlear mechanism, or "cochlear amplifier", appeared to be functional with a gain at an adult level, already early in development. One way or the other, on the assumption that the generation site of an SOAE is locked to a specific set of outer hair cells at a particular location on the cochlear partition, the upward shift of SOAE frequency could be explained by the upward shift of tuning frequency due to the shifting place code.

In conclusion, the results of this longitudinal study show an apparent and consistent upward shift of SOAE frequency in preterm infants. The frequency dependence and time course of this frequency shift strongly suggests cochlear maturation during the last period of gestation.

\section{ACKNOWLEDGMENTS}

Thanks are due to all parents and NICU personnel for their benevolent cooperation during the SOAE registration sessions. Special thanks is given to Geertjan van Zonneveld for his assistance in the creation of Figure 4.2. Supported by grants from the Heinsius-Houbolt Foundation. 


\section{APPENDIX}

For each $\mathrm{SOAE}$ frequency a total of $\mathrm{N}$ registrations were made, forming a series of frequency values $\mathrm{f}_{1}\left(\mathrm{PCA}_{1}\right)$ to $\mathrm{f}_{\mathrm{N}}\left(\mathrm{PCA}_{\mathrm{N}}\right)$, where $\mathrm{PCA}_{\mathrm{N}}>\mathrm{PCA}_{1}$.

The overall frequency shift is simply calculated as the difference between the first and the last SOAE frequency:

$$
f_{M}\left(P C A_{N}\right)-f_{1}\left(P C A_{1}\right)(H z)
$$

Dividing the overall frequency shift by the time in which the shift took place yields the overall frequency shift rate (OFSR) in Hertz per week ( $\mathrm{Hz} / \mathrm{wk}$ ):

$$
O F S R=\frac{f_{N}\left(P C A_{N}\right)-f\left(P C A_{1}\right)}{P C A_{N}-P C A_{1}}(\mathrm{~Hz} / w k)
$$

Or, relative to the initial frequency $\mathrm{f}_{1}\left(\mathrm{PCA}_{1}\right)$ in percent per week $(\% / \mathrm{wk})$ :

$$
\text { OFSR }=\frac{f_{N}\left(P C A_{N}\right)-f_{1}\left(P C A_{1}\right)}{\left(P C A_{N}-P C A_{1}\right) * f_{1}\left(P C A_{1}\right)}(\% / u \cdot k)
$$

Using all intermediate registrations $\mathrm{f}_{\mathrm{n}}\left(\mathrm{PCA}_{\mathrm{n}}\right)$ with $\mathrm{n}=1$ to $\mathrm{N}$, a total of $\mathrm{N}-1$ observations of a PCA dependent SOAE frequency shift rate (FSR) can be calculated as follows:

$$
F S R\left(P C A_{n}\right)=\frac{f_{n}\left(P C A_{n}\right)-f_{m-1}\left(P C A_{n-1}\right)}{\left(P C A_{n}-P C A_{n-1}\right) * f_{n}\left(P C A_{n}\right)}(\% / w k)
$$




\section{REFERENCES}

American Academy of Pediatrics. (1995). "Joint Committee on Infant Hearing 1994 Position Statement, Pediatrics 95, 152-1156.

Bonfils, P., Francois, M., Avan, P., Londero, A., Trotoux, J. and Narcy, P. (1992). "Spontaneous and evoked otodcoustic emissions in preterm neonates," Laryngoscope 102, 182-186.

Brienesse, P., Anteunis, L. J. C., Wit, H. P, Gavilanes, A. W. D. and Blanco, C. E. (1994) "Click evoked emissions in preterm infants: a longitudinal prospective study," 6th Internatuonal Congress of Pediatric Otorhinolaryngology, Rotterdam, The Netherlands, p 182.

Brienesse, P., Anteunis, L. I. C., Wit, H. P., Gavilanes, A. W. D. and Maertzdorf, W. J. (1995). "A longitudinal prospective study of otoacoustic emissions in preterm infants: an indication for cochlear maturation?, "Pediatr Res 37, 251 A.

Brienesse, P., Anteunis, L. J. C., Wit, H. P., Gavilanes, A. W. D. and Maertzdorf, W. J. (1996). "Otoacoustic emissions in preterm infants; indications for cochlear development?", Audiology $35,296-306$.

Burns, E. M. Campbell, S. L. and Arehart, K. H. (1994). "Longitudinal measurements of spontaneous otoacoustic emissions in infants," J Acoust Soc Am 95, 385-394.

Burns, E. M., Harrison, W. A., Bulen, I. C. and Keefe, D. H. (1993). "Voluntary contraction of middle ear muscles: effects on input impedance, energy reflectance and spontaneous otoacoustic emissions," Hear Res 67, 117-127.

Chuang, S. W., Gerber, S. E. and Thornton, A. R. (1993) "Evoked otoacoustic ermissions in preterm infants," Int J Pediatr Otorhinolaryngol 26, 39-45.

Eggermont, J. J., Ponton, C. W., Coupland, S. G. and Winkelaar, R. (1991a). "Maturation of the traveling-wave delay in the human cochlea," J Acoust Soc Am 90, 288-298.

Eggermont, J. J., Ponton, C. W., Coupland, S. G. and Winkelaar, R. (1991b) "Frequency dependent maturation of the cochlea and brainstem evoked potentials," Acta Otolaryngol (Stockh) 111, 220-224.

Harris, D. M. and Dallos, P. (1984). "Ontogenetic changes in frequency mapping of a mammalian ear," Science 225, 741-743.

Hauser, R., Probst, R. and Harris, F. P. (1993). "Effects of atmospheric pressure wariation on spontaneous, transiently evoked, and distortion product otoacoustic emissions in normal human ears," Hear Res 69, 133-145.

Holte, L., Margolis, R. H. and Cavanaugh, R. M., $J_{r}$. (1991). "Developmental changes in multifrequency tympanograms," Audiology 30, 1-24

Keefe, D. H., Bulen, J. C., Arehart, K. H. and Burns, E. M. (1993). "Ear-canal impedance and reflection coefficient in human infants and adults," J Acoust Soc Am 94, 2617-2638.

Kemp, D. T. (1981). "Physiologically active cochlear micromechanics-one source of tinnitus," Ciba Found Symp 85, 54-81. 
Kemp, D. T., Ryan, S. and Bray, P. (1990). "A guide to the effective use of otoacoustic emissions," Ear Hear 11, 93-105.

Kok, M. R., van Zanten, G. A. and Brocaar, M. P. (1993). "Aspects of spontaneous otoacoustic emissions in healthy newborns," Hear Res 69, 115-123.

Lippe, W. and Rubel, E. W. (1983). "Development of the place principle: tonotopic organization," Science 219, 514-516.

Mills, D. M. and Rubel, E. W. (1996). "Development of the cochlear amplifier," J Acoust Soc Am 100, 428-441.

Morlet, T., Collet, L., Salle, B. and Morgon, A. (1993). "Functional maturation of cochlear active mechanisms and of the medial olivocochlear system in humans," Acta Otolaryngol (Stockh) 113, 271-277.

Morlet, T., Lapillonne, A., Ferber, C., Duclaux, R., Sann, L., Putet, G., Salle, B. and Collet, L. (1995). "Spontaneous otoacoustic emissions in preterm neonates: Prevalence and gender effects," Hear Res 90, 44-54.

Probst, R., Lonsbury Martin, B. L. and Martin, G. K. (1991). "A review of otoacoustic emissions," J Acoust Soc Am 89, 2027-2067.

Pujol, R. (1985). "Morphology, synaptology and electrophysiology of the developing cochlea," Acta Otolaryngol (Stockh) Suppl 421, 5-9.

Pujol, R., Lavigne Rebillard, M. and Uziel, A. (1991). "Development of the human cochlea," Acta Otolaryngol (Stockh) Suppl 482, 7-12.

Romand, R. (1983). "Development of the cochlea," in Development of awditory and vestibular systems, edited by R. Romand ( Academic Press, New York), pp. 47-88.

Romand, R. (1987). "Tonotopic evolution during development," Hear Res 28, 117-123.

Rubel, E. W. and Ryals, B. M. (1983). "Development of the place principle: acoustic trauma," Science 219, 512-514.

Saunders, J. C., Doan, D. E. and Cohen, Y. E. (1993). "The contribution of middle-ear sound conduction to auditory development," Comp Biochem Physiol 106, 7-13.

Saunders, J. C., Kaltenbach, J. A. and Relkin, E. M. (1983). "The structural and functional development of the outer and middle ear," in Development of auditory and vestibular systems, edited by R. Romand ( Academic Press, New York), pp. 3-25.

Schloth, E. and Zwicker, E. (1983). "Mechanical and acoustical influences on spontaneous oto-acoustic emissions," Hear Res 11, 285-293.

Smurzynski, J. (1994). "Longitudinal measurements of distortion-product and click-evoked otoacoustic emissions of preterm infants: preliminary results," Ear Hear 15, 210-223.

Smurzynski, J. and Probst, R. (1996). "Error in the calculation of synchronized spontaneous otoacoustic emission frequencies measured with the ILO88 system," J Acoust Soc Am 100, 2555-2557. 
van Zanten, B. G. Kok, M. R., Brocaar, M. P. and Sauer, P. J. (1995) "The click-evoked otoacoustic emission, $C-E O A E$, in preterm-born infants in the post conceptional age range betweern 30 and 68 weeks," Int J Pediatr Otorhinolaryngol 32 Suppl, S187-197.

Wable, $Y$. and Collet, L. (1994). "Can synchronized otoacoustic emissions really be attributed to SOAEs?," Hear Res 80, 141-145.

Wilson, J. P. and Sutton, G. J. (1981). "Acoustic correlates of tonal tinnitus," Ciba Found Symp 85, 82-107. 


\section{CHAPTER}

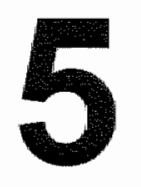

\section{Long-term and short-term variations in amplitude and frequency of spontaneous otoacoustic emissions in preterm infants}

Brienesse, P., Anteunis, L. J. C., Maentzdorf, W. J., Manni, J J and Blanco, C. E. (1998). Audiology 37 , in press. 
Chapter 5 


\section{ABSTRACT}

In preterm infants, spontaneous otoacoustic emission (SOAE) frequencies show an upward shift with time. The present study aimed to monitor the SOAE amplitude variation during this frequency shift. A long-term observation of 87 SOAE frequencies from 18 preterm infants yielded a positive frequency shift of 0.72 percent per week, which was not accompanied by a simultaneous amplitude shift, for the mean variations in SOAE amplitude were practically zero. Furthermore, there was no relation between the short-term SOAE amplitude variation and the infant's post-conceptional age. Only the absolute amount of SOAE amplitude variation seemed to grow with time. Comparison with induced variations in SOAE frequency argues against a middle ear influence on the SOAE frequency shift. In our view, the absence of any amplitude shift during the upward SOAE frequency shift further suggests cochlear development during the last period of gestation. 


\section{INTRODUCTION}

In adults, the frequencies of spontaneous otoacoustic emissions (SOAE's) have shown a remarkable frequency stability with only small variations of typically less than one percent, when observed over time periods of several months (Probst et al., 1991; Whitehead, 1991). In the first two years of life, there is also no substantial shift of individual SOAE frequencies (Burns et al., 1994). In preterm infants, however, the frequencies of SOAE's have shown an apparent and consistent upward shift with increasing post-conceptional age (PCA) (Smurzynski, 1994; Brienesse et al., 1996; Brienesse et al., 1997). Between the PCA of 30 to 40 weeks, the frequency of a SOAE increases at a mean rate of about 0.74 percent per week. This frequency shift tends to slow down with increasing PCA and to stop at about 45 to 50 weeks PCA. The time course and frequency dependence of this SOAE frequency shift strongly suggests cochlear maturation during the last period of gestation (Brienesse et al., 1997).

The amplitudes of SOAE's are far more instable than the individual frequencies, for variations of 10 to $15 \mathrm{~dB}$ have been reported in adults, again when observed over a time period of several months (Schloth, 1983a; Dallmayr, 1985; Whitehead, 1991). In terms of maturation, a drop in SOAE amplitude is known to accur during the first two years of life, which might be expected from the fact that young infants and newborns show higher SOAE amplitudes than adults. In the same period, the frequencies of individual SOAE's remain unchanged, although the overall distribution of SOAE frequencies is still not adultike at the age of 24 months (Burns et al., 1994). Up to now, there are no data on the SOAE amplitude stability in preterm infants.

In various experiments, fluctuations of frequency and amplitude of SOAE's have been induced by for instance the contralateral stimulation with tones or noise (Mott et al., 1989; Burns et al., 1993; Harrison and Burns, 1993) or the application of pressure variation in the external ear canal or middle ear (Wilson and Sutton, 1981; Schloth and Zwicker, 1983b; Hauser et al., 1993; Wada et al, 1995). These induced variations of SOAE often show a close relationship be 
Table 5.1. Characteristics and risk factors, for sensorineural hearing loss of the infants under study.

\begin{tabular}{ll}
\hline Sex (male / female) & $11 / 7$ \\
$\begin{array}{l}\text { Gestational age at birth (weeks) } \\
\text { (median, range) }\end{array}$ & $30.4(24$ \\
Birth weight (g) & \\
(median, range) & 1290 \\
& \\
Risk factors for sensorineural hearing loss (percentage of occur & \\
& \\
Birth weight < 1500 g & $72 \%$ \\
Mechanical ventilation & $39 \%$ \\
Asphyxia at birth & $17 \%$ \\
Administration of aminoglycosides & $61 \%$ \\
Administration of loop diuretics & $6 \%$ \\
Hyperbilirubenaemia & $39 \%$ \\
Multiple bradycardic preriods & $33 \%$ \\
Hypotension & $17 \%$ \\
Sepsis & $28 \%$ \\
Persistent ductus arteriosus & $11 \%$
\end{tabular}

tween the frequency- and amplitude variation. Both the contralateral stimulation and the pressure variation induce an upward SOAE frequency shift which often coincides with a simultaneous drop in amplitude.

The aim of the present study was to document both the short-term and long-term variations of the SOAE amplitude during the upward shift of SOAE frequency in preterm infants. The relation between the amplitude and frequency variation was investigated in an attempt to deduce the underlying mechanism of the upward frequency shift by comparison with induced variations in SOAE frequency and amplitude.

\section{METHODS}

\section{Subjects}

In 18 preterm infants SOAE's were monitored for at least two weeks. Data from 14 of these infants have partly been used in an earlier study of multiple longitudi- 


\section{Chapter 5}

nal SOAE frequency observations (Brienesse et al, 1997). The characteristics of the infants are listed in Table 5.1. The PCA at the time of SOAE registration ranged from 29.1 to 42.3 weeks.

\section{Measurements}

The SOAE measurements were performed using two versions of the ILO Otoacoustic Emission Analyser (Otodynamics London, UK): the ILO92 (with ILO88 software version 3.94) for 16 out of the 18 infants and the ILO96 (ILO88 software version 5.60) for the remaining two infants. The ILO92 was equipped with the H-type otoacoustic emission (OAE) probe and the LO96 with the SNStype probe, both for neonatal ears. Three different types of disposable probe tips were used (T3P, T4.5C and T5.5R, Otodynamics London, UK). All recordings were performed bedside, without disturbing the normal clinical practice of the NICU. Both ILO versions used the same method of recording by time-domain averaging of SOAE's after synchronization of the frequency components by a click stimulus, as described in an earlier study (Brienesse et al., 1997). The mean amplitude of the synchronizing click stimulus was 77.1 dB SPL (peak equivalent) $(n=115, \mathrm{SD}=3.4 \mathrm{~dB} \mathrm{SPL})$. Only SOAE frequencies resulting from a minimum average of 100 single responses with an amplitude above $-15 \mathrm{~dB}$ SPL (measured at at least one occasion) were taken into account, in order to assure a sufficient signal to noise ratio (typically above $10 \mathrm{~dB}$ ) and to prevent the false identification of low amplitude synchronized frequency components as a SOAE frequency (Wable and Collet, 1994). Since this study concerned only relative frequencies, the absolute frequency readouts of the ILO have not been corrected for the known systematic 12.2 Hz error (Smurzynski and Probst, 1996).

\section{Data analysis}

In order to study the long-term variation in SOAE amplitude and frequency, the infants were tested on a weekly basis. After discharge from the NICU, the first and the last SOAE registration were used for further analysis, thereby maximizing the time between measurements. The minimum time interval between measurements was set to 14 days. These long term differences in frequency $\left(\mathrm{df}_{\mathrm{L}}\right)$ and 


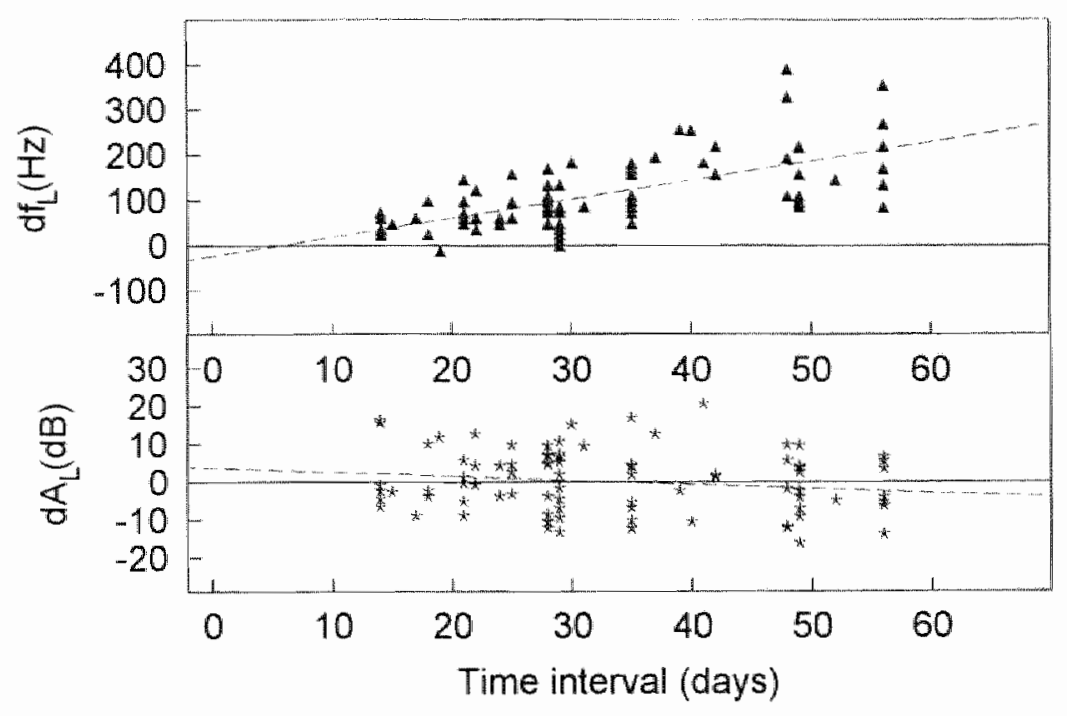

Figure 5.1.

Long-term difference in frequency ( $d f_{L}$, top figure) and amplitude $\left(d A_{L}\right.$, bottom figure) of the 87 $S O A E$ components under study as a function of the time interval between the observations. The dashed linear fits illustrate the upward shift of SOAE frequency in preterm infants, without a simultaneous SOAE amplitude shiff.

amplitude $\left(\mathrm{dA}_{\mathrm{L}}\right)$ of the SOAE components were both calculated as the last minus the first observation.

The short-term variation in SOAE amplitude $\left(\mathrm{dA}_{\mathrm{S}}\right)$ was obtained by calculating the difference in SOAE amplitude between the second observation minus the first observation, in order to investigate the relation between $\mathrm{dA}_{\mathrm{S}}$ and the early PCA.

Multiple regression analysis was performed to investigate the partial correlation of the initial SOAE frequency, the initial SOAE amplitude, the length of the long term time interval, and the $d A_{L}$, with the observed values of $d f_{\mathrm{L}}$. The Pearson product moment correlation test was used to study the relation between $d A_{\mathbb{S}}$ and 


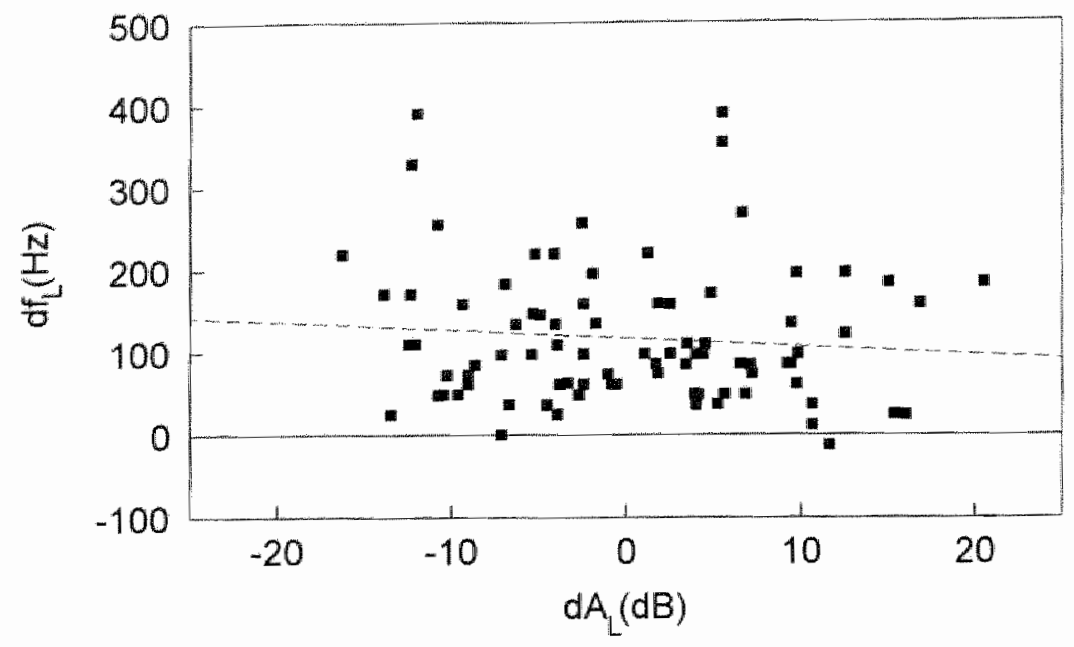

\section{Figure 5.2.}

Interrelation between the long-term difference in SOAE amplitude and frequency. As illustrated by the dashed linear fit, there is no correlation between $d A_{L}$ and $d f_{L}$.

PCA., and the Wilcoxon matched pairs test to compare the differences between the observations of $\mathrm{dA}_{\mathrm{L}}$ and $\mathrm{d} \mathrm{A}_{\mathrm{s}}$. Results were considered significant at $\mathrm{p}<0.05$.

\section{RESULTS}

\section{Long term data}

In 29 ears (17 right, 12 left) of the 18 preterm infants a total of 115 SOAE registrations was made, yielding a total of 87 values of both $\mathrm{df}_{\mathrm{L}}$ and $\mathrm{dA}_{\mathrm{L}}$, at initial $\mathrm{SOAE}$ frequencies ranging from 1001 to $5603 \mathrm{~Hz}(n=87$, mean $=3320 \mathrm{~Hz}, \mathrm{SD}$ $=1100 \mathrm{~Hz}$ ). The initial SOAE amplitudes ranged from -20.7 to $14.5 \mathrm{~dB}$ SPL (mean $=-5.1 \mathrm{~dB}$ SPL, $\mathrm{SD}=8.4 \mathrm{~dB}$ SPL). The mean time interval between the first and the last observation was 33.3 days ( $\mathrm{SD}=12.6$ days, range 14-56 days). The long term difference in SOAE frequency was predominantly positive, for the mean $\mathrm{df}_{\mathrm{L}}$ was $116.8 \mathrm{~Hz}(\mathrm{SD}=83.6 \mathrm{~Hz}$, range -13 to $+391 \mathrm{~Hz})$, whereas there 


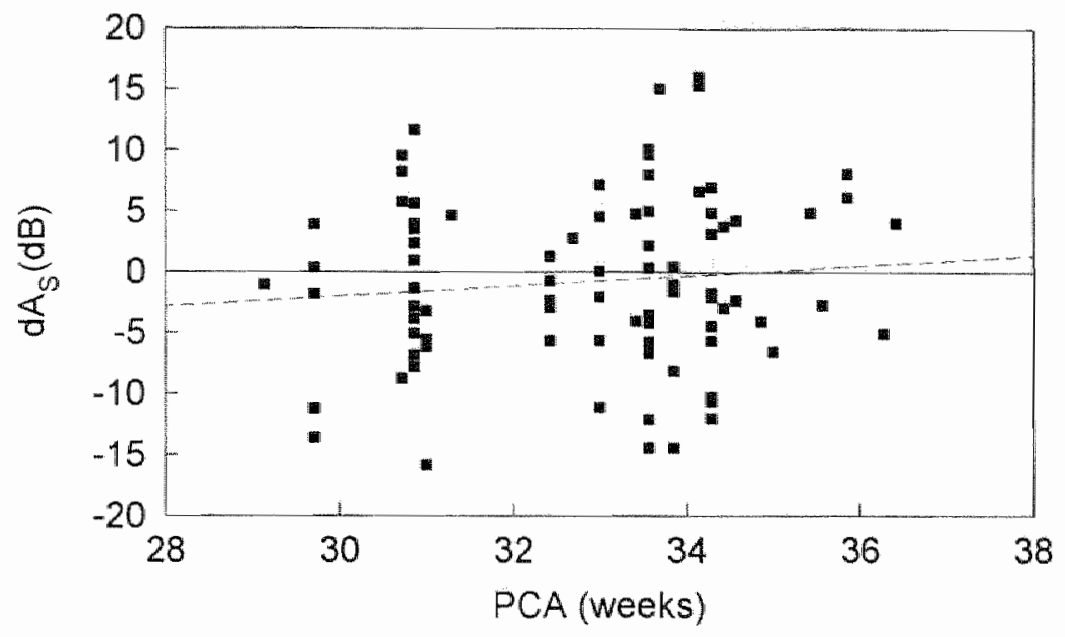

Figure 5.3.

Short-term difference in $S O A E$ amplitude (dA, as a finction of $P C A$, with linear regression line. According to the Pearson product moment correlation test, $d A_{s}$ was not significantly correlated with age $(n=87, r=0.11, p=0.33)$.

was no significant difference in amplitude, according to the mean $\mathrm{dA}_{\mathrm{L}}$ of $0.04 \mathrm{~dB}$ $\mathrm{SPL}(\mathrm{SD}=8.44 \mathrm{~dB} \mathrm{SPL}$, range -16.2 to $20.6 \mathrm{~dB} \mathrm{SPL}$ ).

Multiple regression analysis was performed with $\mathrm{df}_{\mathrm{L}}$ as the dependent variable and $\mathrm{dA}_{\mathrm{L}}$, the time interval, the initial SOAE frequency and the initial SOAE amplitude as independent variables. There proved to be a partial correlation of $\mathrm{df}_{L}$ with both the initial SOAE frequency $(n=87, r=0.647, \mathrm{p}<0.001)$ and the time interval $(r=0.631, \mathrm{p}<0.001)$. On the other hand, there was no correlation between $\mathrm{df}_{\mathrm{L}}$ and both $\mathrm{dA}_{\mathrm{L}}(r=-0.061, p=0.58)$ and the initial SOAE amplitude $(r$ $=0.088, p=0.43$ )

In Figure 5.1 , both $\mathrm{df}_{\mathrm{L}}$ and $\mathrm{dA}_{\mathrm{L}}$ are plotted as a function of the time interval. To 


\section{Chapter 5}

illustrate the positive partial correlation between $\mathrm{df}_{\mathfrak{L}}$ and the long term time interval, a linear regression line has been added to Figure 5.1, showing a consistent positive SOAE frequency shift. Calculation of the SOAE frequency shift velocity, relative to the $S O A E$ frequency, yielded a mean value of 0.72 percent per week $(\mathrm{SD}=0.27 \% / \mathrm{wk}$, range -0.14 to $1.62 \% / w k)$. As can be seen in Figure 5.1 , the difference in SOAE amplitude is not correlated to the time interval between the measurements. Furthermore, $\mathrm{dA}_{\mathrm{L}}$ is not correlated to the simultaneously occurring positive SOAE frequency shift (Figure 5.2).

\section{Short term data}

The mean short term time interval between the first and the second observation of the SOAE frequency components was 10.3 days $(n=87, \mathrm{SD}=6.2$ days, range 3 35 days). The mean short term difference in $\mathrm{SOAE}$ amplitude, $\mathrm{dA}_{\mathrm{S}}$, yielded -0.77 $\mathrm{dB}$ SPL (SD $=7.02 \mathrm{~dB}$ SPL, range -15.8 to $16.1 \mathrm{~dB}$ SPL). Between the PCA ranging from 29.1 to 36.4 weeks at the first observation, $\mathrm{d} A_{S}$ was not significantly correlated with age $(r=0.11, p=0.33)$, as can be seen in Figure 5.3.

A Wilcoxon matched pairs test between $d A_{L}$ and $d A_{S}$ yielded no significant difference ( $n=87, Z=0.87, p=0.39$ ). By comparing the absolute magnitude of the amplitude variations $\left|\mathrm{d} A_{S}\right|$ and $\left|d A_{L}\right|$, the long term $\left|d A_{L}\right|$ proved to be significantly higher than the short term $\left|\mathrm{dA}_{\mathrm{S}}\right|$, again according to the Wilcoxon test $(Z=2.23, \mathrm{p}<0.03)$.

\section{DISCUSSION}

This study shows that there is no SOAE amplitude shift accompanying the SOAE frequency shift in preterm infants, for the mean $d A_{L}$ and $d A_{S}$ were both practically zero, and $\mathrm{dA}_{S}$ was not correlated with PCA. Furthermore, there was no relation between $d f_{L}$ and $d A_{L}$ according to multiple regression analysis. On the other hand, the absolute variation of the SOAE amplitude seemed to increase with time, since $\left|d A_{L}\right|$ was significantly higher than $\left|d A_{s}\right|$.

The mean SOAE amplitude of $-5.1 \mathrm{~dB}$ SPL in the present study is relatively low 
to what is known from previous studies. For instance, Kok et al. (1993) reported a mean SOAE amplitude of $8.0 \mathrm{~dB}$ SPL in healthy newborns. This difference in SOAE amplitude finds its origin in the method of recording. It is known that the use of a synchronizing click in SOAE measurement, as in the present study, results in an about $14 \mathrm{~dB}$ lower amplitude than in SOAE measurement without click-synchronization (Burr et al., 1997). However, this difference in absolute SOAE amplitude has no effect on the present results, since they are based on relative amplitude changes.

The shift of SOAE frequency in preterm infants has been reported and described earlier in 14 of the 18 infants of the present study (Brienesse et al., 1997). It is therefore not surprising that the mean SOAE frequency shift of 0.72 percent per week is in good agreement with our earlier observation of 0.74 percent per week, for it only shows that the four extra infants show similar shifts of SOAE frequency as what is known from preterm infants (Smurzynski, 1994; Brienesse et al., 1996; Brienesse et al., 1997). As reported earlier, the frequency dependence and time course of this frequency shift strongly suggests cochlear maturation (Brienesse et al., 1997). From the present data, it becomes clear that the SOAE frequency shift is not accompanied by a net shift in SOAE amplitude, for both $d A_{S}$ and $d A_{L}$ have zero mean values. Furthermore, both plots in Figure 5.1 and 2 fail to show any significant relation between respectively $d A_{L}$ and the time interwal and $d A_{L}$ and $d f_{L}$. So, whatever the cause of the SOAE frequency shift is, it apparently does not induce any simultaneous amplitude shift.

From instantaneous induced shifts of a SOAE frequency it is known that a simultaneous SOAE amplitude shift can occur. For instance, upward SOAE frequency shifts up to $10 \mathrm{~Hz}$ with a simultaneous amplitude drop of -2 to $-4 \mathrm{~dB}$ SPL have been reported during contralateral stimulation with $76 \mathrm{~dB}$ noise in adults (Harrison and Burns, 1993). Although the role of suppression by trans-cranial conduction of sound energy or the role of acoustic reflex activity cannot always be excluded, the effect is contributed to an efferent influence on cochlear mechanics (Mott et al., 1989; Harrison and Burns, 1993). On the other hand, Morlet et 
al. (1993) reported that contralateral stimulation has no effect on evoked OAE in preterm infants, indicating functional immaturity of the medial olivocochlear system. Since it is not clear when the efferent influence on the cochlea becomes functional, a possible relation between the maturation of the efferent system and the upward SOAE frequency shift in preterm infants cannot be excluded.

The application of positive or negative pressure in the external middle ear in adults usually has a similar effect on SOAE amplitude and frequency as contralateral stimulation. By applying positive or negative pressure to the external ear canal or middle ear, the SOAE frequency is shifted upwards (Kemp, 1981; Wilson and Sutton, 1981; Schloth and Zwicker, 1983b; Hauser et al., 1993; Wada et al., 1995). The upward SOAE frequency shift is possibly caused by changes in resonance at the generation site of the SOAE by altering the load of the middle ear on the cochlea. This pressure-induced SOAE frequency shift is almost without exception accompanied by a drop in SOAE amplitude of typically -4 to $-6 \mathrm{~dB}$ SPL at pressures up to $\pm 4 \mathrm{kPa}$, with maximal drops up to -15 to -20 dB SPL (Wilson and Sutton, 1981; Hauser et al, 1993; Wada et al., 1995). This drop in SOAE amplitude is probably a middle ear effect, since the amplitudes of OAE in general are highly dependent on the transmission status of the middle ear (Probst et al., 1991). The same effect can for instance be achieved by manipulating the middle ear transmission by a voluntary contraction of the middle ear muscles (Burns et al., 1993).

The fact that the SOAE frequency shift described in the present study is not accompanied by a simultaneous change in SOAE amplitude, argues against the attribution of the middle ear in the SOAE frequency shift in preterm infants. The incidence of middle ear disorders such as middle ear effusion can, even in a very mild form, influence the outcome of SOAE measurements in preterm infants admitted to a NICU (Sutton et al., 1996). The fact that the absolute value of SOAE amplitude variation shows an increase with increasing PCA implies that in our study group, such middle ear effects have taken place during the period of observation. In our view, however, it is very unlikely that these fluctuating middle 
ear effects can cause the regular and consistent SOAE frequency shift.

From the observation of the development of external and middle ear properties during the first two years of life, a maturation of the external and middle ear is known to occur during this period, which is not yet completed at the age of 24 months (Keefe et al., 1993; Keefe et al., 1994). Burns et al. (1994) observed the SOAE properties during the same period and found a drop in SOAE amplitude from a mean of about $8 \mathrm{~dB}$ SPL at 1 month to $0 \mathrm{~dB} \mathrm{SPL}$ at 24 months, which they contributed to the developmental changes in the external and middle ear. Although the overall distribution of $\mathrm{SOAE}$ frequencies was still not adultlike at the age of 24 months, individual SOAE's showed no substantial shift in frequency (Burns et al., 1994). Since this observation of decreasing SOAE amplitude at stable SOAE frequencies is in contrast with the present observation of increasing individual SOAE frequencies at stable SOAE amplitudes, it argues against the role of external and middle ear development in the SOAE frequency shift in preterm infants.

In conclusion, the lack of any effect in SOAE amplitude during the upward SOAE frequency shift in preterm infants, further suggests the frequency shift to be a result of cochlear maturation.

\section{ACKNOWLEDGEMENT}

This study was supported by grants from the Heinsius-Houbolt Foundation, and the Special Clinical Research Fund of the University Hospital Maastricht. 


\section{REFERENCES}

Brienesse, P., Anteunis, L. J. C., Maertzdorf, W. J., Blanco, C. E. and Manni, J. J. (1997). "Frequency shift of individual spontaneous otoacoustic emissions in preterm infants," Pediatr Res 42, 478-483.

Brienesse, P., Anteunis, L. J. C., Wit, H. Gavilanes, D. and Maertzdorf, W. J. (1996). "Otoacoustic emissions in preterm infants: indications for cochlear development?" AudiolOgy 35, 296-306.

Burns, E. M., Campbell, S. L. and Arehart, K. H. (1994). "Longitudinal measurements of spontaneous otoacoustic emissions in infants, "J Acoust Soc Am 95, 385-394.

Burns, E. M., Harrison, W. A., Bullen, J. C. and Keefe, D. H. (1993). "Voluntary contraction of middle ear muscles: effects on input impedance, energy reflectance and spontaneous otoacoustic emissions," Hear Res 67, 117-127.

Burr, S. A, Mulheran, M. and Degg, C. (1997) "Characterization of 'Click-Synchronized Spontaneous Oto-Acoustic Emissions" (CSSOAEs) in humans," Br J Audiol 31, 93-94.

Dallmayr, C. (1985). "Spontaneous oto-acoustic emission: statistics and the reaction to acoustic suppression tones," Acustica 59, 67-75.

Harrison, W. A. and Burns, E. M. (1993). "Effects of contralateral acoustic stimulation on spontaneous otoacoustic emissions," J Acoust Soc Am 94, 2649-2658.

Hauser, R., Probst, R. and Harris, F. P. (1993). "Effects of atmospheric pressure variation on spontaneous, transiently evoked, and distortion product otoacoustic emissions in normal human ears," Hear Res 69, 133-145.

Keefe, D. H., Bulen, J. C., Arehart, K. H. and Burns, E. M. (1993). "Ear-canal impedance and reflection coefficient in human infants and adults," J Acoust Soc Am 94, 2617-2638.

Keefe, D. H., Bulen, J. C., Campbell, S. L. and Burns ${ }_{x}$ E. M. (1994). "Pressure transfer function and absorption cross section from the diffuse field to the human infant ear canal," $\mathrm{J}$ Acoust Soc Am 95, 355-371.

Kemp, D. T. (1981). "Physiologically active cochlear micromechanics--one source of tinnitus," Ciba Found Symp 85, 54-81

Kok, M. R., van Zanten, G. A. and Brocaar, M. P. (1993). "Aspects of spontaneous otoncoustic emissions in healthy newborns," Hear Res 69, 115-123.

Morlet, T., Collet, L., Salle, B. and Morgon, A. (1993). "Functional maturation of cochlear active mechanisms and of the medial olivocochlear system in humans," Acta Otolaryngol (Stockh) 113, 271-277.

Mott, J. B., Norton, S. J., Neely, S. T. and Warr, W. B. (1989). "Changes in spontaneous otoacoustic emissions produced by acoustic stimulation of the contralateral ear," Hear Res 38, 229-242.

Probst, R., Lonsbury Martin, B. L. and Martin, G. K. (1991). "A review of otoacoustic emis- 
sions," J Acoust Soc Am 89, 2027-2067.

Schloth, E. (1983a). "Relation between spectral composition of spontaneous otoacoustic emissions and fine-structure of threshold in quiet," Acustica 53, 250-256.

Schloth, E. and Zwicker, E. (1983b). "Mechanical and acoustical influences on spontaneous oto-acoustic emissions," Hear Res 11, 285-293.

Smurzynski, J. (1994). "Longitudinal measurements of distortion-product and click-evoked otoacoustic emissions of preterm infants: preliminary results," Ear Hear 15, 210-223.

Smurzynski, J. and Probst, R. (1996). "Error in the calculation of synchronized spontaneous otoacoustic emission frequencies measured with the ILO88 system," J Acoust Soc Am 100, 2555-2557.

Sutton, G. J., Gleadle, P. and Rowe, S. J. (1996). "Tympanometry and otoacoustic emissions in a cohort of special care neonates," BrJ Audiol 30, 9-17.

Wable, J. and Collet, L. (1994). "Can synchronized otoacoustic emissions really be attributed to SOAEs?," Hear Res 80, 141-145.

Wada, H., Ohyama, K., Kobayashi, T., Koike, T. and Noguchi i, S. (1995). "Effect of middle ear on otoacoustic emissions," Audiology 34, 161-176.

Whitehead, M. L. (1991). "Slow variations of the amplitude and frequency of spontaneous otoacoustic emissions," Hear Res 53, 269-280.

Wilson, J. P. and Sutton, G. J. (1981). "Acoustic correlates of tonal timnitus," Ciba Found Symp 85, 82-107. 
Chapter 5 


\section{CHAPTER}

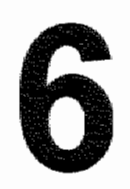

\section{Distortion product otoacoustic emission latency in preterm and term infants. Evidence for cochlear maturation}

Brienesse, P., Anteunis, L. J. C., Maertzdorf, W. J., Blanco, C. E. and Manni, J. J. submitted. 
Chapter 6 


\section{ABSTRACT}

In preterm infants, previous studies have described an increase in amplitude of click evoked otoacoustic emissions (CEOAE) and distortion product OAE (DPOAE), and an increase in frequency of spontaneous OAE (SOAE) from 30 weeks of gestation. These findings suggested cochlear maturation, although a middle ear effect could not be excluded. In the present study, the DPOAE latency was measured using the $f 2$ sweep phase gradient method, which is bellieved to be independent of middle ear status. Longer DPOAE latencies were found in preterm infants than in term infants, which was significant at $2=5 \mathrm{kHz}(p<0.05)$ and 6 $\mathrm{kHz}(p<0,01)$. Furthermore, the DPOAE latency of the term infant group was longer than what is known from comparable studies in adults. The presence of SOAE, sex and ear asymmetries had no influence on the latency results, nor could the latency decrease be explained by a middle ear effect. Other studies in preterm and term infants have shown that there is no decrease in DPOAE latency when derived with the $f 1$ sweep method. As discussed, the difference between the $f 1$ and $f 2$ sweep method suggests maturation of the active cochlear processes at the peak of the traveling wave, involved in the generation of $\mathrm{OAE}$. 


\section{INTRODUCTION}

The study of cochlear maturation of different vertebrate species showed that the stage of development of the organ of Corti depends on the location along the basilar membrane (Romand 1983). The structural development spreads progressively toward both the apex and the basal extremity, starting in the basal first half of the first turn in the cochlea (Romand 1983; Pujol et al., 1991). The first responses during maturation appear within a range of medium to low frequencies, whereas in the adult cochlea, the basal part is most sensitive for high frequencies. Many authors have explained this paradox with the hypothesis known as the shifting place code" (Lippe and Rubel, 1983; Harris and Dallos, 1984; Pujol 1985; Mills and Rubel, 1996), which assumes that early in development, the basal part of the cochlea is tuned to lower frequencies than in a more mature state, and that during maturation, the region of maximal excitation of a particular frequency is shifted to a more apical location on the cochlear partition. Romand (1987; 1997) postulated that the maturation of the outer hair cells in the organ of Corti plays an important role in the shifting place code. He proposed that around 20 weeks postconceptional age (PCA), the inner hair cells are ready to function, but the outer hair cells are still immature (Romand 1983; Pujol 1985; Pujol et al., 1991). As the outer hair cells mature, the mechanical tuning of the basilar membrane is sharpened by the additional motile activity of these outer hair cells, and the frequency of tuning is shifted upward for a specific cochlear location (Romand 1987; Romand 1997). If the outer hair cells play this major role in cochlear development, it is plausible to assume that cochlear development is reflected in otoacoustic emissions (OAE), since the motile activity of the outer hair cells is suggested to be the source of OAE. Recent studies have indeed shown an upward shift of spontaneous OAE (SOAE) frequency in preterm infants at the PCA from 29 to 42 weeks (Smurzynski 1994; Brienesse et al., 1996; Brienesse et al., 1997b), which could be consistent with the shifting place principle. On the assumption that the generation site of a SOAE is locked to a specific set of outer hair cells at a particular location on the cochlear partition, the upward shift of SOAE frequency could be explained by the upward shift of tuning frequency due to the shifting place code (Brienesse et al., 1997b). Other, mostly longitudinal 
studies have shown an increase in amplitude of click evoked OAE (CEOAE) and distortion product OAE (DPOAE) with increasing PCA in preterm infants (Chuang et al., 1993; Smurzynski 1994; van Zanten el al., 1995; Brienesse et al., 1996; Brienesse 1997a). This maturation of OAE amplitudes does not necessarily reflect cochlear maturation, since the amplitude of an $\mathrm{OAE}$ is directly influenced by middle ear status. Apart from the relatively high occurrence of mild and moderate middle ear disorders in preterm infants (Sutton et al., 1996), functional changes in the middle ear might also be expected, like the ossification of the auditory ossicles, clearance of mesenchyme in the middle ear or the changes in orientation of the tympanic membrane (Saunders et al, 1983). In the first two years of life, Keefe et al. (1993) have demonstrated a strong influence of the development of external ear canal and middle ear on input impedance and reflection coefficient responses, so in preterm ages, these developmental influences might even be stronger. However unlikely, even in the upward shift of SOAE frequency in preterm infants (Brienesse et al., 1997b), a middle ear effect cannot be excluded, for a similar upward shift has been demonstrated in adults by altering the loading of the cochlea by the middle ear, through atmospheric pressure variation or contraction of middle ear muscles (Burns et al., 1993; Hauser et al, 1993).

With DPOAE, it is possible to estimate the delay or latency of the in- and outward traveling soundwaves, by altering the frequency $f$ or $f$ of one of the two stimulus tones, and monitoring the thereby induced phase shift of the cubic distortion product (for instance 2/1-f2) (Kimberley et al., 1993; Brown et al., 1994; O Mahoney and Kemp, 1995; Wable et al., 1996). The rate of phase shift due to the relatively small frequency steps is interpreted as the DPOAE latency, and consequently, as an estimate of the 'round-trip' traveling wave delay. This round-trip delay can be interpreted as the delay of the incoming $f 1$ and $f 2$ stimulus tones, plus a build-up time for the generation of the emission, plus the delay of the outgoing 2f1- 2 distortion product (Brown et al, 1994). The DPOAE latency method (or 'phase gradient method') is presumed to be independent of direct influences of the middle ear. It is possible that mild differences in middle ear 
status affect the phase of forward and backward traveling waves through the middle ear, but since the DPOAE latency is derived using only relative phase changes, these are not expected to influence the DPOAE latency outcome directly (Moulin and Kemp, 1996a). Indirectly, the middle ear status can affect the level of the stimulus tones, and thereby altering the DPOAE latency outcome. This effect can be monitored by the amplitude of the DPOAE, which in this case should show a simultaneous decrease. Because of the relative independence of DPOAE latency measurement on middle ear status, it should be suitable for investigation of cochlear maturation. In the present study, we therefore aimed to investigate the differences in DPOAE latency and amplitude between preterm and term infants.

\section{METHODS AND PATIENTS DPOAE recordings}

All measurements were performed using the ILO96 OAE Research System (Otodynamics London, UK) with the software version V5.60H. The ILO96 was equipped with a standard probe, type 'HP', for DPOAE and CEOAE measurements in neonatal ears. Two different types of disposable probe tips were used (' $\mathrm{C} 4.5 \mathrm{C}$ ' and ' $\mathrm{C} 5.5 \mathrm{~B}$ ', Otodynamics London, UK), depending on the size of the external ear canal of the infant under investigation. The probe fitting was optimized by using the real time fast-Fourier transform (FFT) of the ear canal response to a click stimulus, provided by the חL96. The probe was fitted and refitted until the frequency components in the FFT were as equally distributed as possible.

In DPOAE measurement, the stimulus consists of two simultaneous continuous pure tones of frequency $f 1$ and $f 2(\mathrm{kHz})$, and sound-pressure level $L 1$ and $L 2$ (dB). In the ILO96, these stimulus tones are generated separately and delivered in the ear canal through two separate transducers. As in many previous studies on DPOAE we also chose to concentrate on the cubic distortion product at the frequency $2 f 1-f 2$. The ILO96 focuses on a small frequency band around the $2 f 1-f 2$ frequency and records the amplitude and phase of this DPOAE, by calculating the 
average of 16 time samples of $81.92 \mathrm{~ms}$ duration, followed by a FFT. The amplitudes of 10 adjacent frequencies are averaged and interpreted as the mean noise floor around the DPOAE. Only DPOAE with amplitudes of more than two standard deviations above the mean noise floor are taken into account by the ILO96.

The DPOAE latency is derived by the ILO 96 by altering the 2 frequency with $\Omega$ fixed, and registering the induced $2 f 1-\sqrt{2}$ phase shift. In a traveling wave, the amount of phase shift due to a small frequency shift is proportional to the number of periods between the points of generation and registration, and thus proportional to the travel time or latency of the continuous signal. In the same way, the latency of the $2 f 1-2$ DPOAE signal can be derived by the linear relation between a $f 2$ frequency shift and the $2 f 1-f 2$ DPOAE phase shift it induces (Kimberley et al., 1993; O Mahoney and Kemp, 1995; Eggermont et al., 1996). The ILO96 derives the DPOAE latency by circular measurement of the $2 f l-f 2$ phase at four equidistant $f 2$ frequencies with $f 1$ fixed. The amount of these three relatively small $f 2$ frequency steps varies from $12 \mathrm{~Hz}$ for $f 2$ frequencies around $1 \mathrm{kHz}$ to 48 $\mathrm{Hz}$ around $6 \mathrm{kHz}$. In theory, these four data points form a straight line in the 2 frequency versus $2 f 1-2$ phase plane. The slope of a linear fit through the data points results in an estimation of the DPOAE latency. In practice, however, the data points often stray from the theoretical linear fit. Possible explanations for these phase irregularities are interference of SOAE ( $O$ Mahoney and Kemp, 1995; Wable et al., 1997) or the occurrence of cancelation notches in the DPOAE signal due to internal reflections in the cochlea or the combination of tones from multiple DPOAE sources (O Mahoney and Kemp, 1995; Moulin and Kemp, 1996a). Although a small alteration of the tested $/ 2$ frequency in the order of 100 $\mathrm{Hz}$ might overcome these effects (O Mahoney and Kemp, 1995), we chose to purify the data set by the following two inclusion criteria for DPOAE latency measurements: 1) all four data points yield a value at least two standard deviations above the adjacent mean noise floor, and 2) all four data points form a regular line pattern in the $f 2$ frequency versus $2 f 1-12$ phase plane. The first criterion is automatically controlled by the ILO96 software, since it excludes DPOAE within the range of two standard deviations above the mean noise floor from 


\section{Chapter 6}

further latency analysis, so that we only excluded DPOAE latency estimations based on less than four data points. The second criterion was met by excluding data based on linear fits with a coefficient of determination $\left(r^{2}\right)$ under 0.95 .

\section{Measurement protocol}

The DPOAE measurements were part of a broader study on OAE in infants at the NICU, approved by the ethical committee of the University Hospital of Maastricht. In each infant a test battery was performed, starting with a DPOAE 'gram', in which the DPOAE amplitude was measured circularly at all $f$ frequencies under investigation. This test is denoted as 'DP-gram' in the DPOAE software of the ILO96. Secondly, the DPOAE latency was measured at all $f 2$ frequencies separately, starting with the highest $/ 2$ frequency down to the lowest $f 2$. Finally, a CEOAE registration was made, followed by a SOAE test. This test battery was then repeated in the other ear. The sequence in which both ears were tested was chosen arbitrary. All recordings were performed bedside, without disturbing the normal clinical practice of the NICU and with informed consent from the parents. In the present study, we report on the results from the DPOAE latency tests, including the results of DPOAE amplitude since the latency test calibrates the $f 1$ and $f 2$ stimulus amplitude for each frequency separately. The 'DP-gram' option only calibrates the $f 1$ and $f 2$ amplitude at one frequency $(f=2$ $\mathrm{kHz}$ ) which, in our experience, does not assure the desired $f 1$ and $f 2$ stimulus levels at other frequencies, especially at $f 2$ frequencies above 4 to $5 \mathrm{kHz}$. As reported earlier, the ILO96 measures SOAE by time-domain averaging after synchronization of the frequency components by a click stimulus (Brienesse et al., 1996; Brienesse et al., 1997b). The results of the SOAE registration are presented as 'present', 'absent' or 'unknown', merely in order to study their influence on the DPOAE results. SOAE were considered absent if no frequency components could be distinguished after averaging at least 50 individual clicksynchronized responses. A SOAE was considered present if one or more frequency components could be distinguished with an amplitude of at least $10 \mathrm{~dB}$ above the noise level in its vicinity. 
Table 6.1. Parameters of the 7 stimulus conditions ' $6 \mathrm{kHz}$ " through " $\mathrm{l} \mathrm{kHz}$ '.

\begin{tabular}{|c|c|c|c|c|}
\hline Stimulus & $\begin{array}{l}\mathrm{f} \\
\text { (range in } \mathrm{Hz} \text { ) }\end{array}$ & $\begin{array}{l}\mathrm{H} \\
(\mathrm{Hz})\end{array}$ & $\begin{array}{l}2 f /-\Omega \\
\text { (range in } \mathrm{Hz} \text { ) }\end{array}$ & $\begin{array}{l}\text { Rhi } \\
\text { (mange) }\end{array}$ \\
\hline $6 \mathrm{kHz}$ & $5994-6140$ & 4968 & $3942-3796$ & $1.24-1.24$ \\
\hline $5 \mathrm{kHz}$ & $4993-5139$ & 4138 & $3283-3137$ & $1.21-1.24$ \\
\hline $4 \mathrm{kHz}$ & $3992-4065$ & 3308 & $2624-2551$ & $1.21-1.23$ \\
\hline $3 \mathrm{kHz}$ & $2991-3064$ & 2490 & $1989-1916$ & $1.20-1.23$ \\
\hline $2 \mathrm{kHz}$ & $1990-2026$ & 1660 & $1330-1294$ & $1.20-1.22$ \\
\hline $1,5 \mathrm{kHz}$ & $1489-1526$ & 1245 & $1001-964$ & $1.20-1.23$ \\
\hline $1 \mathrm{kHz}$ & $989-1025$ & 830 & $671-635$ & $1.19-1.23$ \\
\hline
\end{tabular}

\section{Study parameters}

The $2 f 1-2$ DPOAE was recorded with an equilevel $f 1$ and $f$ stimulus of $L 1=L 2=65 \mathrm{~dB}$ SPL. The stimulus parameters were set according to the values listed in Table 6.1. These seven stimulus conditions will be denoted as an $/ 2$ frequency of $6,5,4,3,2,1.5$ and $1 \mathrm{kHz}$, according to the half octave values closest to the actual $f 2$ frequency. The preferred frequency ratio of $f / f 1$ was set to 1.22 , which resulted in a $f / f 1$ ratio ranging from 1.19 to 1.24 . The amplitude of the synchronizing click stimulus used in the SOAE registration ranged from 80.8 to $83.1 \mathrm{~dB}$ peak equivalent.

\section{Patients}

In 70 ears of 43 infants at the NICU, the DPOAE measurement protocol could be completed. In the 27 infants in which both ears were investigated, a random selection between the two ears was performed to assure the independence of all observations of DPOAE amplitude and latency. Patients were divided in two groups: 1) a preterm infant group, consisting of 20 infants with a PCA at the test date below 37 weeks, and 2) a "term" infant group, consisting of 23 infants with a PCA at the test date of 37 weeks or more. The characteristics of both groups are listed in Table 6.2.

\section{Data analysis}

The nonparametric Kolmogorov-Smimov two-sample test was used to test the differences in results between the preterm and the term group, given the low 
Table 6.2. Characteristics of 20 preterm and 23 term infants.

\begin{tabular}{|c|c|c|}
\hline & $\begin{array}{l}\text { Preterm infants } \\
(n=20)\end{array}$ & $\begin{array}{l}\text { Term infants } \\
(n=23)\end{array}$ \\
\hline $\begin{array}{l}\text { PCA at birth" } \\
\text { (weeks) }\end{array}$ & $\begin{array}{l}31.9 \\
(24.6-35)\end{array}$ & $\begin{array}{l}366^{\dagger} \\
(25.9-42.3)\end{array}$ \\
\hline $\begin{array}{l}\text { Birth weight" } \\
\text { (g) }\end{array}$ & $\begin{array}{l}1633 \\
(550-2750)\end{array}$ & $\begin{array}{l}1990 \\
(780-4150)\end{array}$ \\
\hline $\begin{array}{l}\text { Sex } \\
\text { (male / female) }\end{array}$ & $10 / 10$ & $12 / 11$ \\
\hline $\begin{array}{l}\text { Ear under investigation } \\
\text { (left / right) }\end{array}$ & $8 / 11$ & $8 / 15$ \\
\hline $\begin{array}{l}\text { PCA at test date } \\
\text { (weeks) }\end{array}$ & $\begin{array}{l}35.2 \\
(31.6-36.6)\end{array}$ & $\begin{array}{l}38.6^{\dagger} \\
(37.1-45.4)\end{array}$ \\
\hline $\begin{array}{l}\text { SOAE } \\
\text { (present / absent / unknown) }\end{array}$ & $\| 1 / 5 / 4$ & $10 / 10 / 3$ \\
\hline \multicolumn{3}{|c|}{$\begin{array}{l}\text { Risk factors for sensorineural hearing loss: } \\
\text { (percentage of infarts) }\end{array}$} \\
\hline Birth weight $<1500 \mathrm{~g}$ & $45 \%$ & $26 \%$ \\
\hline Mechanical ventillation & $25 \%$ & $17 \%$ \\
\hline Asphyxia at birth & $15 \%$ & $9 \%$ \\
\hline Administration of aminoglycosides & $50 \%$ & $22 \%$ \\
\hline Administration of lloop diuretics & $20 \%$ & $13 \%$ \\
\hline Hyperbilirubenaemia & $10 \%$ & $9 \%$ \\
\hline Multiple bradycardic periods & $5 \%$ & $4 \%$ \\
\hline Hypotension & $15 \%$ & $9 \%$ \\
\hline Sepsils & $20 \%$ & $22 \%$ \\
\hline Persistent ductus arteriosus & $10 \%$ & $0 \%$ \\
\hline Menigitts & $0 \%$ & $9 \%$ \\
\hline
\end{tabular}

t:Significant difference between groups $(p<0.001)$. For all other characteristics listed, there were no significant differences (Kolmogorov-Smirnov, Chi-square).

number of observations in some of the DPOAE stimulus conditions and in consequence the lack of evidence for the normality of distribution of the concerning variables. The Chi-square test was used to test the differences in the binomial characteristics of the preterm and the term group. The Kolmogorov-Smimov test 


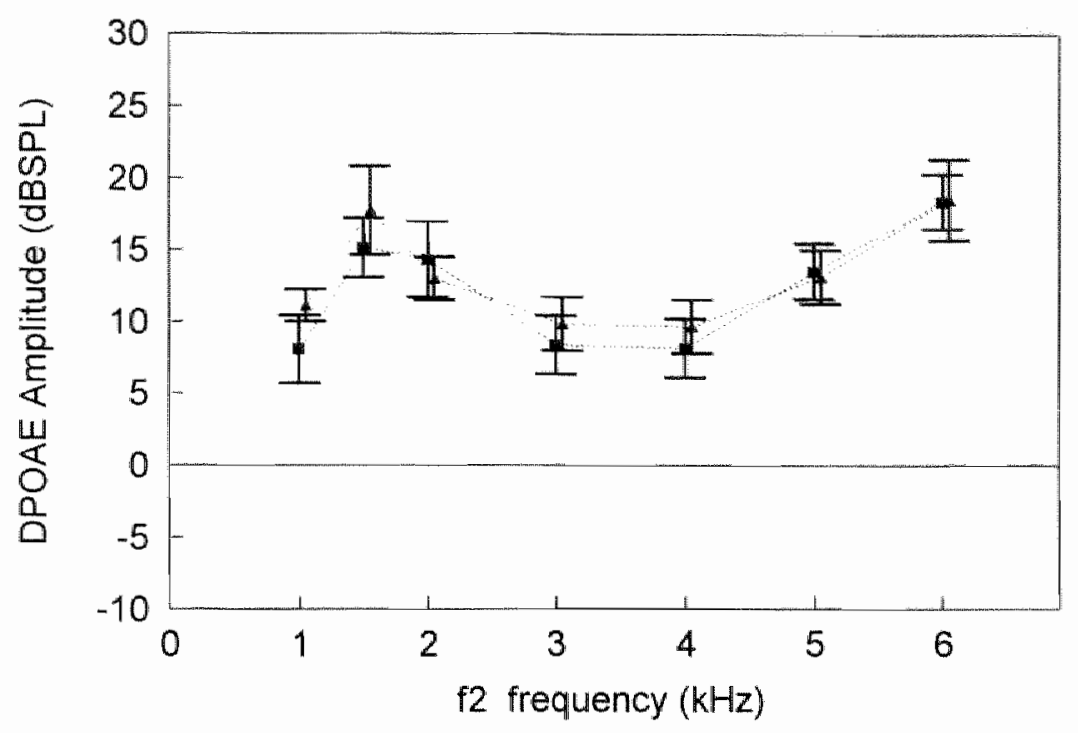

Figure 6.1.

Mean DPOAE amplinude of the preterm (squares) and term (triangles) infants. The vertical lines denote the plus and mimus one standard error range arourd the mean. As can be seen from the standard error overlap, there was no significant difference in DPOAE amplitude between preterm and term infants.

was also used to compare results from male and female infants, from left and right ears, and from ears with and without SOAE. Results were considered significant at $p<0.05$.

\section{RESULTS}

The analysis of the data comprised 20 observations (in 11 right and nine left ears) from the 20 preterm infants and 23 observations (in 15 right and eight left ears) from the 23 term infants. There were no significant differences between both groups of infants for all characteristics listed in Table 6.2, except for the PCA at test date $(p<0.001)$ and the PCA at birth $(p<0.001)$. A total of 36.8 percent of the initial recordings was excluded for phase irregularities on the criteria described above. This percentage of exclusion varied from 22.8 percent at $2 \mathrm{kHz}$ to 
Table 6.3. Mean DPOAE latency in the preterm and lerm group at the $7 \mathrm{f} 2$ stimulus frequencies.

\begin{tabular}{llll}
\hline Stimulus & $\begin{array}{l}\text { Preterm infants } \\
(n=20)\end{array}$ & $\begin{array}{l}\text { Term infants } \\
(n=23)\end{array}$ & p \\
\hline $6 \mathrm{kHz}$ & $\begin{array}{l}7.5 \pm 1.3 \\
(n=9)\end{array}$ & $\begin{array}{l}5.5 \pm 1.1 \\
(n=12)\end{array}$ & $<0.01$ \\
$5 \mathrm{kHz}$ & $\begin{array}{l}6 \pm 1.9 \\
(n=12)\end{array}$ & $\begin{array}{l}6.7 \pm 1.8 \\
(n=18)\end{array}$ & $<0.05$ \\
& $8.9 \pm 2.3$ & $7.7 \pm 1.8$ & \\
$4 \mathrm{kHz}$ & $(n=15)$ & $(n=16)$ & n.s. \\
& $9.6 \pm 3.3$ & $7.7 \pm 2.1$ & \\
$3 \mathrm{kHz}$ & $(n=12)$ & $(n=15)$ & n.s. \\
& $10.5 \pm 1.9$ & $9.1 \pm 1.9$ & n.s. \\
$2 \mathrm{kHz}$ & $(n=9)$ & $(n=15)$ & n.s. \\
& $11.0 \pm 1.3$ & $9.0 \pm 2.6$ & \\
$1.5 \mathrm{kHz}$ & $(n=9)$ & $(n=6)$ & n.s. \\
& $14.4 \pm 1.8$ & $12.9 \pm 0.9$ & \\
$1 \mathrm{kHz}$ & $(n=3)$ & $(n=5)$ &
\end{tabular}

Data are mean \pm standard deviation, $n$ denotes the number of samples in each group of infants and stimulus condition, and p demotes the statistical significance of the Kolmogorov-Smirnov two-sample test.

56.2 percent at $6 \mathrm{kHz}$.

\section{DPOAE amplitude}

The observations of DPOAE amplitude were registered using the DPOAE latency test of the ILO96. According to the Kolmogorov-Sminov two-sample test, there was no significant difference in DPOAE amplitude between the preterm and term group, at all seven $/ 2$ frequencies under investigation. Figure 6.1 illustrates the mean DPOAE amplitude of both groups as a function of the 2 frequency.

\section{DPOAE latency}

The results of the DPOAE latency revealed a general trend of longer latency in preterm infants than in term infants, at all seven 2 frequencies (Table 6.3, Figure 


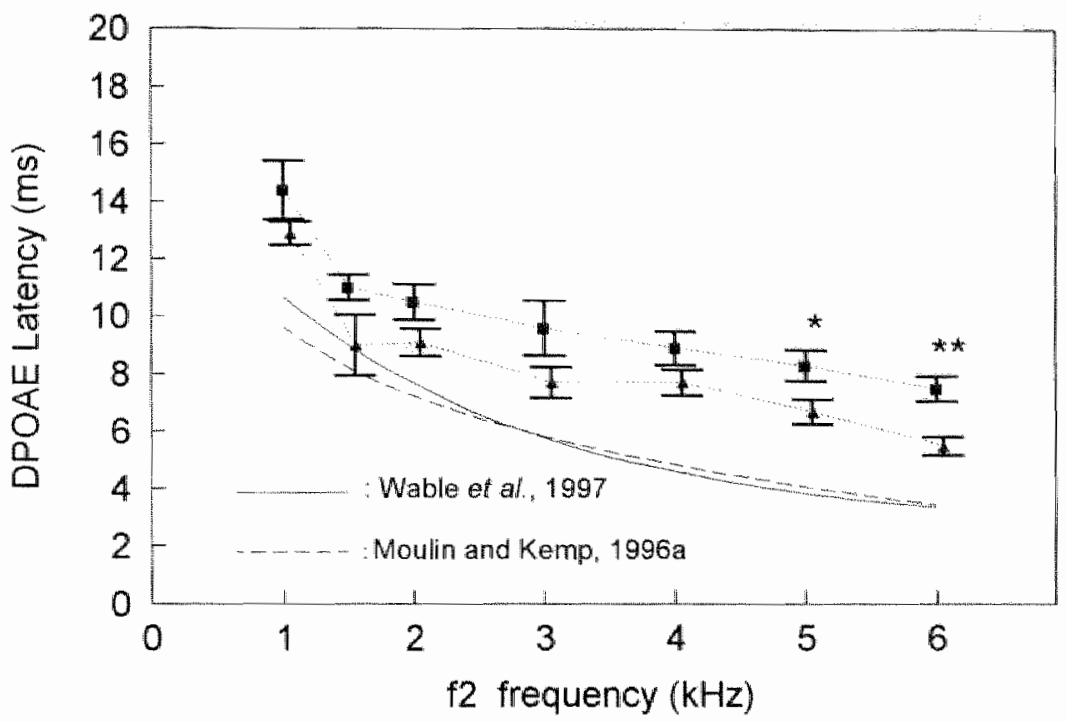

\section{Figure 6.2.}

Mean DPOAE latency values of the preterm (squares) and term infants (triangles) at the seven f2 stimulus conditions. The vertical lines denote the plus and mimus one standard error range around the mean latency. According to the Kolmogorov-Smimov two-sample test, the latencies at $5 \mathrm{kHz}$ and $6 \mathrm{kHz}$ were significantly longer in preterm than in term infants $\left(^{*}: p<0.05, * *: p\right.$ $<0.01)$. The solid lime indicates the exponential fit through the data of Wable et al. (1997) (latency $=13.04 * \exp /-0.0007 *$ frequency $2 \pi, j 21+2.54)$, measured with an f2 sweep method in adulls with $L I=L 2=65 \mathrm{~dB}$ SPL. The dashed fit is deducted from similar data measured with $L 1 / L 2=65 / 60$ dB SPL by Moulin and Kemp (1996a) (latency $=9.6-7.9 * \log (f 2 J)$.

6.2). The latency difference between the preterm and term infants was significant at $5 \mathrm{kHz}(p<0.05)$ and $6 \mathrm{kHz}(p<0.01) / 2$ stimulus frequency.

\section{Effect of sex and ear asymmetry}

There were no significant differences between both DPOAE amplitudes and latencies from male $(n=22)$ and female $(n=21)$ infants. Testing the difference between left $(n=17)$ and right $(n=26)$ ears yielded no significant difference in DPOAE latency at all stimulus frequencies. Only at the $6 \mathrm{kHz}$ stimulus, the DPOAE amplitude was significantly higher in right ears than in left ears (19.8 dB 


\section{Chapter 6}

SPL versus $16.3 \mathrm{~dB}$ SPL respectively, $p<0.05$ ). At all other frequencies, there were no significant differences in DPOAE amplitude, nor were there trends indicating that DPOAE amplitudes were generally higher in right ears than in left ears.

\section{Effect of SOAE presence}

The presence of SOAE was confirmed in 21 infants (Table 6.2). A total of 133 SOAE frequencies ranging from $830 \mathrm{~Hz}$ to $6079 \mathrm{~Hz}$ was registered. In 15 infants there proved to be no SOAE activity. In the remaining seven out of the total 43 infants, SOAE presence could neither be proven nor excluded, mostly due to a noisy environment during SOAE registration. Comparison of the two groups of infants with $(n=21)$ and without $\operatorname{SOAE}(n=15)$, yielded a general trend of higher DPOAE amplitude in infants with $\mathrm{SOAE}$ at all seven stimulus conditions, with a mean difference in amplitude ranging from $2.9 \mathrm{~dB}$ at $1 \mathrm{kHz}$ to $7.9 \mathrm{~dB}$ at 5 $\mathrm{kHz}$. At $4 \mathrm{kHz}$ and $5 \mathrm{kHz}$, this difference in DPOAE amplitude proved to be significant $(p<0.01$ and $p<0.05$ respectively). Considering the DPOAE latency, there was no trend in the latency difference between infants with and without SOAE. Only at $5 \mathrm{kHz}$ however, the DPOAE latency proved to be significantly longer in the infants with SOAE $(8.5 \mathrm{~ms})$ than in infants without SOAE $(6.0 \mathrm{~ms}, p$ $<0.01)$.

\section{DISCUSSION}

By comparison of DPOAE latency measurements in 20 preterm and 23 term infants, the present study showed that the DPOAE latency was generally longer in preterm infants. This effect was the strongest in the higher $f$ stimulus frequencies around $5 \mathrm{kHz}$ and $6 \mathrm{kHz}$. The DPOAE amplitude, on the other hand, did not show any trend or difference between term and pretern infants.

\section{DPOAE amplitude}

The mean DPOAE amplitudes reported in the present study are comparable with the results of similar studies. Smurzynski (1994) for instance, reported similar results in preterm infants with $L 1=L 2=65 \mathrm{~dB}$ SPL. Other studies in normal new- 
born infants resulted in about $5 \mathrm{~dB}$ lower mean DPOAE amplitudes with equilevel stimuli around $65 \mathrm{~dB}$ SPL (Bonfils et al., 1992; Smurzynski et al., 1993). This small difference was more pronounced at $f=6 \mathrm{kHz}$. It is therefore possibly related to the calibration protocol of the latency test of the MO96 used in the present study, which calibrates $L 1$ and $L 2$ at each $/ 2$ separately. As stated earlier, to our experience, calibration of $L 1$ and $L 2$ at only one $f$ level often results in lower $L 1$ and $L 2$ at $f 2$ around 5 and $6 \mathrm{kHz}$. On the other hand, the present results of DPOAE amplitude are relatively low compared to a study by Marco et al. (1995), reporting about 5 to $10 \mathrm{~dB}$ higher mean amplitudes in healthy newborns at just slightly higher stimulus levels of $L 1=\angle 2=75 \mathrm{~dB}$. So on the whole, the DPOAE amplitude data is considered to be in good agreement with previously reported results.

\section{Effects of sex, ear asymmetries and presence of SOAE}

Although the preterm group of infants showed a significant lower PCA at birth compared to the "term at test date" group, there were no significant differences in all other characteristics, including the risk factors for sensorineural hearing loss. Thereby the two groups were fairly homogeneous. The effect of sex and ear asymmetries on the DPOAE results were further tested by comparing male with female, and left- with right ear results using the total group of 43 infants. Both sex and ear asymmetry did not show any significant effect on the DPOAE latency results. On the other hand, the comparison of DPOAE latency results from ears with SOAE activity and without SOAE activity, yielded a significantly longer latency at $5 \mathrm{kHz}$ in the SOAE group than in the non-SOAE group $(p<0.01)$. Furthermore, comparison of DPOAE amplitudes from ears with and without SOAE yielded a significantly higher DPOAE amplitude in ears with SOAE. This effect of SOAE presence on DPOAE amplitude was however diminished by reordering the data in a term and a preterm infant group, since there was no effect nor trend in the difference in DPOAE amplitude between preterm and term infants. In addition to this, the Chi-square test yielded no significant difference in SOAE presence between the preterm and term infant group. In the present study, a contribution of the SOAE presence on the difference in DPOAE latency be- 
tween preterm and term infants is therefore not to be expected.

\section{Comparison with other studies}

\section{Aduits}

In the present study, the DPOAE latency was derived with a $f 2$ sweep phase gradient method, with $f 1$ fixed. O Mahoney and Kemp argued that the $/ 2$ sweep data are expected to have a greater dependence on physiologically dependent aspects of cochlear mechanics than the $f 1$ sweep data, and that an $f 1$ sweep therefore underestimates the true traveling wave delay. It is therefore logical to alter $f 2$ in order to optimize the chance of obtaining the data most relevant to active cochlear processes (O Mahoney and Kemp, 1995). Others however, propagate an alternative $f 1$ sweep method with $/ 2$ fixed, on the assumption that the traveling wave delay is evaluated better by keeping the DPOAE source fixed (Kimberley et al., 1993; Brown et al., 1994; Eggermont et al., 1996; Stover et al., 1996). It is known that the $f 2$ sweep method results in longer DPOAE latencies compared with the $f 1$ sweep method, with a latency difference in adults ranging roughly between 1 to $2 \mathrm{~ms}$ at all $f 2$ frequencies (O Mahoney and Kemp, 1995; Moulin and Kemp, 1996a; Moulin and Kemp, 1996b). The results of the present study should therefore be compared with results from other $f 2$ sweep studies, which at this point only comprised results from adult ears (O Mahoney and Kemp, 1995; Wable et al., 1996; Moulin and Kemp, 1996a; Wable et al., 1997). These latter studies vary only slightly in the used $L 1$ and $L 2$ values, namely $L 1 / L 2=70 / 60 \mathrm{~dB}$ SPL (O Mahoney and Kemp, 1995), 70/70 dB SPL (Wable et al., 1996), 65/60 dB SPL (Moulin and Kemp, 1996a), and $L 1=L 2=40$ up to $80 \mathrm{~dB}$ SPL in $5 \mathrm{~dB}$ steps (Wable et al., 1997), for which they are comparable to the $L 1=L 2=65 \mathrm{~dB}$ SPL of the present study. The DPOAE latency in adult ears varied from about $3.5 \mathrm{~ms}$ at $f 2=6 \mathrm{kHz}$ to about $9 \mathrm{~ms}$ at $f=1 \mathrm{kHz}(\mathrm{O}$ Mahoney and Kemp, 1995; Wable et al., 1996; Moulin and Kemp, 1996a; Wable et al., 1997). For comparison with the present preterm and tern infants data, two exponential fits through latency data from adults ears (Moulin and Kemp, 1996a; Wable et al., 1997) have been added to Figure 6.2. The DPOAE latency in the preterm infants proved to be about $4 \mathrm{~ms}$ longer, and in the term infants about 2.5 
ms longer than in adults.

\section{Preterm and term infants}

Eggermont et al. (1996) studied DPOAE latency in preterm and term infants using an $f 1$ sweep method, with $L 1 / L 2=60 / 45 \mathrm{~dB} \mathrm{SPL}$. The results in their study show a striking discrepancy with the present results. As expected, the $f$ sweep DPOAE latency values from their study were considerably lower than the present $f 2$ sweep results, namely about 2 to $2.5 \mathrm{~ms}$ around $f=6 \mathrm{kHz}$ up to about 4.5 to 5 ms around $f=2 \mathrm{kHz}$, but the difference of their data with the present data is more pronounced than what is to be expected from latency differences between $f l$ and $f 2$ sweep methods in adults. This large difference is even more striking when the relatively low $L 1$ and $L 2$ stimulus levels used by Eggermont $e t$ al. (1996) are taken into account, which are expected to reduce rather than increase the difference between the two studies (Stover et al., 1996; Wable et al., 1997). Furthermore, Eggermont et al. (1996) found no significant difference in the DPOAE latency data between three groups of neonatal infants (two groups of preterm infants with a PCA from 30 to 33 weeks and 34 to 37 weeks and one term group with a PCA from 38 to 42 weeks). Comparison of their data with adult DPOAE latency data resulted in a substantially longer latency (relative to the travel time at $f 2=10$ to $11 \mathrm{kHz}$ ) in adults above $f 2=3 \mathrm{kHz}$ compared with all neonatal groups (Eggermont et al., 1996). Brown et al. (1994) made similar observations using the same $f$ sweep method with $L 1 / L 2=60 / 45 \mathrm{~dB}$ SPL. At $f 2=3$ to $5 \mathrm{kHz}$, the aduit DPOAE latency was longer than in a term infant group. So both these $f 1$ sweep studies reported opposite findings compared with the present observation of decreasing DPOAE latency with increasing age.

\section{2 sweep versus $f 1$ sweep results}

On the assumption that the 2 sweep method comprises more information about cochlear mechanics than an $f 1$ sweep, as argued by $O$ Mahoney and Kemp (1995), the discrepancy between $f 1$ and $f 2$ sweep results suggests that the decrease of DPOAE latency, as described in the present study, reflects a maturation of the active cochlear processes which is missed by the $f 1$ sweep latency studies. 
Although many elements of DPOAE generation are still poorly understood, one can assume that the DPOAE source is fixed to the envelope of the $f 2$ wave, since this more basical situated $/ 2$ envelope is the place of interaction between both stimulus tones. On this assumption, the main difference between an $f 1$ sweep and an $/ 2$ sweep is that an alteration of $/ 2$ alters the location of the DPOAE source, whereas the location of this source stays fixed when $f 1$ is being altered. Because of the proximity of the $\Omega$ traveling wave envelope to the DPOAE source, the effects on the latency outcome by altering $f 2$ are greater than in altering the $f$ frequency which is situated further from the site of DPOAE generation (Moulin and Kemp, 1996b). In contrast with the $f 1$ sweep method, the $f 2$ sweep method is also dependent of transmission time components relevant to the peak of the traveling wave (O Mahoney and Kemp, 1995). Since the peak of the traveling wave is enhanced by the active cochlear processes related to $\mathrm{OAE}$ activity, one would expect the $f 2$ sweep method to be more sensitive to changes in these cochlear mechanisms ( $O$ Mahoney and Kemp, 1995). The fact that the maturation of DPOAE latency, as reported here, is absent when the $f 1$ sweep method is used (Brown et al., 1994; Eggermont et al., 1996), therefore suggests maturation of the active cochlear processes at the peak of the traveling wave.

\section{Middle ear effects on the latency results}

It is not expected that the middle ear directly affects the measurement of DPOAE latency by the phase gradient method. If a change in the middle ear characteristics would change the phase of the incoming $f 1$ and $f 2$, and/or the outgoing $2 f l-f 2$, it would probably do so at all four equidistant $/ 2$ frequencies in an equal amount, when the $\delta$ frequency steps are relatively small. The phase gradient method is, however, based on relative phase changes, so that a net influence of this absolute phase change on DPOAE latency is not to be expected (O Mahoney and Kemp, 1995). On the other hand it is known that a slight decrease in middle ear function can affect DPOAE latency indirectly, through a decrease in level of the incoming stimulus tones, which is undetected by a microphone in the ear canal (Eggermont et al., 1996). In this way, the middle ear is capable of increasing the DPOAE latency (Stover et al., 1996; Wable et al., 1997), and decreasing the DPOAE 
amplitude outcome (Bonfils et al., 1992; Hauser et al., 1993; Osterhammel et al., 1993). The present findings of decreasing DPOAE latency with increasing PCA are, however, unaccompanied by simultaneous DPOAE amplitude changes. The DPOAE amplitudes reported in the present study are comparable to other studies (Bonfils et al., 1992; Smurzynski et al., 1993; Smurzynski 1994; Marco et al., 1995), and do not change with increasing PCA. Furthermore, if the present findings were the result of middle ear changes, the same effect would be expected in other $f 1$ sweep studies, since Moulin and Kemp (1996a) demonstrated that the effect of middle ear changes on DPOAE amplitude and latency is comparable between the $f 1$ and $f 2$ sweep method. As stated earlier, the present observations were not confirmed by comparable $f 1$ sweep latency data (Brown et al., 1994; Eggermont et al., 1996). In our view, this indicates that practically no middle ear effect was involved in the present findings.

\section{Latency decrease and the shifting place principle}

The present results of a decrease in DPOAE latency with increasing PCA are not directly in agreement with the concept of the shifting place principle. According to this principle, the frequency of tuning at a fixed place on the cochlear partition is shifted upward. This means that the location of tuning of a specific frequency is shifted apically along the cochlear partition, thereby increasing the distance from the base of the cochlea. The shifting place principle therefore implies that during maturation, the location of the two DPOAE stimulus frequencies $f 1$ and $f 2$ is shifted apically, causing an increase of the distance covered by the traveling waves of both the incoming stimuli and the outgoing distortion product. On these grounds, the DPOAE latency is expected to increase rather than decrease during maturation. On the assumption that the DPOAE latency consists of both travel times of the traveling waves plus a build-up time for the generation of the emission (Brown et al., 1994), the reported decrease of DPOAE latency is more likely to be related to maturation of the active cochlear processes involved in the generation of $O A E$. 


\section{CONCLUSION}

This study demonstrated a decrease of DPOAE latency with PCA using the $/ 2$ sweep method. At term age, the mean latency is still longer than what is known from comparable studies in adults. The presence of $\mathrm{SOAE}$, sex and ear asymmetries had no influence on the latency results, nor could the latency decrease be explained by a middle ear effect. The fact that this decrease in DPOAE latency is absent when using the $f 1$ sweep method, suggests maturation of the active cochlear processes at the peak of the traveling wave.

\section{ACKNOWLEDGEMENTS}

The authors wish to thank Prof. Dr. Rudolf Probst for the very helpful comments on an earlier version of the manuscript. This study was supported by the Special Clinical Research Fund of the University Hospital Maastricht, and the HeinsiusHoubolt Foundation. 


\section{REFERENCES}

Bonfils, P., Avan, P., Francois, M., Trotoux, J. and Narcy, P. (1992) "Distortion-product otoacoustic emissions in neonates: normative data," Acta Otolaryngol (Stockh) 112, 739744.

Brienesse, P. (1997a). "Maturation of otoacoustic emissions: longitudinal versus cross-sectional study (letter to the editor)." Int J Pediatr Otorhinolaryngol 40, 73-74.

Brienesse, P., Anteunis, L. J. C., Maertzdorf, W. J., Blanco, C. E. and Manni, J. J. (1997b). "Frequency shift of individual Spontaneous OtoAcoustic Emissions in preterm infants." Pediatr Res 42, 478-483.

Brienesse, P., Anteunis, L. J. C., Wit, H. P., Gavilanes, A. W. D. and Maertzdorf, W. J. (1996). "Otoacoustic emissions in preterm infants: indications for cochlear development?" Audjology 35, 296-306.

Brown, D., Kimberley, B. and Eggermont, J. (1994). "Cochlear traveling-wave delays estimated by distortion-product emissions in normal hearing adults and term-born neonates," I Otolaryngol 23, 234-238.

Burns, E. M., Harrison, W. A., Bulen, J. C. and Keefe, D. H. (1993). "Voluntary contraction of middle ear muscles: effects on input impedance, energy reflectance and spontaneous otoacoustic emissions," Hear Res 67, 117-127.

Chuang, S. W., Gerber, S. E. and Thornton, A. R. (1993). "Evoked otoacoustic emissions in preterm infants," Int J Pediatr Otorhinolaryngol 26, 39-45.

Eggermont, J. J., Brown, D. K., Ponton, C. W. and Kimberley, B. P. (1996). "Comparison of distortion product otoacoustic emission (DPOAE) and auditory brain stem response (ABR) traveling wave delay measurements suggests frequency-specific synapse maturation," Ear Hear 17, 386-394.

Harris, D. M. and Dallos, P. (1984). "Ontogenetic changes in frequency mapping of a mammalian ear," Science 225, 741-743.

Hauser, R., Probst, R. and Harris, F. P. (1993). "Effects of atmospheric pressure variation on spontaneous, transiently evoked, and distortion product otoacoustic emissions in normal human ears," Hear Res 69, 133-145.

Keefe, D. H. Bulen, J. C., Arehart, K. H. and Burns, E M. (1993). "Ear-canal impedance and reflection coefficient in human infants and adults," $J$ Acoust Soc Am 94, 2617-2638.

Kimberley, B. P., Brown, D. K. and Eggermont, J. J. (1993) "Measuring human cochlear traveling wave delay using distortion product emission phase responses," I Acoust Soc Am 94, 1343-1350.

Lippe, W. and Rubel, E. W. (1983). "Development of the place principle: tonotopic organiza" tion," Science 219, 514-516.

Marco, J., Morant, A., Caballero, J., Ortells, I., Paredes, C. and Brines, J. (1995). "Distortion 
product otoacoustic emissions in healthy newborns: normative data," Acta Otolaryngol (Stockh) 115, 187-189.

Mills, D. M. and Rubel, E. W. (1996). "Development of the cochlear amplifier," J Acoust Soc Am 100, 428-441.

Moulin; A. and Kemp, D. T. (1996a). "Multicomponent acoustic distortion product otoacoustic emission phase in humans. I. General characteristics," I Acoust Soc Am 100, $1617-1639$.

Moulin, A. and Kemp, D. T. (1996b). "Multicomponent acoustic distortion product otoacoustic emission phase in humans. II. Implications for distortion product otoacoustic emissions generation," J Acoust Soc Am 100, 1640-1662.

O Mahoney, C. F. and Kemp, D. T. (1995). "Distortion product otoacoustic emission delay measurement in human ears," J Acoust Soc Am 97, 3721-3735.

Osterhammel, P. A., Nielsen, L. H. and Rasmussen, A. N. (1993). "Distortion product otoacoustic emissions. The influence of the middle ear transmission," Scand Audiol 22, 111-116.

Pujol, R. (1985). "Morphology, synaptology and electrophysiology of the developing cochlea," Acta Otolaryngol (Stockh) Suppl 421, 5-9.

Pujol, R, Lavigne Rebillard, M. and Uziel, A. (1991). "Development of the human cochlea," Acta Otolaryngol (Stockh) Suppl 482, 7-12.

Romand, R. (1983). "Development of the cochlea ${ }$ " in Development of auditory and vestibular systems, edited by R. Romand (Academic Press, New York), pp. 47-88.

Romand, R. (1987). "Tonotopic evolution during development," Hear Res 28, 117-123.

Romand, R. (1997). "Modification of tonotopic representation in the auditory system during development.," Progress in Neurobiology 51, 1-17.

Saunders, J. C., Kaltenbach, J. A. and Relkin, E. M. (1983). "The structural and functional development of the outer and middle ear," in Development of auditory and vestibular systems, edited by R. Romand (Academic Press, New York), pp. 3-25.

Smurzynski, J. (1994). "Longitudinal measurements of distortion-product and click-evoked otoacoustic emissions of preterm infants: preliminary results," Ear Hear 15, 210-223.

Smurzynski, J., Jung, M. D., Lafreniere, D., Kim, D. O., Kamath, M. V., Rowe, J. C., Holman, M. C. and Leonard, G. (1993). "Distortion-product and click-evoked otoacoustic emissions of preterm and full-term infants," Ear Hear 14, 258-274.

Stover, L. J., Neely, S. T. and Gorga, M. P. (1996). "Latency and multiple sources of distortion product otoacoustic emissions," J Acoust Soc Am 99, 1016-1024

Sutton, G. J" Gleadle, P. and Rowe, S. J. (1996). "Tympanometry and otoacoustic emissions in a cohort of special care neonates," Br J Audiol 30, 9-17.

van Zanten, B. G., Kok, M. R., Brocaar, M. P. and Sauer, P. J. (1995). "The click-evoked oto- 
acoustic emission, $c-E O A E$, in preterm-born infants in the post conceptional age range between 30 and 68 weeks," Int J Pediatr Otorhinolaryngol Suppl 32, S187-197.

Wable, J., Collet, L., Berger Vachon, C. and Chery Croze, S. (1997). "2f1-f2 distortion product otoacoustic emission latency: changes with frequency and level of primaries," Audiology 36, 72-82.

Wable, J., Collet, L. and Chery Croze, S. (1996). "Phase delay measurements of distortion product otoacoustic emissions at $2 \mathrm{fl}-\mathrm{f} 2$ and $2 \mathrm{f} 2-\mathrm{fl}$ in human ears," J Acoust Soc Am 100, 2228-2235. 
Chapter 6 


\section{CHAPTER}

\section{General discussion}

and

summary 
Chapter 7 
Although hindered by the far from ideal circumstances for the registration of otoacoustic emissions (OAE) in the neonatal intensive care unit (NICU), the present thesis proved that bedside OAE measurement is feasible in preterm infants from 29 to 30 weeks post-conceptional age (PCA) onward. Longitudinal observation of click evoked OAE (CEOAE) and spontaneous OAE (SOAE) in the period between 29 and approximately 40 weeks PCA showed that the amplitude of CEOAE increased with a rate of about $1.3 \mathrm{~dB}$ per week, whereas the frequency of SOAE increased with approximately $0.7 \%$ per week (Chapter 3 and 4), without any significant changes in SOAE amplitude (Chapter 5). Cross-sectional comparison of distortion product OAE (DPOAE) from preterm infants with data from infants who were term-at-test-date, indicated a decrease of DPOAE latency with increasing PCA, without any marked differences in DPOAE amplitude (Chapter 6).

By registration of these changes in the OAE of preterm infants, the goal of the present study was to gain insight in the underlying mechanisms of cochlear and middle ear maturation. As already stated in the general introduction, the development of middle ear structures in preterm infants firmly suggests the occurrence of marked changes in the transfer function of the middle ear during the PCA of interest. All types of OAE are influenced by this middle ear transfer, for all OAE travel through the middle ear in the retrograde way. Furthermore, in the case of evoked OAE, an additional effect of middle ear development can be expected on the incoming stimuli.

This thesis, however, mainly focused on the possible influence of cochlear maturation on the registered changes in $\mathrm{OAE}$. Any relationship between changes in $\mathrm{OAE}$ characteristics and cochlear maturation might provide clues for the understanding of the generation mechanisms of $\mathrm{OAE}$, and ultimately contribute to the knowledge of the mechanisms of hearing itself. The main problem in the present research therefore was to discriminate between middle ear and cochlear influences on the observed OAE data, lacking a validated method of investigating the middle ear function in preterm infants. 


\section{Chapter 7}

The longitudinal observations in Chapter 3 demonstrated an overall increase of CEOAE amplitude with increasing PCA. These data rejected the conclusions of Bonfils et al. (1992) and Morlet et al. (1993), who believed the outer hair cell properties to be mature at 32 weeks PCA, since no statistically significant variation could be found in CEOAE amplitude and spectrum by cross-sectional comparison of different age groups ranging from 32 to 41 weeks PCA. However, discrimination between cochlear and middle ear effects is not possible based on these observations of CEOAE amplitude, since the middle ear directly affects the amplitude of an $\mathrm{OAE}$. It is therefore merely a confirmation of the notion that there is a functional development of the outer and/or middle ear in the PCA between 30 and 40 weeks.

In the case of the upward shift of SOAE frequency with increasing PCA, as described in the Chapters 3,4 and 5 , the possible influence of the middle ear is less straightforward. Nevertheless, similar upward shifts of SOAE frequency can be accomplished by an increase in meatal air pressure or the voluntary contraction of middle ear muscles. This alters the frequency specific loading of the cochlea by the middle ear, which possibly results in a change of the cochlear mechanics at the generation site of an SOAE, thereby inducing an upward shift in SOAE frequency. On the other hand, it is known that these middle ear manipulations induce mainly upward SOAE frequency shifts accompanied with a simultaneous decrease in amplitude, whereas there is no such relationship between the changes in SOAE frequency and amplitude in preterm infants (Chapter 5). But theoretically speaking, the upward shift of SOAE frequency in preterm infants could solely be caused by the development of the middle ear. One of the most prominent arguments against the sole influence of the middle ear development on the SOAE frequency can be found in a longitudinal study by Burns et al. (1994) of SOAE in infants in the first two years of age. While Keefe et al. (1993) reported profound changes in outer and middle ear transfer during this period, Burns et al. (1994) reported no substantial shift of SOAE frequency, whereas the SOAE amplitude showed a gradual decrease toward adult values. This is in contradiction with the present findings of increasing SOAE frequency (Chapter 4) 
without any noticeable change in SOAE amplitude (Chapter 5), although even more profound changes in middle ear transfer might be expected in preterm infants. Furthermore, the fact that the upward SOAE frequency shift in preterm infants was proportionally constant relative to the SOAE frequency, and could be represented by a similar percentage at all SOAE frequencies, further suggests an analogy with the cochlear tonotopic organization.

As introduced in Chapter 6, the measurement of round-trip traveling wave delay or DPOAE latency by means of relative DPOAE phase shifts is believed to be unaffected by temporary or developmental changes in middle ear transfer. The observation of decreasing DPOAE latency with increasing PCA therefore concludes the present evidence for cochlear maturation in preterm infants. An indirect influence of middle ear characteristics on the DPOAE stimuli might result in, for example, a decrease of the level of both stimulus tones, thereby eliciting longer DPOAE latencies at lower DPOAE amplitudes. There was, however, no significant change in DPOAE amplitude accompanying the decrease of DPOAE latency, which practically excludes this possibility of interference by the middle ear. More recently, the data in Chapter 6 have been confirmed by Quinonez and Crawford (1998), who reported a similar DPOAE latency decrease in a longitudinal study in preterm infants. The influence of the middle ear on their data could not be excluded since no data were given on the changes in DPOAE amplitude.

In conclusion, our research provided evidence for cochlear maturation in preterm infants. Especially the SOAE frequency shift suggests that this maturation continues through term, possibly up to the PCA of 45 to 50 weeks (Chapter 4). In view of the limited knowledge of the generation mechanism of OAE at present, interpretation of the data in terms of cochlear mechanics is difficult. Nevertheless, the present results could be consistent with theories of cochlear maturation. The upward shift of SOAE frequency, for instance, could be consistent with the concept of the 'shifting place principle', which predicts that the frequency of tuning at a fixed place on the cochlear partition is shifted upward throughout maturation. On the other hand, the same principle predicts the location of tuning 
of a specific frequency to shift toward the apex, thereby resulting in an increase of the traveling wave delay, rather than the observed decrease in DPOAE latency. Since the DPOAE latency includes a built up time for generation of the emission, the reported decrease of DPOAE latency is therefore more likely to be related to maturation of the active cochlear processes involved in the generation of OAE.

At the present time, the lack of a validated method for analysis of the middle ear transfer prevents a further differentiation between middle ear and cochlear effects on the present OAE data. Further study should therefore preferably focus on the investigation of middle ear transfer in preterm infants and its influence on the different types of OAE. In view of the four to seven times higher prevalence of sensorineural hearing loss in survivors of the NICU, the possible clinical merits of the use of OAE in the NICU for monitoring the cochlear function during treatment deserve further investigation. 


\section{REFERENCES}

Bonfils, P., Francois, M., Avan, P., Londero, A., Trotoux, J. and Narcy, P. (1992). "Spontam neous and evoked otoacoustic emissions in preterm neonates," Laryngoscope 102, 182-186.

Burns, E. M., Campbell, S. L. and Arehart, K. H. (1994). "Longitudinal measurements of spontaneous otoacoustic emissions in infants," J Acoust Soc Am 95, 385-394.

Keefe, D. H., Bulen, J. C., Arehart, K. H. and Burns, E. M. (1993). "Ear-canal impedance and reflection coefficient in human infants and adults," J Acoust Soc Am 94, 2617-2638.

Morlet, T., Collet, L., Salle, B. and Morgon, A. (1993). "Functional maturation of cochlear active mechanisms and of the medial olivocochlear system in humans," Acta Otolaryngol (Stockh) 113, 271-277.

Quinonez, R. E. and Crawford, M. R. (1998). "Longitudinal distortion product otoacoustic emission (DPE) latency changes in preterm neonates," Acta Otolaryngol (Stockh) 118, 2631 . 


\section{SAMENVATTING}

OtoAkoestische Emissies (OAE) zijn zwakke geluiden met een geluidsniveau rond de gehoordrempel, die met een voldoende gevoelige microfoon in de gehoorgang geregistreerd kunnen worden. Deze emissies reflecteren de integriteit van de cochleaire structuren die betrokken zijn bij de transductie van akoestische energie naar elektrische activiteit in de gehoorzenuw. OAE worden gezien als een bijprodukt van de "cochleaire versterker", die door mechanische terugkoppeling ook zwakkere akoestische signalen voldoende energie geeft om te worden waargenomen. De exacte werking van deze cochleaire versterker is grotendeels onbekend, doch een belangrijke rol wordt op dit moment toegeschreven aan de buitenste haarcellen, die na elektrische stimulatie lengteveranderingen kunnen laten zien, die mogelijk verantwoordelijk zijn voor een extra opslingering van de zwakkere mechanische trillingen van het basilair membraan.

Dit proefschrift beschrijft verschillende typen OAE van prematuren met een postconceptionele leeftijd van ca. 30 tot 40 weken. Het doel was het registreren en vervolgen van veranderingen in de $O A E$, ten einde inzicht te krijgen in de onderliggende maturatie van het perifere gehoororgaan. Deze gegevens vormen op termijn mogelijk aanknopingspunten voor de uitbreiding van de kennis omtrent de samenstelling en ontwikkeling van de cochleaire versterker.

Registratie van OAE blijkt technisch goed mogelijk op de neonatale intensive care afdeling. Uit de resultaten van Hoofdstuk 2 blijkt dat acht procent van totaal 226 pogingen tot registratie van een Click Evoked OAE (CEOAE) faalde door onrust van de prematuur of een onvermijdbaar hoog niveau van achtergrondgeluid. Het feit dat bij slechts 69 procent van de pogingen daadwerkelijk een $\mathrm{CEO}$ $\mathrm{AE}$ geregistreerd kon worden, wordt voornamelijk toegeschreven aan een hogere prevalentie van middenoorpathologie bij prematuren dan bij a terme pasgeborenen. Een gevalideerde methode ter evaluatie van de middenoorfunctie van prema* turen is op dit moment echter niet voor handen.

Aan de hand van longitudinale observaties beschrijft Hoofdstuk 3 dat de amplitu- 
de van de $C E O A E$ in prematuren een stijging vertoont bij vorderende conceptionele leeftijd, van gemiddeld $1.3 \mathrm{~dB}$ per week. De rol van het middenoor in deze amplitudestijging is echter niet nader te specificeren, zodat op grond van deze observatie alleen geen uitspraken kunnen volgen omtrent de maturatie van de cochlea.

Een ander, zeer opvallend fenomeen wordt beschreven in Hoofdstuk 4: de frequentie van individuele Spontane OAE (SOAE) vertoont vrijwel zonder uitzondering een verschuiving naar een hogere waarde bij toenemende conceptionele leeftijd. Dit in tegenstelling tot de SOAE frequenties van volwassenen en kinderen van 0 tot 2 jaar, die in eerdere onderzoeken geen substantiële verschuiving vertoonden. De SOAE frequentieverschuiving in prematuren suggereert sterk de invloed van cochleaire rijping, aangezien hogere frequenties ook een proportioneel hogere frequentieverschuiving vertonen. Met andere woorden, de SOAE frequentieverschuiving is uit te drukken in een voor alle frequenties constant percentage van de initiële SOAE frequentie (ca. $0.7 \%$ per week), hetgeen sterk aan de cochleaire tonotopie doet denken. Aangezien middenoormanipulaties bij volwassenen eveneens SOAE frequentieverschuivingen kunnen induceren, is de invloed van de maturatie van het middenoor echter niet geheel uit te sluiten.

In Hoofdstuk 5 blijkt de amplitude van de SOAE in prematuren geen netto verandering te vertonen. Middenoormanipulaties bij volwassenen gaan daarentegen naast een stijging van de SOAE frequentie gepaard met een daling van de SOAE amplitude. Dit ondersteund de hypothese dat de SOAE frequentieverschuiving in prematuren het gevolg is van cochleaire rijping. Bovendien is bekend dat bij jonge kinderen tussen 0 en 2 jaar een geleidelijke afname plaatsvindt van de amplitude van SOAE bij een constante SOAE frequentie, hetgeen toegeschreven wordt aan rijping van de middenoorstructuren. Het feit dat de SOAE in prematuren een tegengesteld verloop vertonen, namelijk een toename van SOAE frequentie bij constante amplitude, vormt een verdere aanwijzing voor cochleaire maturatie. 
Een meetmethode die vrijwel onafhankelijk is van middenoorinvloeden is de meting van de latentie van Distorsie Produkt OAE (DPOAE) en wordt beschreven in Hoofdstuk 6. Deze latentie wordt gezien als de som van de looptijd van de twee-tonige stimulus naar de plaats in de cochlea waar de OAE gegenereerd wordt, de opbouwtijd van de DPOAE en de looptijd van de DPOAE terug naar de gehoorgang. Onder de voorwaarde van een constante DPOAE amplitude, worden veranderingen in de latentie van DPOAE toegeschreven aan cochleaire processen. In een cross-sectionele vergelijking tussen premature en a terme kinderen blijkt de DPOAE latentie af te nemen bij toenemende conceptionele leeftijd. Daar de amplitude van de DPOAE geen verschil tussen de groepen laat zien, wordt de latentiedaling toegeschreven aan de rijping van de actieve cochleaire structuren die betrokken zijn bij de generatie van $O A E$.

Het verklaren van de beschreven $O A E$ veranderingen in prematuren vanuit veranderingen in de cochleaire mechanica is een complexe taak. Afgezien van de onbekende invloed van de maturatie van de middenoorstructuren, zou de SOAE frequentieverschuiving in overeenstemming kunnen zijn met het concept van het "shifting place" principe, wat voorspelt dat de frequentie, waarop een specifieke plaats langs het basilair membraan is afgestemd, tijdens de cochleaire rijping naar een hogere waarde verschuift. Met name de afname van de DPOAE latentie met toenemende conceptionele leeftijd suggereert sterk de rijping van de cochleaire versterker zelf. In het algemeen moet echter geconcludeerd worden dat een vertaling van de $O A E$ veranderingen in termen van cochleaire mechanica op dit moment voldoende kennis ontbeert van de werking van de cochlea in het algemeen en het generatiemechanisme van $\mathrm{OAE}$ in het bijzonder. 


\section{LIST OF PUBLICATIONS}

van Langen, $H$., Brienesse, $P$., Kopinga $K$. and Wijn, $P$. (1993). "Dynamic response of a neontatal catheter-manometer system in situ," J Clin Monit 9, 335-340.

Brienesse, P. (1995). "Zijn OtoAkoestische Emissies bruikbaar voor gehoorscreening in Nederland?", Klin Fys 1995/3, 29.

Brienesse, P., Anteunis, L.. Wit, H., Gavilanes, D. and Maertzdorf, W. (1996). "Otoacoustic emissions in preterm infants: indications for cochlear development?" Audiology 35, 296306.

Brienesse, P., Anteunis, L. J., Maertzdorf, W. J., Blanco, C. E. and Manni, I. J. (1997). "Frequency shift of individual spontaneous otoacoustic emissions in preterm infants," Pediatr Res 42, 478-483.

Brienesse, P. and Debyelaan, P. (1997). "Maturation of otoacoustic emissions: longitudinal versus cross-sectional study [letter]," Int J Pediatr Otorhinolaryngol 40, 73-75.

Brienesse, P., Anteunis, L. J. C., Maertzdorf, W. J., Manni, J. J. and Blanco, C. E. (1998). "Click evoked otoacoustic emission measurement in preterm infants," Eur J Pediatr, in press.

Brienesse, P., Anteunis, L. J. C., Maertzdorf, W. J., Manni, J. J. and Blanco, C. E. (1998). "Long-term and short-term variations in amplitude and frequency of spontaneous otoacoustic emissions in preterm infants," Audiology 37, in press.

Anteunis, L. J. C., Brienesse, P. and Schrander, J. J. P. (1998). "Otoacoustic emissions in screening cleft lip and/or palate children for hearing loss, a feasibility study," Int $J$ Pediatr Otorhinolaryngol, in press.

Brienesse, P., Anteunis, L. J. C., Maertzdorf, W. J., Blanco, C. E. and Manni J. J. "Distortion product otoacoustic emission latency in preterm and term infants. Evidence for cochlear maturation," submitted.

\section{ABSTRACTS AND PROCEEDINGS}

Brienesse, P., Anteunis, L. J. C., Wit, H. P., Gavilanes, A. W. D. and Blanco, C. E. (1994). "Click evoked emissions in preterm infants: a longitudinal prospective study," 6th International Congress of Pediatric Otorhinolaryngology, Rotterdam, The Netherlands, 182.

Brienesse, P., Anteunis, L. J. C., Wit, H. P., Gavilanes, A. W. D. and Blanco, C. E. (1995). "A longitudinal prospective study of otoacoustic emissions in preterm infants: an indication for cochlear maturation?," European Conference on Audiology, Noordwijkerbout, The Netherlands, Nederlandse Vereniging voor Audiologie, 77-81.

Brienesse, P., Anteunis, L. J. C., Wit, H. P., Gavilanes, A. W. and Maertzdorf, W. J. (1995).

"Click evoked otoacoustic emissions in preterm infants," Pediatr Res 37, 197A.

Brienesse, P., Anteunis, L. J. C., Wit, H. P., Gavilanes, A. W. D. and Maertzdorf, W. J, 
(1995). "A longitudinal prospective study of otoacoustic emissions in preterm infants: an indication for cochlear maturation?", Pediatr Res 37, 251A.

Anteunis, L. J. C. and Brienesse, P. (1996). "Feasibility of screening neonates with faciall cleft abnormalities using click evoked otoacoustic emissions," 4 th International Conference on Pediatric E.N.T., Sienna, Italy, 26.

Brienesse, P., Anteunis, L. J. C. and Maertzdorf, W. J. (1996). "Systematische frequentieverschuiving van spontane oto-akoestische emissies van premature kinderen; een indicatie voor cochleaire maturatie?," Ned Tijdschr Geneeskd 140, 692.

Brienesse, P., Anteunis, L. J. C., Gavilanes, A. W. D. and Maertzdorf, W. J. (1996). "Systematische Frequenzverschiebung der spontanen otoakustischen Emissionen bei frühgeborenen. Eine Indikation für cochleäre Reifung?," 67 Jahresversammlung Deutsche Gesellshaft für Hals-Nasen-Ohren-Heilkunde, Kopf- und Hals-Chirurgie, Aachen, Germany.

Brienesse, P., Anteunis, L. J. C., Maertzdorf, W. J. and Wit, H. P. (1996). "Frequency shift of spontaneous otoacoustic emissions in preterm infants," XXIII International Congress of Audiology, Bari, Italy, 126

Bal, M. P., Brienesse, P., Anteunis, L. J. C. and Maertzdorf, W. J. (1998). "Click evoked otoacoustic emissions in small for gestational age infants," 7th International Congress of Pediatric Otorhinolaryngology, Helsinki, Finland, 502.

Bal, M. P., Brienesse, P. and Maertzdorf, W. J. (1998). "Delayed peripheral auditory maturation in small for gestational age infants; a matched control study of click evoked otoacoustic emissions," Pediatr Res 43, 245A. 


\section{NAWOORD}

Het in dit proefschrift beschreven onderzoek zou niet mogelijk zijn geweest zonder de hulp, steun en medewerking van vele direct of indirect betrokkenen, aan wie ik mijn dank verschuldigd ben. Ik hoop iedereen nog zoveel mogelijk persoonlijk te kunnen aanspreken, doch een aantal wil ik hier alvast hartelijk bedanken:

Mijn promotoren, Prof. dr. J.J. Manni en Prof. dr. C.E. Blanco voor het vertrouwen en de hoge mate van vrijheid die mij gedurende het onderzoek werd gegeven;

mijn co-promotor dr. W.J. Maertzdorf, Wiel, voor de manier waarop jij voor mij altijd de ideale contactpersoon bent geweest met de afdeling neonatologie, maar ook met de kindergeneeskunde in het algemeen;

de student-assistenten Ankie Hamaekers en Miriam Bal, waarvan ik hoop dat jullie er net zoveel aan gehad hebben (en nog zullen hebben?) als ik;

Ruud Hamers voor al je kundige hand- en spandiensten bij het verzamelen van de gegevens;

Ron Jongen, die ik niet langer lastig zal vallen met vragen omtrent "oude" programmatuur (ook ik werk inmiddels met Word);

en natuurlijk het verpleegkundig personeel en de ouders die hun kinderen aan het onderzoek hebben laten deelnemen, zonder wie deze studie niet mogelijk zou zijn geweest.

Ir. J.J.T. Hendriks, beste Jacques, hoewel er inhoudelijk weinig contact tussen ons is geweest, is jouw bijdrage aan dit proefschrift van een niet te onderschatten belang. Gedurende het hele proces ben je in staat geweest de randvoorwaarden te scheppen die mij naast mijn opleiding de gelegenheid gaven de promotie af te ronden. Ook met de helft van jouw vermogen om zaken van de grond te krijgen (vanuit je motto "werk hèbben is éen, maar werk houden is nummer twee"), zou ik al tevreden zijn. Hoewel ik er zelf in het begin nogal sceptisch tegenover stond, en het lange tijd geduurd heeft voordat ik er ook zelf in geloofde dat het zover zou komen, heb je hiermee inderdaad laten zien dat het mogelijk is vanuit een 
perifeer audiologisch centrum te promoveren.

Drs. L.J.C. Anteunis, beste Lucien, zonder jouw inbreng in het onderzoek zou het zeker niet zover zijn gekomen. Het heeft weliswaar enkele jaren geduurd voordat je toegaf dat de eerste internationale presentaties van de resultaten vanuit een "jongensachtige brutaliteit" zijn ontstaan. Toch heeft jouw konstante input en aandringen de resultaten te presenteren ervoor gezorgd dat de broodnodige internationale kontakten en ideeën zijn ontstaan, met name in de beginfase van het onderzoek. Ook buiten het vakgebied heb ik veel van je geleerd. Zo weet ik mu waar de Maas ontspringt (ook al moesten we daar niet zijn) en waar de mooiste Bonsaibomen van Europa staan (ook al lag het niet op de route). Verder heb je me de smaak van "dooie zwembeesten" leren waarderen, met als hoogtepunt de lobsters van het No Name Restaurant in Boston. Ik denk er met veel plezier aan terug.

Annemarijke, bedankt woor alle steun en ruimte die je me hebt gegeven, en voor de wijsheid dat half tien een mooie tijd is om weer aan andere dingen te denken. Ik hou van je. 


\section{CURRICULUM VITAE}

Patrick Brienesse werd op 15 maart 1967 te Utrecht geboren. In 1985 behaalde hij aan de Rijks Scholen Gemeenschap te Heerenveen het diploma ongedeeld V.W.O., waarna hij startte met de studie technische natuurkunde aan de Technische Universiteit Eindhoven. In april 1991 studeerde hij af. Vervolgens vervulde hij de militaire dienstplicht, waarna hij in juli 1992 als audioloog in opleiding in dienst trad van het Audiologisch Centrum Hoensbroeck. In het kader van deze opleiding werd in november 1993 gestart met het onderzoek van otoakoestische emissies bij prematuren in het Academisch Ziekenhuis Maastricht. Na het voltooien van de opleiding volgde in september 1996 de registratie als klinischfysicus audioloog bij de Nederlandse Vereniging voor Klinische Fysica. Nadien is het dienstverband verlengd tot juli 1998, waarbij hij door het Audiologisch Centrum Hoensbroeck halftijds is gedetacheerd bij de afdeling Keel- Neus en Oorheelkunde van het Academisch Ziekenhuis Maastricht, ter voltooiing van het onderzoek dat uiteindelijk tot deze promotie heeft geleid. Sinds juli 1998 is hij in dienst van de Nederlandse Stichting voor het Dove en Slechthorende Kind, als hoofd van het Audiologisch Centrum in Alkmaar.

Op 30 juni 1994 is hij getrouwd met Annemarijke Beuzel. 